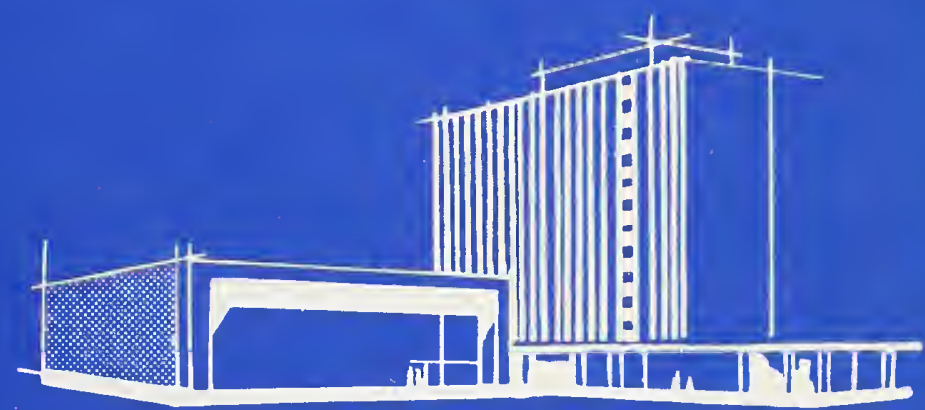

U.S. ARTMENT OF DMMERCE

National

Bureau of $-A-d s$ 35 158 1.37
The Effect of Moisture on the Heat Transfer Performance of Insulated Flat-Roof Constructions 


\section{The Building Science Series}

The Building Science Series disseminates technical information developed at the National Bureau of Standards on building materials, components, systems and whole structures. The Series presents research results, test methods and performance criteria related to the structural and environmental functions and the durability and safety characteristics of building elements and systems.

These publications, similar in style and content to the NBS Building Materials and Structures Reports (1938-59), are directed toward the manufacturing, design, construction and research segments of the building industry, standards organizations and officials responsible for building codes.

The material for this Series originates principally in the Building Research Division of the NBS Institute for Applied Technology. The publications are divided into three general groups: Building Systems and Processes; Health, Safety and Comfort; and Structures and Materials. Listed below are other publications in the category of-

\section{Health, Safety, and Comfort}

- Doors as Barriers to Fire and Smoke, (C13.29/2:3) 15 cents

- Field Burnout Tests of Apartment Dwelling Units, (C13.29/2:10) 25 cents

- Fire Resistance of Steel Deck Floor Assemblies, (C13.29/2:11) 25 cents

- Performance of Square-Edged Orifices and Orifice-Target Combinations as Air Mixers, (C13.29/2:12) 15 cents

- Algorithms for Psychrometric Calculations (Skeleton Tables for the Thermodynamic Properties of Moist Air), (C13.29/2:21) 55 cents

- Investigation of Performance Characteristics for Sanitary Plumbing Fixtures, (C13.29/2:22) 70 cents

- Radiation Error in Air Ducts under Non-Isothermal Conditions Using Thermocouples, Thermistors and a Resistance Thermometer, (C13.29/2:26) 25 cents

- Performance of Louvered Devices as Air Mixers, (C13.29/2:27) 30 cents

Send orders (use Superintendent of Documents Catalog Nos.) with remittance to: Superintendent of Documents,

U.S. Government Printing Office, Washington, D.C. 20402. Remittance from foreign countries should include an additional one-fourth of the purchase price for postage.

[See mailing list announcement on last page.] 


\title{
The Effect of Moisture on the Heat Transfer Performance of Insulated Flat-Roof Constructions
}

\author{
Frank J. Powell and Henry E. Robinson \\ Building Research Division \\ Institute for Applied Technology \\ National Bureau of Standards \\ Washington, D.C. 20234
}

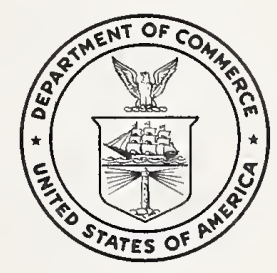

Building Science Series 37

Nat. Bur. Stand. (U.S.), Bldg. Sci. Ser. 37, 81 pages (Oct. 1971) CODEN : BSSNB

Issued October 1971 
Library of Congress Catalog Card Number: 76-611463 


\section{Contents}

\section{Part I. Concrete Decks}

1. Introduction to Part I

2. Experimental Exposure Conditions and Method of Test

3. Specimens and Procedures

4. Results

5. Discussion of Results.

5.1. Effect of Moisture on Insulating Value, and the Influence of Exposure Conditions on this Effect

5.2. Effects of Vapor Barriers and of Dense Concrete Decks

5.3. Behavior of Specimens Having No Dense Concrete Deck or Vapor Barrier

5.4. Pressure Relieving Vents.

5.5. Changes of Indoor Air Temperature and Relative Humidity

5.6. Roof Insulating Materials..

5.7. Comment

6. Summary, Part I.

7. References, Part I, Part II

Figures 1 through 13

\section{Part II. Self-Drying Designs}

8. Introduction to Part II.

9. Experimental Exposure Conditions and Method of Test.

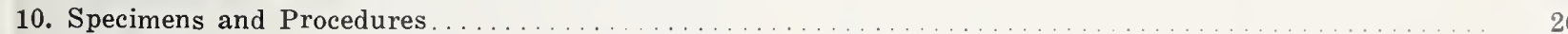

11. Results

12. Discussion of Results

12.1. Effect of Moisture on Insulating Value

12.2. Summer Self-Drying, Initial Construction Moisture

12.3. Winter Gain of Moisture.

12.4. Self-Drying From Roof Leaks.

12.5. Arrangement and Physical Properties of Components

12.6. Design Criteria

12.6.2. Thermal Insulating Value

12.6.3. Self-Drying Time for Initial Construction Moisture and Equilibrium Moisture Content

12.6.4. Equilibrium Moisture Content

12.6.5. Regain of Moisture-Winter Exposure Conditions

12.6.6. Summer Self-Drying Time for Winter Regain Moisture

12.6.7. Summer Self-Drying Time for a Simulated Roofing Leak

12.6.8. Water Vapor Permeance and Hygroscopic Moisture Capacity

12.6.9. Exposure Conditions 



\title{
The Effect of Moisture on the Heat Transfer Performance of Insulated Flat-Roof Constructions
}

\author{
Frank J. Powell and Henry E. Rohinson
}

A solution to the problem of unwanted moisture in the thermal insulation of flat roofs was found during a recently completed laboratory investigation of the effects of moisture on heat transfer through these constructions. The objective of the research was to ascertain how much the insulating performance of conventional constructions, having insulation over concrete decks, was affected by moisture. This is presented as Part I. Also, the objective was to investigate properties of materials, their arrangement and dimensions which would yield a construction having an adequate degree of self-drying ability, combined with low winter moisture regain rate. This is presented as Part II. The results show that the best insulating and moisture performance was obtained by utilizing the heat of the summer sun on the roof to vaporize and transfer to the room beneath any free moisture contained within the construction. Roof specimens made from moderately vapor-permeable materials without conventional vapor barriers were, in winter, able to accommodate the small quantity of slowly accumulated condensation without dripping or severe loss of insulating value. During the nine-year investigation, the performance characteristics of 73 insulated roof deck specimens were obtained and two new methods of measurement were developed. Criteria for the design of selfdrying insulated flat roofs were developed and limits of the parameters containing the main variables that affect performance were suggested.

This paper presents complete results of the research which was sponsored jointly by the National Bureau of Standards, the Army, the Navy, and the Air Force.

Key words: Flat roofs; heat transfer; moisture transfer; thermal insulation.

\section{Part I. Concrete Decks}

\section{Introduction}

The primary functions of a roof are to provide permanent protection to the structure from the elements, to maintain the comfort and privacy of the occupants, and to serve as protection for valuable property within the building. Insulated flat roofs are widely used on large area buildings, such as Government buildings, shopping centers, industrial plants and multistoried office buildings. Flat roofs are selected primarily because they are functional and economical, are relatively easy to build and maintain, and they are aesthetically pleasing.

Many designs of insulated flat roofs are available. Most designs consist of a structural support or deck, insulation, and built-up roofing for protection from the weather. A typical much-used design consists of a steel-reinforced structural concrete deck covered with a factorymade board-type of insulation or an insulating fill material placed on the job. A water-vapor barrier, when used, is located between the insulation and the interior of the building. The exterior built-up roofing is usually covered with gravel or slag. This type of construction is the subject of Part I of this paper.

A literature search reveals that flat roofs covered with built-up roofing have performed satisfactorily more often than not. However, some expensive failures have occurred that have required replacement of built-up roofing, wet insulations, and other components of the construction $[1,2,3,4] .{ }^{1}$ Hutcheon [5] stated in 1958 that by far the most costly building moisture problem is that encountered in roofs consisting of impermeable coverings laid over in-

\footnotetext{
${ }^{1}$ Figures in brackets indicate the literature references on p. 18.
}

sulation on flat decks or slabs. The reasons for failure generally have been attributed to premature deterioration of the built-up roofing allowing water leaks; installation of wet materials whose trapped moisture may contribute to pressure buildup when the roof is sun-heated; and transmission of water vapor from the interior of the building with subsequent condensation in the insulation beneath the roofing. Failure of the built-up roofing manifests itself in the forms of loss of adhesion, open laps, alligatoring, blistering, hummocking, or cracking. Principal reasons for built-up roofing failure are the presence of moisture in the construction, poor workmanship, and excessive damaging traffic on the flat roof. The processes of failures have been explained in detail $[2,3,4$, $5,6,7,8]$. Generally, the forces that produced failure were generated by changes in temperature and pressure in the presence of moisture, causing stress, dimensional changes, and fracture of materials.

Designers of roof constructions usually compute the heat transfer coefficient of the assembly on the basis of published values for the thermal conductivity or thermal resistance of the dry component materials [9]. The thicknesses of the various materials used are selected to provide adequate structural strength and to yield the desired insulating value. In service, some moisture is usually present. Moisture contents of materials in service are variable and unpredictable. Useful information on the insulating value of materials in service with moisture present in them is scarce. This is because of the difficulty in measuring heat transfer in moist materials and because the effect on heat transfer of a given amount of moisture is influenced by its distribution within the materials, 
which in turn is controlled by the properties of the materials, their arrangement in the construction, and variations of temperature imposed upon them by climatic exposure. Also, changes in insulating value are apt to be gradual requiring long term exposures to observe them, such as a full summer or winter season.

In general, the effect of moisture in permeable roof insulation is to reduce seriously its insulating value, and to cause deterioration of the roofing or other components of the roof construction. Failure of a roof to produce its insulating value causes increased expense for heating and cooling the building, and may cause the heating and cooling systems to be inadequate if their capacity has been selected on the basis of dry insulation in the roof construction.

In 1954, an experimental investigation was undertaken at the National Bureau of Standards under the joint sponsorship of the Office of the Chief of Engineers, U.S. Army; the Bureau of Yards and Docks, U.S. Navy; and the Office of Civil Engineering, U.S. Air Force. The initial objective was to obtain laboratory data as to the impairment of insulating value of insulated flat roof constructions as a result of contained moisture. Part I of this paper presents the experimental exposure conditions selected for laboratory tests, a brief description and reference for the method of test devised, a tabulation of specimens and materials, the test procedures, results in tabular and graphic form, a discussion of meaningful results, and a summary. Exposure tests for Part I, Concrete Decks, spanned a total of three years and 46 insulated specimens were used, each 18 inches $^{2}$ square. Specimens were subjected to successive periods of simulated summer and winter outdoor surface temperature conditions, each with simulated daily solar heating of the roofing surface. The tests included exposures of specimens initially at an "as-received" moisture content, initially at an oven-dry condition, and initially oven-dry with later addition of known amounts of water.

\section{Experimental Exposure Conditions and Method of Test}

\subsection{Experimental Temperature Exposure Conditions}

If water is present in a roof construction, the distribution of moisture and the migration of vapor are subject to the saturated vapor pressures of the water at the various temperatures existing within the construction where there is liquid water, as well as to such properties of the materials as moisture sorbency, capillarity, and vapor and air permeability. The thickness of materials, their capacity for storing heat, and their hygroscopic nature must also be con-

See metric conversion table on page 47 . sidered. The movement of moisture as vapor and the effect of moisture present on insulating value are affected very substantially by temperature level, since the vapor pressure of water increases more than linearly with the absolute temperature. It was necessary in this work, therefore, to select experimentally feasible temperature conditions representative of those experienced by roofs in service.

For summer conditions, it was assumed in 1954 that the temperature of the outdoor surface of built-up roll roofing of a flat insulated roof would be $75^{\circ} \mathrm{F}$ at night, on the average. During the day, when the roof was subject to solar heating, its temperature was assumed to rise to about $150{ }^{\circ} \mathrm{F}$. For the condition designated as winter, it was assumed that the average temperature of the roofing at night would be about $38^{\circ} \mathrm{F}$ and that, due to solar heating, it would rise during the day to about $75^{\circ} \mathrm{F}$. For the condition designated as severe winter, the roofing temperature was assumed to be about $22^{\circ} \mathrm{F}$ at night, and $53{ }^{\circ} \mathrm{F}$ when heated by the sun. Other investigators $[2,7,10,11,12]$ have recently shown that exposed roof surface temperatures vary widely and depend chiefly on the angle of incident solar radiation, the color of the surface, wind velocity, and whether insulation is present immediately beneath the surface. Their observations and calculated estimates indicate that roof surface temperatures may rise as much as $95{ }^{\circ} \mathrm{F}$ above ambient in summer, and about $30^{\circ} \mathrm{F}$ in winter. The temperatures selected for experimental use in 1954 , in general, show good agreement with the references cited and were applied with slight modifications until 1964 when the laboratory work given here was finished. Exposure temperatures originally selected were considered to be auspicious.

The roofing surface was heated or cooled by air regulated in temperature in accordance with the daily cycle shown in figure $1 .^{3}$ In the tests, the steady-state temperatures of the roofing of well-insulated specimens approached the air temperature quite closely, and thus approximated those postulated. Only slight differences in specimen insulating value were found between the nighttime temperature of $38^{\circ} \mathrm{F}$ and the below-freezing temperature of $22^{\circ} \mathrm{F}$. Accordingly, the so-called severe winter exposure condition was abandoned early in the program. The relative humidity of the outdoor air was not controlled, since the roofing constituted an almost perfect vapor barrier between the air and the insulation of a specimen.

The indoor air condition beneath the specimens was $90^{\circ} \mathrm{F}$ and 70 percent relative humidity, or a dewpoint of $79^{\circ} \mathrm{F}$ and a vapor pressure of 1.00 inch of $\mathrm{Hg}$. These conditions were maintained closely throughout all winter test

\footnotetext{
3 Figures 1 through 13 follow page 18. Figures 14 through 45 follow page 47.
} 
exposures, but during summer exposures, the indoor air tended to rise in response to heat transmitted downward through the test specimens during the simulated solar heating period, as shown in figure 1 by dashed lines. The temperature of $90^{\circ} \mathrm{F}$ was selected in order to maintain a more easily measurable temperature difference across the specimens from indoors to outdoors under summer exposure conditions when the outdoor temperature was $75^{\circ} \mathrm{F}$ in the early morning hours. The dewpoint temperature of the indoor air rose above $79{ }^{\circ} \mathrm{F}$ during periods when the indoor air temperature rose above $90^{\circ} \mathrm{F}$ because the humidifier control was set to maintain a relative humidity of 70 percent.

The temperature and relative humidity selected for the indoor air were higher than might be expected in the majority of buildings, in the winter at least, but they were adopted to speed the rate of moisture accumulation in specimens under winter exposures. The dewpoint temperature of $79^{\circ} \mathrm{F}$, maintained under the specimens, was always higher than the roofing temperature during the winter conditions and the night hours of the summer conditions. Therefore, during these times, the water vapor pressure differences were such as to cause vapor flow into the specimens toward the outdoors. However, it was intended that the vapor pressure difference would be directed toward the indoors during the solar-heating hours of the summer exposure. In view of the much greater vapor pressures that would exist in a wet specimen at the relatively high temperatures prevailing in the insulation during the solar-heating period, it was estimated that the somewhat high indoor water vapor pressure would cause only a small percentage reduction of the vapor pressure difference directed toward the indoors.

Near the end of the program for Part I the indoor air conditions were changed to observe effects on the insulating values of the specimens. The changes made are given in table 1 .

TABLE 1. Changes in indoor air conditions

\begin{tabular}{|c|c|c|c|}
\hline & \multicolumn{3}{|c|}{ Test conditions changed } \\
\hline & From & To & To \\
\hline $\begin{array}{l}\text { Indoor air temperature, }{ }^{\circ} \mathrm{F} . \\
\text { Relative humidity, per cent. } \\
\text { Water vapor pressure, in. of } \\
\text { mercury ............... } \\
\text { Dewpoint temperature, }{ }^{\circ} \mathrm{F} .\end{array}$ & $\begin{array}{r}90 \\
70 \\
1.0 \\
79\end{array}$ & $\begin{array}{r}80 \\
50 \\
0.52 \\
60\end{array}$ & $\begin{array}{r}88 \\
39 \\
0.52 \\
60\end{array}$ \\
\hline
\end{tabular}

\subsection{Method of Test}

A primary need in this investigation was to be able to measure the effective thermal resistance of the insulation of a roof deck specimen, and to record its changes as the specimen was subjected to repeated daily cycles of tempera- ture change simulating those to which a roof is subject, under both summer and winter climatic conditions. To simulate the daily and seasonal temperature conditions in a controlled and repetitive way 15 specimens, each 18 inches square, were mounted flat in 3 rows of 5 each on a steel grid-support mounted in the lower half of a large horizontally divided box. See figures 2 and 3 . The desired temperature conditions were achieved by varying the temperature of the air in the upper well-insulated box in accordance with the patterns shown in figure 1 , while maintaining the air in the lower box at constant conditions. The heat flux at the upper surface of each specimen was measured by means of a 4-inch square heat flow meter bonded to the center of the built-up roofing that covered each specimen. See figure 4.

If steady-temperature conditions prevail, the observed heat flow meter reading and the temperature drop across the insulation enable calculation of the effective thermal resistance of the layer of insulation. As figure 1 shows, the air temperatures in the chambers of the box were substantially constant from 2 a.m. to 10 a.m. Sample temperatures and heat flow patterns observed at 75-minute intervals throughout typical 24-hour cycles of the imposed summer and winter exposure conditions are shown in figure 5 (summer) and 6 (winter). The two insulations, labeled (a) and (b) in each figure are representative of the extremes of insulation thickness and heat capacity. These figures show that the temperatures in the specimens became nearly constant from 5 a.m., or earlier, to 10 a.m. The heat flow meter readings also became substantially constant in this period. Thus, with substantially steady conditions prevailing for more than five hours prior to 10 a.m., observations of heat flow and temperature difference across the insulation, made between 8:30 and 10 a.m., should yield reasonably comparable values of the effective thermal resistance of the insulation at its existing moisture content and distribution. It was expected that the thermal resistance so obtained would be influenced by, and serve as a measure of, the combined effect of both the amount of moisture in the insulation, and its average distribution as governed by the imposed temperature cycle. Further details of the method of measurement and the test apparatus are given in reference [6].

\section{Specimens and Procedures}

\subsection{Description of Specimens}

The fabrication and installation details of a typical specimen are shown in figure 4 . The heat flow meter was bonded to the surface of the built-up roofing membrane and thermally lagged with a $1 / 2$-inch thick steel plate to damp out temperature fluctuations when recording 
observations. All temperatures were measured by means of No. 30-gage copper-constantan thermocouples with a manually operated potentiometer readable to the nearest microvolt, corresponding to a temperature difference of about $0.05 \mathrm{deg} F$. Each specimen was moisturesealed except for its bottom face and insulation was packed between adjacent specimens and against exposed sides of specimens to reduce transverse flow of heat and edge effects in each specimen. The roofing was held in place on the specimen periphery by aluminum angles retained by rods screwed into the steel frame that supported all specimens.

The construction of each of the 46 specimens tested is given by the first three columns in table 2. Each 18-inch square specimen was designed to provide an overall calculated thermal transmittance, or U-value, of about $0.12 \mathrm{Btu} /$ $\mathrm{hr} \mathrm{ft}^{2} \operatorname{deg} \mathrm{F}$ on the basis of published thermal conductivity values for the dry materials. The thicknesses of the various insulations used were selected accordingly. Some specimens were assembled omitting the concrete deck, others contained phenolic plastic tubes inserted in the dense concrete deck to allow indication of pressure within the specimen, and some contained a 0.004 -inch thick polyethylene plastic film between the insulation and the concrete deck to act as a vapor barrier. In the last phase of the investigation selected specimens were equipped with pressure-relieving vents through the roofing made from 3/16-inch inside diameter phenolic plastic tubes that projected for a distance of 1 inch above the roofing. The vents were also used to admit water to the insulation at selected times during the exposure periods as given in the footnotes to table 2 . The materials for specimens were selected to provide as wide a range as possible of physical properties of thermal conductivity, water vapor permeability, density, hygroscopicity, capillarity, and water absorptiveness.

\subsection{Testing Procedures}

The specimens were subjected to simulated daily periodic solar heating as shown in figure 1. Daily observations of heat flow and temperatures were made just prior to 10 a.m. when the specimens most closely approached steady-state conditions at the existing moisture content and distribution. Effective thermal resistances were calculated by dividing the appropriate temperature difference by the heat flow meter heat flux per unit area. Daily and weekly changes of effective thermal resistance were considered to indicate the effect of moisture on heat transfer. Each specimen, and its components, was weighed at the start and end of its exposure. Gain or loss of moisture during exposure was determined as the accumulated effect of the succession of imposed test conditions, with an allowance made for the weight of water added, if any. Final moisture content was determined by oven-drying the specimen to constant weight and, if possible, its separate components.

The investigation was conducted in three phases prosecuted in sequence. Each phase consisted of alternating seasonal periods of exposure that simulated winter or summer temperature conditions. Each of the seasonal periods was of several weeks duration, varying in length as necessary to observe apparent trends in the insulating value of the majority of the 15 simultaneously exposed specimens.

The three phases were aimed at somewhat different objectives, reflecting the changing emphasis of the investigation as it progressed. Summarized briefly, the chief objectives and the types of specimens employed in each phase were as follows:

Phase 1. "Investigation of the insulating value of roof constructions employing boardtype or light-weight concrete insulations placed on a 3-inch dense concrete deck, with or without a vapor barrier".

The specimens were constructed from materials with "as-received" moisture contents, that is, factory-made materials were taken from cartons stored a few months in the laboratory; dense concrete decks were air-dried approximately 4 months in the laboratory; insulating concretes were air-dried in the laboratory from 3 to 7 weeks.

Phase 2. "Investigation of the effects of known amounts of moisture on the insulating value of various insulated roof constructions under simulated seasonal exposure conditions."

This was accomplished with specimens, ovendried prior to installation, into which water was introduced during later exposure periods in incremental amounts of 1,2 , and 7 percent to give a total of 10 percent by volume of the insulation. Also, because of the apparent high vapor resistance of the dense concrete decks observed in Phase 1 , the effect of omitting these decks on the average effective resistance of the insulating materials was investigated in Phase 2. Selected specimens were continued in Phase 2 unchanged from Phase 1 for information on the effects of a prolongation of exposure.

Phase 3. "A more thorough investigation of the apparent self-drying characteristics observed in Phase 2 of some constructions not made with dense concrete decks."

Observations were made of the performance of several types of roof constructions without dense concrete decks, and also of the effects of opening the pressure-relieving vents through the roofing, and of changes of the indoor air temperature and reduction of the water vapor pressure of the indoor air from the original value of 1 inch of mercury to about $1 / 2$ inch. 


\section{Results}

The tabular results for all three phases of the investigation are given in table 2 , columns 4 through 17. Sample results showing temperatures and heat fluxes for one day of a summer and a winter exposure period for two specimens are given on figures 5 and 6 . These are typical of the temperature and heat flux results obtained for all 46 specimens in all seasonal exposure periods used. These two specimens were selected as samples because they represented the extremes of thermal conductivity, thickness, and heat capacity. In the interest of saving space typical results for the remaining 44 specimens are not given here. Results that illustrate conclusions are presented in figures 7 to 13 , where each plotted value of $R / R_{0}$ is the average of the daily values obtained during each week, usually five in number.

Table 2 gives for each specimen the type of insulation used, its thickness, its dry density and thermal conductivity, the weight of water added to the insulation during exposure (if any), and gain or loss of weight from the time of installation to the completion of testing for each phase. The heat transfer results are given in terms of a ratio of thermal resistance for the insulations, $R / R_{0} . R$ is the weekly average effective thermal resistance. $R_{0}$ is the value of $R$ obtained under winter exposure conditions when the insulation was in an oven-dry condition, or, if the specimen had not been ovendried, when its observed resistance was a maximum. The observed resistance under winter conditions of an insulation containing only moderate amounts of moisture approached closely that of an oven-dry insulation. The values of $R / R_{0}$ given in the table generally apply to the last week of each exposure period shown, $S_{1}, W_{1}$, and so forth, since at these times the trend of the effect of moisture on the insulating value had been established. The total number of weeks of exposure at each winter or summer exposure condition is also given in the table for each phase of the investigation. In sequence, the order of tests during Phase 1 was $\mathrm{S}_{1}, \mathrm{~W}_{1}, \mathrm{~W}_{\mathrm{c}}$, and $\mathrm{S}_{2}$. The severe winter condition,

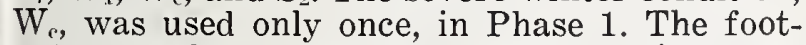
notes to table 2 identify for each specimen the time during exposure when water was added to the insulation and when the vent through the roofing was opened during Phase 3.

Plotted data in figures 7 through 13 cover all weeks of exposure given in table 2 for these specimens and each individual specimen can be further identified by means of symbols in the figures.

\section{Discussion of Results}

Daily and weekly changes of thermal resistance were considered to be a measure of the effect of moisture on heat transfer through the insulations of flat roof constructions. Observations made just prior to 10 a.m., figures 5 and 6 , yielded thermal resistance data for a condition approaching as nearly to an ideal steadystate condition as was possible within the restrictions of the imposed 24-hour periodic temperature cycle. Values of heat flux and temperature during the simulated solar-heating portion of the cycle, 10 a.m. to 4 p.m., and the cooling portion, 4 p.m. to about 10 p.m., were clearly transient and would not have yielded a meaningful insulation resistance. Use of the heat-flow meter and presentation of results as a ratio $R / R_{0}$ has several advantages: (a) proportionate values of thermal resistance can be given on a scale from 0 to 1 . For example, an $R / R_{0}$ of 0.5 indicates that the effective thermal resistance or insulating value is one-half that of the winter value for substantially dry insulation; (b) relative changes of thermal resistance of different constructions are readily compared; and (c) the absolute value of the calibration constant of the heat-flow meter is not involved, provided only that it remains substantially constant.

\subsection{Effect of Moisture on Insulating Value, and the Influence of Exposure Conditions on this Effect}

\subsubsection{Insulating Concrete Type Specimens}

Appreciable amounts of moisture in permeable roof insulations seriously reduced their insulating value under both winter and summer conditions. This effect is illustrated in figure 7 for the cellular concrete insulation of Specimen 14. During the initial 10 -week summer exposure period $\mathrm{S}_{1}$, the values of $R / R_{0}$ ranged from 0.39 to 0.50 . During subsequent winter exposure periods $\mathrm{W}_{1}$ and $\mathrm{W}_{\mathrm{c}}$ values of $R / R_{0}$ became substantially constant at about 0.70 and 0.73 , respectively, and in the final six-week summer exposure period of Phase $1, \mathrm{~S}_{2}$, the values of $R / R_{0}$ ranged from 0.43 to 0.50 . These tests were made with the specimen materials at "asreceived" moisture contents or moderately airdried. The quantity of moisture present was not determined at the start of the test for Phase 1, but the specimen weight was recorded. When the specimen was assembled, the top surface of the cellular concrete insulation appeared dry and a good bond between the built-up roofing and the insulation was obtained. During the exposure of Phase 1, Specimen 14 gained 1.1 pounds or about 0.9 percent by weight (see table 2). At the conclusion of exposure period $\mathrm{S}_{2}$ of Phase 1, Specimen 14 was oven-dried and lost 10 pounds or 8.2 percent by weight. The dried specimen was re-installed in tne apparatus for exposure in Phase 2 and re-numbered as Specimen 29.

Figure 8 shows the performance of the cellu- 


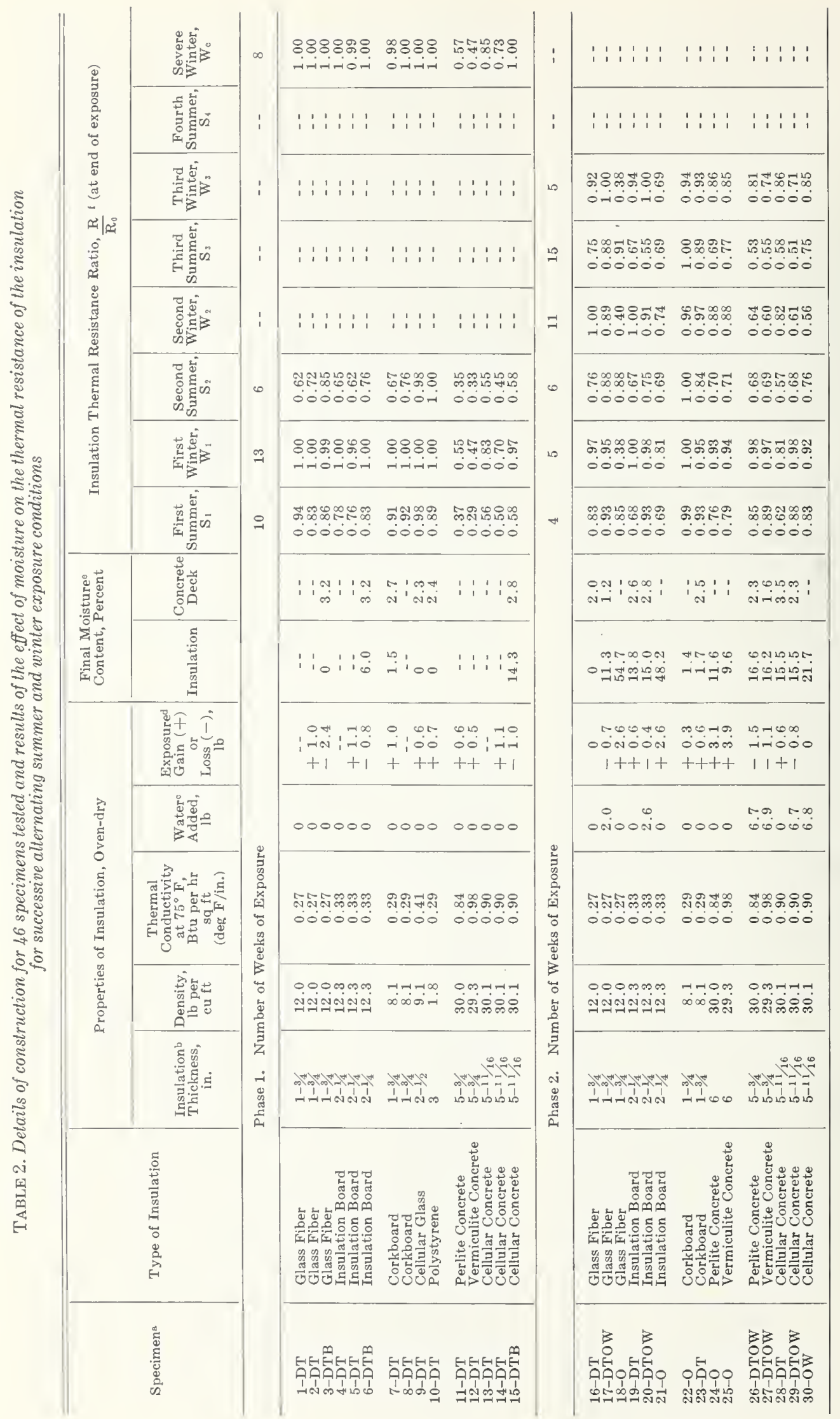




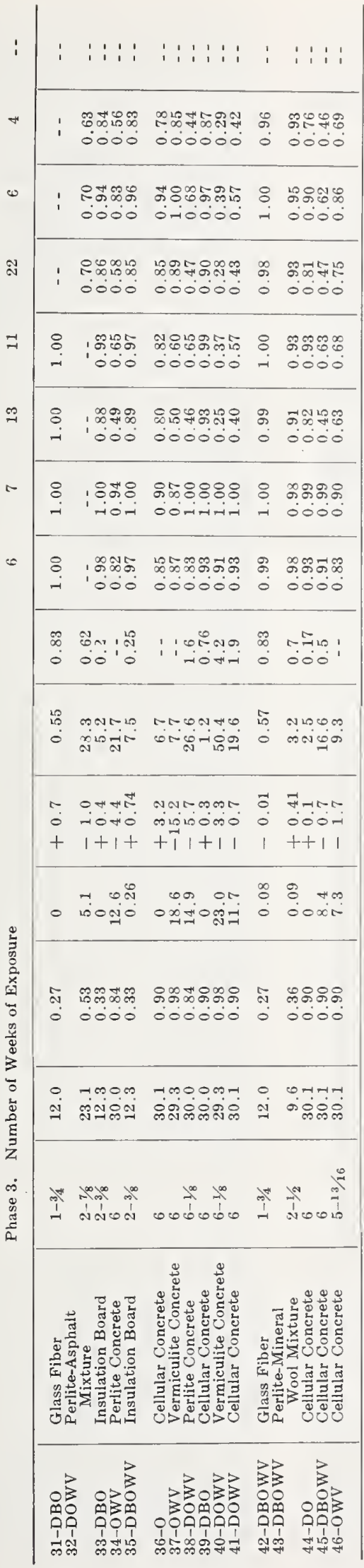

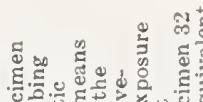

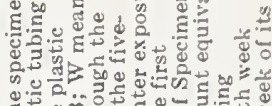

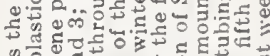
क

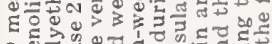

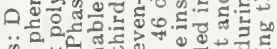
管

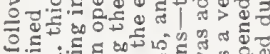

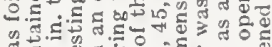
of

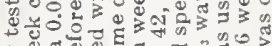
wo

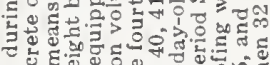
年 等

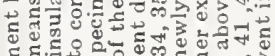
E.E.

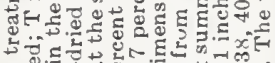
过.

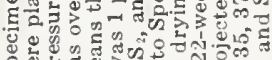

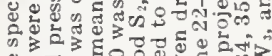

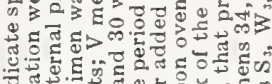

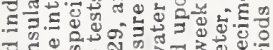
क. 等

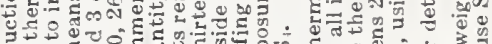

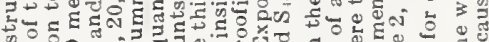
要

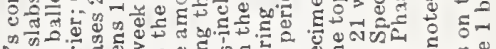

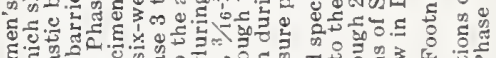

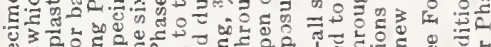

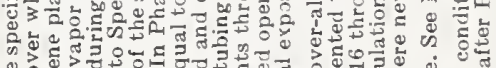

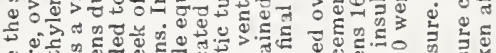

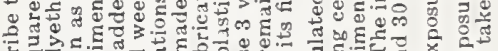

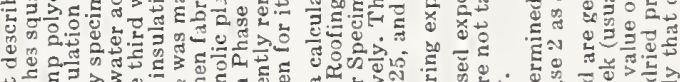

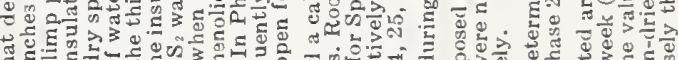

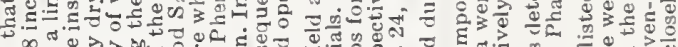

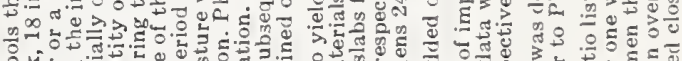

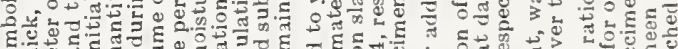

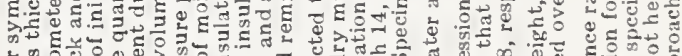

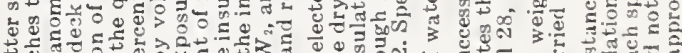

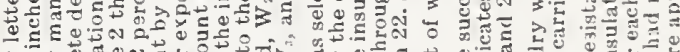

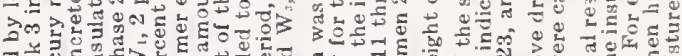

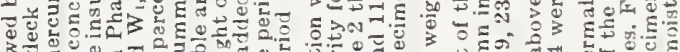

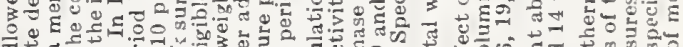
言造

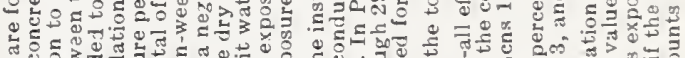
0.0

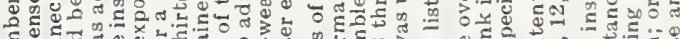

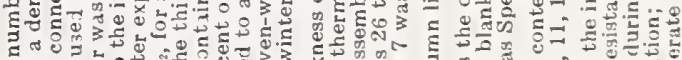

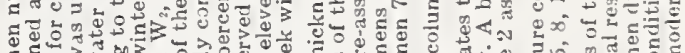

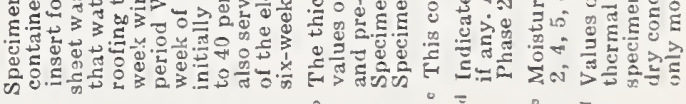


lar concrete insulation of Specimen 29 during Phase 2 . The values of $R / R_{0}$ for the first fourweek summer exposure period, $\mathrm{S}_{1}$, ranged from 0.83 to 0.88 and at the start of the five-week winter exposure period, $W_{1}$, was about 1.0 . After cumulative amounts of water, equal to 10 percent of the insulation volume $(6.7 \mathrm{lb}$.$) ,$ had been introduced into the specimen during periods $\mathrm{W}_{1}, \mathrm{~S}_{2}$, and $\mathrm{W}_{2}$, the value of $R / R_{0}$ decreased sharply during the fourth week of the eleven-week winter exposure period $W_{2}$ when an increment of water 7 percent by volume was added. During the subsequent fifteen-week summer exposure period, $\mathrm{S}_{3}, R / R_{0}$ increased slowly from 0.43 to 0.51 . For the five-week winter exposure period $\mathrm{W}_{3}$, the values of $R / R_{0}$ increased from 0.68 to 0.71 and this range is comparable with winter exposure periods $W_{1}$ and $W_{c}$ of Phase 1 on figure 7 . At the completion of winter exposure period $W_{3}$ of Phase 2 the specimen was oven-dried. Table 2 shows that the cellular concrete insulation contained $\mathbf{1 5 . 5}$ percent moisture by weight at this time and the dense structural concrete deck contained 2.3 percent; the moisture content for the specimen as a whole was 6.0 percent.

Figure 9 shows the performance of the cellular concrete insulation of Specimen 41 during Phase 3. Specimen 41 was closely similar in construction and physical properties to Specimens 14 and 29. The specimen was oven-dried iust prior to installation and was found to contain 11.7 pounds of water or 10 percent of specimen weight. This amount was subseauently added to the insulation of the specimen during exposure in Phase 3 . The value of $R / R_{0}$ near the end of the first six-week summer exposure period, $S_{1}$, was 0.93 and about 1.0 for the first seven-week winter exposure period $W_{1}$, indicating that the specimen was substantially dry during these exposures and contained only hygroscopic moisture. At the start of the second thirteen-week summer exposure period, $\mathrm{S}_{2}$, 11.7 pounds of water was added to the specimen, causing the $R / R_{n}$ ratio to decrease to 0.37 and it remained less than 0.41 over ten more weeks of exposure. This behavior is similar to that observed during the third summer exposure period $S_{3}$ of Phase 2 for Specimen 29 (figure 8 ) when 6.7 pounds of water were added to the insulation, causing the $R / R_{n}$ ratio to drop to 0.43 and increase slowly to about 0.51 after fourteen weeks of continuous exposure. Similarly, the $R / R_{0}$ ratio under winter exposure conditions for Specimens 41 and 29 ranged from about 0.5 to 0.57 and 0.6 to 0.72 , respectively, in Phases 2 and 3.

Valore [13] reports on literature sources that indicate for cellular concrete types of materials at ordinary temperatures an increase in effective thermal conductivity of from 2 to 4 percent for each percent increase in density due to moisture. The data shown in figures 8 and 9 indicate an average increase of 67 to 100 percent for winter exposure conditions versus 41.8 and 69.2 percent as would be predicted by the concept of a 2 to 4 percent increase of conductivity for each percent increase in density. For summer exposure conditions a similar comparison shows 122 to 170 percent versus 83.6 and 137.4 percent. The concept of a proportional increase of effective conductivity with density due to moisture is desired because of its simplicity. Use of this concept for predicting heat transfer in insulation of flat roof decks in service does not appear to be valid because of seasonal differences observed when the boundary conditions of temperature simulating solar exposure for winter and summer conditions were applied experimentally. Pratt [14] concludes that the relationship between conductivity and moisture, however reliably known, is of little value in matters of practical insulation without knowledge of the moisture content of the material in actual installations.

Sereda and Hutcheon [15] state that understanding of the phenomena of moisture migration is as yet only partial and has not progressed to the point of development of an adequate set of equations describing it. Also, they state that it seems necessary to suppose from what is already known that some variables that enter into the micro-distribution of both thermal and moisture potentials will always have to be accounted for by coefficients obtained by empirical methods.

Exposure conditions definitely influenced the insulating value when the same quantity of moisture was present in a specimen. Summer exposure conditions yielded lower insulating values than winter conditions. In figure 7 , the moisture content of Specimen 14 was little changed from week 10 , summer period $S_{1}$, to week 12 , winter period $W_{1}$. However, the values of $R / R_{0}$ for these two conditions were quite different; 0.50 and 0.67 for summer and winter, respectively. An explanation for these results is the different effect of the exposure conditions on the distribution of moisture in the insulation. In the summer exposure condition, the temperature gradient in the insulation reversed direction daily. See figure 5. Moisture present in the insulation would tend to migrate back and forth in response to the temperature gradient reversals and thus to be distributed and available for latent heat transfer. In the winter exposure condition, there was no daily reversal of temperature gradient (except possibly in the upper portion of the thickness of insulation) and the larger part of the thickness of insulation was relatively dry, and therefore the overall effect was a higher $R / R_{0}$ ratio as compared to the summer exposure conditions.

The discussion of results thus far has been limited to the cellular concrete insulation of Specimens 14, 29, and 41 . The results and com- 
parisons obtained for other types of insulating concrete specimens placed over structural concrete decks are similar (Specimen groups 13, $28,44,45 ; 15,39 ; 11,26,38 ; 12,27,40$ ) hence will not be presented in detail. Table 2 allows comparison of results amongst specimens of the same type of material and similar specimens containing different insulations. However, in the interest of brevity, in table 2 only the values of the ratio $R / R_{0}$ for the last week of each exposure period are given, since these values are considered to be indicative of the long-term performance of most specimens.

\subsubsection{Board Type Insulation Specimens}

The $R / R_{0}$ ratio for board types of insulation in Specimens 1 through 10 was higher in Phase 1 , as compared to the insulating concretes, Specimens 11 through 15, because they contained only hygroscopic moisture when installed, although their concrete decks contained moisture estimated at 3 to 4 percent by weight. During exposure in Phase 1 , moisture from the concrete decks plus water vapor from the indoor air, was transferred into permeable insulations during the consecutive thirteen-week winter period, $W_{1}$, and the eight-week severe winter period, $W_{c}$, of those specimens that did not contain a vapor barrier between the board insulation and concrete deck. Table 2 shows that Specimens 2, 5, and 7 gained 1.0, 1.1, and 1.0 pound, respectively, from the start to the end of exposure during Phase 1 . The effect of the moisture transferred into the permeable insulations on the insulating value is shown by comparing in table 2 the respective $R / R_{0}$ ratios at the ends of Phase 1 summer exposure periods $S_{1}$ and $S_{2}$ for Specimens 2, 5, and 7. Results for Specimens 1, 4, and 8 were similar in Phase 1, since these specimens were identical in construction to their counterpart Specimens 2, 5, and 7 respectively. The decline of the $R / R_{0}$ ratio was attributed to the moisture added to the insulations during the winter exposures. After exposure period $S_{2}$ of Phase 1 , Specimens 2 and 5 were oven-dried, but not disassembled, in preparation for Phase 2 exposures of the specimens. They each released 4.1 pounds of moisture.

Inspection of table 2 will show that in Phase 1 the practically vapor-impermeable board-type insulations of Specimens 9 and 10 show little change in $R / R_{0}$ values under summer and winter exposure conditions, even though the dense concrete deck, and vapor permeation through the deck during winter exposures, would have been sources of moisture to cause an effect during the second summer exposure period, $S_{2}$, if the insulations had been permeable. Table 2 shows that these specimens did show a net gain of weight during exposure in Phase 1. This gain was attributed to a gain in hygroscopic mois- ture content of the dense concrete since the insulations did not contain evaporable moisture upon oven-drying at the conclusion of Phase 1. These specimens were eliminated from the program after Phase 1.

\subsubsection{Comparison of Insulation Types}

Figure 10 shows a comparison of three specimens whose insulations cover a span of values for such physical properties as thermal conductivity, water vapor permeance, hygroscopicity, and water absorptiveness. Each specimen was oven-dried prior to installation in the apparatus and had water added to the insulations in increments as shown. In winter exposure period $\mathrm{W}_{2}$ the $R / R_{0}$ value for the cellular concrete, Specimen 29, dropped rapidly and remained low; but the wood-fiber, Specimen 20, and glassfiber, Specimen 17, insulation boards regained their insulating value after an initial drop because they allowed moisture to migrate more freely to the cold side. During the subsequent summer exposure period, $\mathrm{S}_{3}$, the $R / R_{0}$ ratio for the hygroscopic and absorptive materials of wood-fiber and cellular concrete was about 0.5 and showed only a slight tendency to increase with prolonged exposure, whereas, the $R / R_{0}$ for glass-fiber was initially low but showed a tendency to increase with time of exposure. From the start of Phase 2 to its end, Specimens 17, 20 , and 29 showed a gain in weight of $1.3,2.2$, and 5.9 pounds, respectively. The respective weights of water purposely added were 2.0, 2.6 , and 6.7 pounds, so that the specimens had net losses of $0.7,0.4$ and 0.8 pounds, respectively, over the whole of Phase 2. Apparently, each specimen allowed some transfer of moisture through its dense concrete deck since it is not impermeable and for the case of Specimen 17 the amount was sufficient to allow an increase in the $R / R_{0}$ ratio upon extended summer exposure in period $S_{3}$, but the quantity of moisture transferred was not enough to significantly affect the $R / R_{0}$ ratios of Specimens 20 and 29 because these specimens contained more water in the insulations and concrete decks than Specimen 17 as is shown by their final moisture contents in table 2. Later work presented in Part II of this paper will show that when a larger quantity of water-about 5 pounds-was added to the same thickness of glass-fiber insulation placed over a concrete deck, its $R / R_{0}$ ratio remained lowered for over ten weeks and did not show a tendency to increase.

The performances of all board types of insulation placed over dense concrete decks in Phases 2 and 3 can be similarly deduced and explained using the values given in table 2 . It will be noted that all board types of insulation that were dry or contained only small amounts of moisture yielded good insulating value under both summer and winter exposure conditions. 
During Phase 3, Specimen 31 was removed from the apparatus after its eleven-week winter exposure period $W_{2}$. In its place, Specimen 32 was installed in an oven-dry condition. Figure 9 shows the performance results obtained for Specimen 32. As shown, the $R / R_{0}$ ratios for summer and winter were high but declined when water was added to the specimen.

\subsection{Effects of Vapor Barriers and of Dense Concrete Decks}

Dry insulations protected by a vapor barrier and placed over a structural concrete deck tended to remain dry and provide good insulating value. Omission of the vapor barrier allowed moisture to migrate from, and to some extent through, the green concrete decks to the insulations. When the insulations were wetted, as in simulations of a roofing leak, they tended to remain moist and showed poor insulating values for long periods of time because of the impedance of the vapor barrier or concrete deck to movement of water vapor.

In Phase 1, Specimens 3, 6, and 15 had a sheet vapor barrier under the insulation, others did not. Table 2 shows that at the end of summer exposure $\mathrm{S}_{2}$ the values of $R / R_{0}$ were about the same as they were for the initial summer exposure $\mathrm{S}_{1}$, although they had been subjected for a total of 21 weeks to winter exposure periods $W_{1}$ and $W_{c}$, during which moisture from the dense concrete or the air below would ordinarily have tended to migrate into the insulations. Similarly constructed Specimens 1 and 2, 4 and 5, 13 and 14, respectively, which had no sheet vapor barriers, had average values of $R / R_{0}$ in Period $\mathrm{S}_{2}$ appreciably lower than those in $\mathrm{S}_{1}$, indicating increase in insulation moisture content due to winter exposures $W_{1}$ and $W_{c}$. Similar behavior was recorded for the insulations of Specimens 7 and 8, which were initially fairly dry and were moderately vapor-permeable, but not for the insulations of Specimens 9 and 10 , which had very low water vapor permeance. It should be noted that only the specimens having vapor barriers-3, 6, and 15-showed a loss in weight during exposures in Phase 1 as shown in table 2. This presumably was the result of drying of the dense concrete deck, the moisture of which could not enter the insulation during winter exposures $\mathrm{W}_{1}$ and $\mathrm{W}_{\mathrm{c}}$. Why a similar loss of weight did not occur for Specimens 9 and 10, which had quite vapor-resistant insulations, although no vapor barriers, has not been accounted for. It is speculated that the hygroscopic moisture equilibrium of these specimens was initially lower than that which would be obtained upon exposure to $90^{\circ} \mathrm{F}$ and 70 percent relative humidity indoor air. Also, the precise free moisture content of the concrete deck for each specimen was not determined before Phase 1 exposure and it would be expected to find absolute differences among the 15 slabs used. The weight data given in table 2 confirm that moisture did migrate into the insulation of the specimens without vapor barriers. From the start to the end of Phase 1, Specimen 2 without a vapor barrier gained 1 pound, while Specimen 3 with a vapor barrier lost 2.4 pounds. Upon oven-drying Specimen 2 lost 4.1 pounds and Specimen 3 lost 2.9 pounds. Before oven-drying at the end of exposure period $S_{2}$, the insulation of Specimen 3 contained no measurable moisture and its concrete deck contained 3.2 percent by weight. Since Specimen 2 was carried over intact to Phase 2, as Specimen 17, the moisture content of its materials was not determined after Phase 1 . Similar comparisons may be made of the data in table 2 for Specimens 6 and 5, and Specimens 15 and 14.

Further data on the effect of a vapor barrier can be seen in table 2 for Specimens 39 and 44 . Both were oven-dry at the start of exposure $\mathrm{S}_{1}$ in Phase 3; Specimen 39 had a sheet vapor barrier, 44 had only a dense concrete deck. Throughout all exposure periods of Phase 3, these insulations had $R / R_{0}$ ratios only moderately less than 1.0 ; although for both the ratios show a tendency to decrease slowly in successive similar exposure conditions. For Specimen 39 the decrease of $R / R_{0}$ was relatively less than for 44 , indicating the effect of the vapor barrier. It will be noticed, however, that the dense concrete deck of Specimen 44 evidently had substantial vapor resistance, and also that the deck was initially oven-dry and therefore unable to contribute moisture of its own to the oven-dried insulation. Similar behavior of other dry insulations was recorded for Specimens 31 and 33.

On the other hand, $R / R_{0}$ ratios for moist insulations used on concrete decks with or without a sheet vapor barrier remained low for long periods of exposure. This is evident in table 2 for Specimens 17, 20, 26, 27, and 29 in Phase 2 and Specimens $32,35,38,40,41$, and 45 in Phase 3 by comparing the $R / R_{0}$ ratios of these specimens during exposure periods when they were dry and when they contained moisture. For example, table 2 for Specimen 29 shows $R / R_{0}$ values of 0.88 and 0.98 for the cellular insulation at the ends of exposure periods $S_{1}$ and $W_{1}$. After water was added the $R / R_{0}$ ratios declined to 0.6 and 0.51 for $W_{2}$ and $S_{3}$, respectively, and remained low for many weeks during exposure $S_{3}$ as shown in figure 8. Figure 9 shows similar characteristics for Specimens 32 and 41, and figure 10 for Specimens 17, 20, and 29. Specimens $1,4,8$, and 13 in Phase 1 and Specimens 16, 19, 23, and 28 in Phase 2 did not have water added to them. However they did contain some moisture and the differences between summer and winter $R / R_{0}$ values for the several exposures are evident in table 2. 


\subsection{Behavior of Specimens Having No Dense Concrete Deck or Vapor Barrier}

Specimens consisting of roofing on a layer of insulation, without a vapor barrier or dense concrete deck beneath, showed, when once wet, a marked tendency to regain insulating value, presumably due to drying under the simulated summer exposure conditions. Under winter conditions, a slight decrease in insulating value occurred with continued exposure, presumably due to moisture gain from the indoor air, when the moisture absorptive capacity was large. However, for a vapor permeable construction of low moisture absorptive capacity, the insulating value was seriously impaired on continued winter exposure.

In Phase 2, three board type insulations (Specimens 18, 21, and 22) and three fill-type insulating concrete materials (Specimens 24, 25 , and 30) were exposed without dense concrete decks or vapor barriers underneath. Specimen 18 was highly permeable to vapor, but of very low moisture absorptiveness; Specimens 21 and 22 were moderately vapor permeable and of substantial absorptiveness; Specimens 24,25 , and 30 were moderately vapor permeable and highly absorptive. All specimens were oven-dried before installation, but some may have gained moisture hygroscopically before the test exposures started. Only Specimen 30 had water added to it during exposure. Table 2 gives $R / R_{0}$ ratio data for all specimens and figure 11 shows Phase 2 performance for Specimens 18,21 , and 30 .

Specimen 18 showed, to an extreme degree, rapid decreases in its $R / R_{0}$ ratio during winter exposures, and rapid increases during summer exposures, in all periods of Phase 2. This behavior would be expected for a permeable material exposed to a high relative humidity and during the first winter exposure period, $W_{1}$, a quantity of water dripped from the undersurface of the specimen. Evidently this insulation was too permeable to vapor, and too little absorptive of moisture, to endure long winter exposure without accumulation of excessive free water, when used without a vapor resistance underneath. At the end of the five-week winter exposure $W_{3}$ the average moisture content of the insulation of Specimen 18 was 54.7 percent by weight as shown in table 2 .

For Specimen $21, R / R_{0}$ values changed moderately with different exposure conditions, and tended to decrease slightly during winter exposures. For the exposure conditions imposed, the insulation appeared to reach repetitive $R / R_{0}$ values for alternating summer and winter exposure conditions, because of the ability of the material to hold sorbed moisture and dissipate it as vapor to the indoors under summer exposure conditions. The performance of Specimen 22 was similar to Specimen 21 except that its
$R / R_{0}$ ratios were higher as shown in table 2 . However, it is believed that for longer winter exposures than those shown in figure 11, some vapor protection underneath Specimens 21 and 22 would be necessary to avoid the extremes of the type evidenced by Specimen 18.

Specimen 30 showed decreases in its $R / R_{0}$ ratio under winter conditions especially when water was added in periods $W_{1}$ and $W_{\text {g }}$ of Phase 2. However, when Specimen 30 was given a long-term summer exposure, $S_{3}$ in figure 11, the $R / R_{0}$ ratio showed a definite increasing trend, indicating that the specimen was drying from its undersurface and recovering its insulating value. This observation was considered important because it showed experimentally the feasibility of self-drying insulated roof constructions that have become wetted from roofing leaks.

At the end of winter exposure period $W_{3}$ of Phase 2, figure 11, the percentages of moisture by volume were about the same (approximately 10 percent) in Specimen 18, made from glassfiber board, and Specimen 30, made from cellular concrete, but their $R / R_{0}$ ratios were very different, as shown. The difference appears to be due to the greater thickness, volume, and much greater moisture absorptive capacity of the insulating concrete specimen, and possibly also to its lower vapor permeability and higher thermal conductivity (which reduces temperature gradients in the insulation). Thus, although an exposed somewhat vapor-permeable insulation may gain moisture from indoors during winter exposures, such gains do not have an excessive depressive effect on the $R / R_{0}$ ratio if the moisture absorbing capacity of the construction is adequate.

The self-drying trend observed in Phase 2 was further investigated in Phase 3. Figure 12 shows a comparison of results for Specimens 37 and 40. Similar results were observed for Specimens 34 and 38 , and 46 and 41 , as can be seen in table 2. Specimens 37 and 40 were similar, except that 37 had no dense concrete deck. Both were initially oven-dried and both had water added to them at the start of summer exposure period $S_{2}$, in amounts equal to that removed when they were oven-dried (18.6 and 23.0 pounds, respectively). The $R / R_{0}$ ratios for both specimens were approximately the same during exposure periods $S_{1}$ and $W_{1}$. Addition of water at the start of exposure period $S_{2}$ caused an immediate sharp decrease in $R / R_{0}$ ratio for both specimens, but during the remainder of $\mathrm{S}_{2}$, the $R / R_{0}$ for Specimen 37 increased considerably while that for Specimen 40 showed only a minor change. In subsequent winter exposure period $W_{2}$, values of $R / R_{0}$ were markedly different. In summer exposure period $\mathrm{S}_{3}$, the $R R_{0}$ ratio for Specimen 37 increased to 0.90 , while the $R / R_{0}$ ratio for Specimen 40 increased to only 0.28 . In winter exposure period $W_{3}$, and 
summer exposure period $\mathrm{S}_{4}$, the $R / R_{0}$ ratio for Specimen 37 reproduced approximately the values observed in exposures $W_{1}$ and $S_{1}$ when it was substantially oven-dry. But for Specimen 40 , the $R / R_{0}$ ratio in exposures $W_{3}$ and $S_{4}$ had values only a little larger than those in exposures $W_{2}$ and $S_{3}$ when the specimen contained much moisture. Table 2 shows that Specimen 37 had an exposure loss of weight of 15.2 pounds, and Specimen 40 had a loss of 3.3 pounds. The final moisture content of the insulation of Specimen 37 was 7.7 percent by weight as compared with the insulation of Specimen 40 , which was 50.4 percent by weight. The conclusion that the increase of $R / R_{0}$ ratio of Specimen 37 was due to drying during summer exposure period $S_{3}$ is supported by the change of its $R / R_{0}$ ratio from winter exposure period $W_{2}$ to winter period $W_{3}$, while in the case of Specimen 40 this change was negligible.

The factors that influence the ability of wetted roof insulation materials to dry to the room beneath under summer exposure conditions, and of withstanding winter exposure conditions without serious loss of insulating value due to moisture gain from the indoor air are believed to be the moisture-absorbing capacity of the construction, and probably also the thickness, thermal conductivity, water vapor permeance, and arrangement of the components of the construction. The question of the deteriorating effects of freezing and thawing of moisture in the construction also requires consideration, but the importance of this problem is probably greater for a roof that does not dry in service than for one that does.

The insulating value of some roof constructions moderately permeable underneath after being wetted tended to reach from below a stable or plateau value that was not greatly different from that reached from above by similar initially dry constructions when both were exposed to the same alternating seasonal exposure conditions of summer and winter.

This observation is shown in figure 13. Specimens 36 and 46 had no dense concrete deck or vapor barrier and both were initially oven-dried before Phase 3 exposure. Their $R / R_{0}$ ratios were almost identical during exposure periods $S_{1}$ and $W_{1}$. At the start of exposure period $S_{2}$ water was added to Specimen 46 in an amount equal to its original moisture content, 20.8 percent by weight. Subsequently the $R / R_{0}$ values for Specimen 46 increased during summer exposure periods $\mathrm{S}_{2}$ and $\mathrm{S}_{3}$, while $R / R_{0}$ values for Specimen 36, which had no water added to it, decreased slightly during exposure periods following $W_{1}$. At the end of exposure period $\mathrm{S}_{4}$ the $R / R_{0}$ values for Specimens 36 and 46 were 0.78 and 0.69 , respectively, and their insulation moisture contents were 6.7 and 9.3 percent, respectively. In short, without dense concrete decks beneath them, a specimen of insulating concrete initially oven-dried, and one brought to 20.8 percent moisture content, tended toward the same operating values of thermal resistance and moisture content after a period of about 1 year exposure to the test conditions. Although there were no other pairs of specimens for making similar comparisons, it is evident that Specimen 37, figure 12, to which water was added, rapidly approached, during simulated summer exposures, $R / R_{0}$ values and a moisture content ( 7.7 percent after period $\mathrm{S}_{4}$, table 2) typical of fairly dry insulation.

\subsection{Pressure-Relieving Vents}

The use of small pressure-relieving vents through the roofing of specimens having moist permeable insulations had no appreciable effect in reducing the effective thermal resistance of the insulation. The vents used were sufficient to relieve internal pressures in pervious insulations, but were not ventilating channels through which outdoor air might move as a result of wind forces.

In all specimens in Phase 1 , a tubular connection was made between the interior of the insulation and either a manometer or limp polyethylene balloon of about 0.1 cubic foot volume when distended. Observed changes of volume of the balloon as a result of air volume changes were on the order of 75 to 100 cubic inches, during summer exposure $S_{1}$, for a cellular concrete specimen which had a relatively large void volume. The mercury manometer readings indicated daily changes of internal pressure in specimens for the same period equal to not more than 3 pounds per square foot. Since the specimens to which manometers were attached did not have sheet vapor barriers, it is believed that pressure relief occurred through the dense concrete slab, since otherwise pressure differences as large as 100 to 200 pounds per square foot would be expected for the temperature changes experienced by the insulations.

In view of the breathing action observed with the limp balloons, which was approximately of the magnitude to be expected, an effort was made in Phase 3 to determine if breather-type vents through the roofing would assist in increasing the $R / R_{0}$ values obtained with moist insulations. Accordingly, such vents were installed in 11 specimens as shown in table 2 . These specimens, which were installed in ovendried condition, had restored to them during summer exposure period $\mathrm{S}_{2}$ the amount of moisture removed by the oven-drying process. Fifteen weeks later, during winter exposure $W_{2}$, the vents were opened to communicate with the air over the roofing.

The criterion used for evaluating the effect of such vents was that if they had a substantial effect, it would be indicated by a change in the 
trend of the $R / R_{0}$ ratios in period $\mathrm{W}_{2}$ and subsequent periods. For the specimens shown in figures 9,12 , and 13 , and all other specimens, the trends that were established in periods $\mathrm{S}_{2}$ and $W_{2}$ before the vents were opened were not materially changed after the vents were opened.

A calculation of the probable drying rate of a cellular concrete specimen as a result of breathing action, based on daily venting of air saturated at the higher mean temperature of the insulation and its replacement by dry air as the specimen cooled during a summer exposure indicated that years would be required to effect a change in moisture content of only a few percent. The experimental evidence was in accordance with the calculated estimate.

\subsection{Changes of Indoor Air Temperature and Relative Humidity}

Changing the indoor air to a lower temperature and relative humidity decreased the insulating value during summer exposure of specimens containing much moisture but had much less effect on specimens of similar materials containing little moisture.

An example of the statement above is shown in figure 12. In Phase 3 during summer exposure $\mathrm{S}_{3}$, Specimen 40 shows a decrease in $R / R_{0}$ value in the time period when the indoor conditions were changed while the drying trend of Specimen 37, which contained much less moisture, was less affected. The observed decrease was probably caused by a redistribution of moisture in the specimen and possibly by a decrease in sensitivity of the apparatus when operated with small temperature differences of about $5{ }^{\circ} \mathrm{F}$ across the specimens prevailing during these weeks. The change of indoor air temperature from 80 to $88^{\circ} \mathrm{F}$, but with no change in vapor pressure, resulted in $R / R_{0}$ values which continued, approximately, the trend of $R / R_{0}$ values existing prior to the change, when the same indoor air vapor pressure was maintained. However, Specimens 37, 36, and 46, all without dense concrete decks, showed an immediate increase at week number 54 when the temperature was increased from 80 to $88^{\circ} \mathrm{F}$, as shown in figures 12 and 13 , respectively. This was attributed to a redistribution of the moisture in the specimens, which for these specimens was already much lower in quantity as compared with similar wetted specimens which contained a dense concrete deck.

It is important to note that the indoor dewpoint temperature for all exposures from week number 50 on was $60{ }^{\circ} \mathrm{F}$, whereas before that time it was $79^{\circ} \mathrm{F}$. For lowered dewpoints, which would be probable for all ordinary buildings in winter, the plateau-values of $R / R_{0}$ for constructions having self-drying characteristics probably would be greater and their moisture contents probably would be somewhat lower, than the values obtained experimentally.

\subsection{Roof Insulating Materials}

The roof insulating materials used in this investigation can be separated into groupings that have common characteristics important in connection with moisture problems and the effect on insulating value of moisture present in the roof construction. There are differences between insulation materials in each group, but such differences are less important than those between groups. A general description of the materials in each group and, based on data obtained in this investigation, the common general characteristics of each group are summarized below.

\section{Group 1.}

This group comprises insulations that are practically impermeable to vapor or moisture: Specimen 9, cellular glass; Specimen 10, expanded polystyrene. The effective thermal resistances were substantially equal to those of dry materials, and within the precision of the measurements were approximately the same for both summer and winter exposure conditions. Their resistances did not change appreciably with exposure time, under conditions where moisture was available from the dense concrete deck underneath.

\section{Group 2.}

This group comprises vapor permeable insulations which are delivered and installed in a substantially-dry condition: Specimens 1, 2, 3, $16,17,18,31$, and 42 , glass-fiber; Specimens 4 , $5,6,19,20,21,33$, and 35 , vegetable fiber insulation board; Specimens 7, 8, 22, and 23, corkboard; Specimen 32, a perlite-asphalt mixture fill insulation; and Specimen 43, a perlite-mineral wool insulation board.

These materials when installed at air-dry or oven-dry moisture contents, over a good vapor barrier, maintained effective thermal resistances approximately corresponding to those of the dry materials, throughout the duration of the tests. However, effective thermal resistances were perceptibly lower under summer exposure conditions than under winter exposure conditions and there was some evidence that thermal resistance tended to decrease slightly with time, presumably as a result of slow moisture gain through the vapor barrier.

Installed over "air-dry" dense concrete decks without a vapor barrier, the insulations apparently gained enough moisture from the decks in a relatively short time to cause perceptible decreases in effective thermal resistance during summer exposure conditions, but not during 
iter conditions. Effective thermal resistances leased slowly with exposure time, the demeases becoming observable during both summer and winter conditions.

Upon addition of appreciable water to these insulations, effective thermal resistance values decreased markedly, and were substantially less during summer exposure conditions than during winter conditions. Thermal resistance ralues with water added in the amount of 10 ercent of the insulation volume were from 50

67 percent of values expected for dry materials under summer exposure conditions, and from 83 to 100 percent under winter conditions. The specimens so treated had no vapor barriers; if there had been vapor barriers to impede transfer of some of the added water to the concrete deck, the effective thermal resistances would almost certainly have been still

Installed without a dense deck, or a vapor arrier, so that the insulation was exposed to the air underneath, these insulations were subect to apparent gains of moisture during the inter exposure conditions and losses during summer exposure conditions, as indicated by changes in effective thermal resistance values. These changes were apparently dependent on the permeability and moisture absorptive capacity of the insulation. See discussion under ection 5.3 .

The essential conclusions concerning permeable insulations of Group 2 when used over dense concrete decks are: a) that when dry, and kept dry by a vapor barrier, they yield approximately their dry-value insulating effect; that with a vapor barrier, and more so when placed directly on a dense concrete deck without a vapor barrier, they tend to decrease slowly in insulating value, especially for summer conditions; c) that if they are wetted, as by a leak through the roofing, or are installed with excessive moisture, their insulating effect is ver'y seriously reduced, especially for summer conditions, and is thereafter kept for long periods of time at reduced values as a result of the moisture transfer resistarce of a dense concrete deck and/or of the vapor barrier usually placed under these insulations. Except for insulations of this kind of moderately low vapor permeance and high moisture absorptiveness, they should not be used alone directly exposed to the air underneath.

\section{Group 3.}

This group comprised permeable insulations nixed with water in the process of application, and any of the second group which for any reason contained moisture, when installed, in excess of their normal hygroscopic moisture content or were made wet by adding water: Specimens 13, 14, 15, 28, 29, 30, 36, 41, 44, 45, and 46 , cellular concrete; Specimens 11, 24, 26,
34, and 38, perlite aggregate concrete; Specimens $12,25,27,37$, and 40 , vermiculite aggregate concrete. The water-mixed insulations of this group had free moisture contents ranging from about 20 to 60 percent by weight after several days of air drying. When used as specimens at these air-dry moisture contents, their insulating effects were from about one-half to one-quarter of their observed values when ovendry, depending upon whether they were being subjected to winter or summer exposure conditions, respectively. When insulations were placed on dense concrete decks, the impaired insulating values continued almost without significant improvement, throughout the period of observation. The lack of improvement is considered due to the effective resistance or impedance of the dense concrete decks to moisture escape frrom the undersurface of the insulation.

The same insulations, exposed to the air below without a dense concrete deck underneath, increased rapidly in insulating effect during exposure to a few alternations of the imposed summer and winter exposure conditions. In one case, the insulation attained, during the period of observation, an apparent plateau-value of insulating effect scarcely different from that of the substantially dry material, although its moisture content had been increased to about 63 percent by weight at the start. Similarlytreated specimens of other insulating concretes without decks showed an approach to the same behavior, but at a less rapid rate.

Specimens of these insulations, without decks, installed in an oven-dried condition, decreased perceptibly in insulating value when subjected to alternations of the test summer and winter exposures, and tended to approach, from a dry initial condition, the approximate plateau-value of insulating effect being reached from the other extreme by similar insulations to which water had been added.

\subsection{Comment}

\subsubsection{Test Conditions}

Surprisingly small values of effective thermal resistance were obtained in this investigation for moist insulations during the imposed summer exposure condition. In many cases, they were so much smaller than the values obtained for the same materials when dry that it appears reasonable to attribute a large part of the decrease to latent heat transfer involving evaporation of moisture at one place, its migration as vapor to a cooler region, and its condensation there.

In a noncapillary peimeable insulating material subjected to a steady temperature gradient in one direction, this distillation process usually results in a concentration of the moisture in the cooler parts of the insulation. Thus, most of the insulation contains only the moisture cor- 
responding to its hygroscopicity at humidities lower than 100 percent, and the over-all effective resistance is only moderately decreased by the loss of thermal resistance of the wetter portion. This was, in fact, approximately the result observed during the winter conditions of this investigation for insulations containing moderate amounts of moisture.

Under the imposed summer conditions of this investigation, however, the daily simulated solar heating caused daily reversals of temperature gradient in the insulation and thus, by distillation back and forth in each day, kept probably the whole thickness of the insulation at a condition of sufficient free water content to allow substantial latent heat transfer. This process affords reason to believe that the simulated solar heating period in the imposed summer exposure condition was the essential cause for the small effective resistances observed with moist insulations. In this connection it should be noted that for substantially dry insulations, effective resistances were approximately the same during the imposed summer and winter conditions; that is, when there were, and when there were not, daily temperature gradient reversals, respectively, and therefore that heat capacity effects at the times when resistances were determined were not the cause.

Whether the very low effective resistances indicated for moist permeable insulations in this investigation actually occur in roofs in service, and whether this finding is important practically, depends therefore upon whether daily temperature gradient reversals do occur in roof insulations in service, during summer or other seasons. There is little doubt that in summer, at least, in most areas of this country, the top surface of an insulated roof is considerably hotter than its undersurface during the sun-hours of the day, and that at night the undersurface of the roof is warmer than its top surface, for buildings not air-conditioned and possibly also for air-conditioned buildings, since roof surfaces are subject to comparatively rapid cooling by the night air and by radiation to a clear sky. Accordingly, one must conclude that free moisture in excess of the hygroscopic capacity of an insulation very seriously impairs the insulating effect of a permeable roof insulation in service under summer exposure conditions. It is felt, in fact, that if the investigation had been conducted without a simulated daily solar heating period causing temperature gradient reversals, this practically-important finding might easily have been missed.

It must be pointed out that in this investigation, effective thermal resistances were obtained during the substantialiy steady temperature conditions existing just before the onset of the solar heating period. However, during the solar heating period, and subsequently while the insulation was regaining the steady tempera- ture conditions mentioned above, considerably steeper temperature gradients must have existed within the insulation. Consequently, latrnt heat transfer must have been occurring at greater rates at these times than at the time measurements were made. Pecause of heat capacity effects, it is not feasib]e to estimate the over-all effective resistance of the insulation during the times of changing temperatures. Nevertheless, it seems reasonable that times over-all effective resistances of moist sulations were less than the values at the time observations were made. In other words, effective resistances given are probably greater than the average values over the 24-hour daily cycle.

One further point should be made concerning the exposure conditions used. The roofing surface temperatures were probably reasonably typical for roofs in service, but the $79^{\circ} \mathrm{F}$ dew point temperature maintained under the specimens throughout most of the tests undoubtedly was higher than typical for ordinary buildings More typical maximum dewpoints would prob ably not exceed $65^{\circ} \mathrm{F}$ in summer and $40{ }^{\circ} \mathrm{F}$ in winter. The effect of the $79{ }^{\circ} \mathrm{F}$ dewpoint in these tests was in the direction of greater gain, and smaller loss, of moisture by a specimen through its undersurface, than would occur at lower under-roof dewpoints. The effect therefore to decrease to some extent the "plateau-values" of effective resistance discerned in these results. The effect on values obtained for specimens containing considerable free moisture was probably small, but the inferred "drying-rates" observed would probably have been greater with lower under-roof dewpoints. Some slight evidence of increased dry ing-rates was obtained for Specimens 34, 37 , and possibly 45, during Phase 3 when the bottom air dewpoint was lowered to $60^{\circ} \mathrm{F}$.

\subsubsection{The Moisture Problen}

As mentioned in the introduction, there are several avenues by which excessive moisture can enter an insulated roof construction in service. The degree to which precipitation or roofing faults or punctures during construction may contribute moisture is an imponderable that is peculiar to each application and its history. Possibly in the same category is the moisture content of a dense concrete roof deck on which an insulation may be placed without a vapor barrier-but almost certainly, such a deck contains some excess moisture.

Insulations of appreciable hygroscopicity very probably contain moderate amounts of moisture when installed, depending on the anbient relative humidity. If the average moisture content is not well below the maximum hygroscopic capacity of the insulation, it is likely that its concentration by a temperature gradi- 
ent would yield "free moisture" in parts of it, and that latent heat transfer effects would be appreciable with reversing temperature gradients. It must be added that even hygroscopic moisture redistributes under a temperature gradient, and that for permeable insulations of high hygroscopicity some latent heat transfer will occur, at least while temperatures are changing.

Water-mixed insulations must be considered as containing excess moisture when roofed over. In view of the serious effects of this moisture, the only practical recourse appears to be to arrange matters so that these initially-moist insulations will dry out in a comparatively short time in service. As discussed below, this appears to be a possibility.

The most difficult problem is that of inleakage of water through leaks in the roofing. The possible quantity is an imponderable, except that usually a leak is not suspected until water has appeared at the undersurface of the roof. Apart from accidental leaks in new roofs, it must be regarded as a practical certainty that eventually leaks will occur as the roofing ages. In such event, maintenance of satisfactory insulating performance would require either that the insulation be removed and dried or replaced, or that the roof construction be capable of adequate self-drying in service. In this respect, insulations wetted by leaks and the water-mixed insulations are allied, and a common solution is required.

\subsubsection{Self-Drying Roofs}

By a self-drying roof is meant an insulated roof construction which under its in-service exposure conditions will expel excessive moisture from its insulation in a relatively short time; that is, in one summer or one year, and which subsequently will yield an insulating effect approximating that to be expected with the insulation dry. It is assumed that the moisture expulsion will take place through the undersurface of the roof, rather than through a system of ventilating channels or ports in the roof, which may constitute an effective means of drying a wet roof construction if suitable means are provided to attach and preserve the built-up roofing.

In this investigation, and for the exposure conditions used, it was found that wet insulations over vapor barriers, or on dense concrete decks, dried very slowly, if at all. On the other hand, roof specimens of thick monolithic insulating concrete exposed to the under-roof air dried quite substantially in 20 or 30 weeks of the imposed summer conditions. In one case, the insulation attained, after being wetted, the performance it had when installed oven-dried.

It is desirable to explain clearly what has been shown-namely, and merely, that a dense concrete deck under an insulating concrete im- pedes its necessary drying, and that without this deck satisfactory drying occurs. Apart from the important practical questions of the strength, and feasibility, of a roof of monolithic insulating concrete, one must consider that a form-board or decking is necessary to pour the roof. The question enlarges therefore to a consideration of practical permanent deckings other than dense concrete, and what properties these must have so as not to impede drying, or allow excessive moisture gain under winter conditions. It was found desirable in Part II to investigate self-drying designs for a wider selection of insulations than only the water-mixed insulating concretes, in view of the ubiquitous problem of roof leaks.

At present, understanding of the mechanisms of movement of moisture as water or vapor in materials is quite incomplete. When a problem involves differences in temperatures, and changing differences, as in the case of roofs, present knowledge does not allow a rigorous analytical approach with the complexities involved, although it does indicate possible fruitful lines of experimental attack. For instance, the impedance of a dense concrete deck for outward moisture passage has been thought here to be possibly a result of the relatively small temperature gradient in it because of its high conductivity. If this should be so, a deck material of low conductivity and probably of moderate permeability might be much more satisfactory for the construction of self-drying roofs. Because of the complexity of the total problem, and the need for temperature regimes simulating those of a roof construction in service, however, it was believed necessary to examine the various possibilities by means of laboratory or field roof exposure tests.

\section{Summary}

Appreciable amounts of moisture in permeable roof insulations seriously reduced their insulating value under both simulated winter and summer exposure conditions. For approximately the same moisture content, the effective thermal resistance of a permeable insulation was considerably less under summer conditions than under winter conditions, both of which included simulated solar heating of the roof for part of the daily cycle of temperature exposure.

For some insulations containing considerable but probably not untypical amounts of moisture, such as insulating concrete, the effective thermal resistances observed were as little as one-quarter of the values observed for the dry insulation, under the same summer exposure conditions, and about one-half the dry values, under winter exposure conditions. For nearlydry insulations, the decreases and seasonal differences were much smaller. 
A possible explanation for the smaller insulating effect of a given amount of moisture under summer exposure conditions as compared with winter conditions is that for the simulated summer exposure condition used, the temperature gradients in the insulation reversed direction daily. The reversal would tend to cause moisture to migrate back and forth each day, thus keeping it distributed throughout the insulation during the summer condition and available for latent heat transfer. Under the simulated winter condition used, there was no daily reversal of direction of the temperature gradient, except possibly in the upper portion of the insulation for a relatively short time, and the moisture would tend to migrate to and concentrate in the colder upper part of the insulation leaving the remainder of the insulation thickness relatively dry. Thus, the method of measurement used revealed that cyclic temperature conditions were essential to properly evaluate the effect of moisture on heat transfer in roof insulations.

The degree of impairment of insulating value with moisture content varied with the properties and the arrangement of the component materials of the specimens. In general ,the reduction of insulating value was not proportional to moisture content, since it was also a function of the temperature conditions imposed and the resulting distribution of the moisture in the specimen.

For roof insulations that are dry, a vapor barrier and a dry dense concrete deck are advantageous, since they help keep the insulation dry. But for roof insulations which initially contain appreciable moisture, or those made wet from a leak in the roofing during service, the moisture transfer resistance of a vapor barrier and/or of the dense concrete deck impedes drying of the insulation through its undersurface, and keeps the insulation in a moisture condition at which its insulating value may be seriously reduced.

A vapor barrier between an initially-dry roof insulation and a concrete deck that is not dry prevents dampening of the insulation in winter by moisture from the deck, which otherwise would occur because air-dried concrete contained approximately 1.3 pounds of water per square foot of deck.

Changes in the effective thermal resistance of permeable roof insulations with time for the same seasonal exposure condition were almost inappreciable when a sheet vapor barrier separated the insulation and the dense concrete deck. In most cases, changes were also materially retarded when the insulation was placed directly on the deck without the sheet vapor barrier, apparently because of the effective resistance to moisture transfer of the dense concrete deck.

Apparent self-drying tendencies were ob- served for roof specimens consisting of roofing and a layer of insulating material installed without a dense concrete deck or sheet vapor barrier underneath. For insulations of moderate permeability to water vapor and relatively high absorptive capacity installed in this way, it was found that the originally low effective thermal resistance of the initially moist insulation tended to increase rapidly during the simulated summer exposures, and to approach a value not much less than that of the dry insulation, presumably as a consequence of drying through the undersurface. When the insulation was initially dry relatively small and slow decreases in thermal resistance were observed because of a slow gain in hygroscopically held moisture. The results indicated that for some insulations the effective thermal resistance, whether the insulation was dry or moist initially, tended to reach an approximately stable level value, or plateau, not greatly different from that of the substantially dry material during corresponding seasonal conditions.

The same type of behavior was observed for all specimens without dense concrete decks underneath and such constructions were considered to be generally satisfactory for practical use except for those specimens containing insulations of high permeability to water vapor and of low absorptive capacity. Changes in effective thermal resistance of the latter with changes in seasonal exposure were extreme, and the level of resistance observed for winter was considered unsuitable for practical use.

Specimens of some insulations used without dense concrete decks, initially at appreciable moisture contents, attained high values of effective thermal resistance in one or two alternations of the imposed summer and winter exposure periods. In contrast, for specimens of similar insulations, also initially appreciably moist, placed on dense concrete decks with or without a sheet vapor barrier, the effective thermal resistance remained at substantially their original low values throughout the same exposure periods.

The fact that some constructions had the ability to self-dry through permeable undersurfaces under simulated summer exposure has major practical significance. Even the best built-up roofing will ultimately leak and should a roofing leak develop it would easily be detected because no vapor barrier was used. Once repaired, the roof would tend to recover its original insulating value due to self-drying and expensive replacement of large areas of insulation and roofing would be eliminated. The performance of suitable self-drying constructions is the subject of Part II.

The use of small pressure-relieving vents through the roofing of specimens having moist permeable insulations had no appreciable effect in reducing the effective thermal resistance of 
the insulation. The vents used were sufficient to relieve internal pressures in pervious insulations, but were not ventilation channels through which outdoor air might move as a result of wind forces.

Changes of the indoor air to a lower temperature and relative humidity decreased the effective insulating value during summer exposure of specimens containing much moisture but had much less effect on specimens of similar materials containing little moisture.

\section{References}

[1] Prestrud, Kristian K., Compact roofs (in Norwegian with English summary), Royal Norwegian Council for Scientific and Industrial Research, Building Research Department, Report No. 4, 69.024.3:693.55, (1951).

[2] Lund, C. E., and Granum, R. M., Principles affecting insulated built-up roofs, Engineering Experiment Station Bulletin No. 34, University of Minnesota Institute of Technology, (May 1952).

[3] Roof decks and built-up roofing, Federal Construction Council Technical Report No. 16, File C, Building Research Advisory Board, National Academy of Sciences-National Research Council (August 1955).

[4] Gumpertz, Werner H., Insulation for flat roofs, Progressive Architecture, (December 1964).

[5] Hutcheon, N. B., Vapor problems in thermal insulation, Anierican Society of Heating and Air Conditioning Engineers Journal Section, Heating, Piping and Air Conditioning, (August 1958).

[6] Powell, F. J., and Robinson, H. E., Measurement of effect of moisture on heat-transfer through insulated flat-roof constructions, Special Technical Publication No. 312, Symposium On Methods of Testing Building Constructions, American Society For Testing and Materials, (1962).

[7] Topping, C. H., Myhre, A. M., Warren, W. B., and Allen, J. R., A study to improve bituminous roofs, Monograph No. 1, Building Research Institute, National Academy of Sciences-National Research Council, (1960).

[8] Joy, F. A., Premature failure of built-up roofing, Better Building Report No. 5, Engineering Ex- periment Department, Building Research, Pennsylvania State University, (1963).

[9] American Society of Heating, Refrigerating and Air-Conditioning Engineers Guide and Data Book, Fundamentals, (1967).

[10] Ballantyne, E. R., and Spencer, J. W., Temperatures of bituminous roof surfaces, Bulletin, American Society for Testing and Materials, No. 223 (July 1957, TP 135).

[11] Ballantyne, E. R., and Martin, K. G., Bituminous roofs, Building Study No. 1, Division of Building Research, Colnmonwealth Scientific and Industrial Research Organization, Australia (1960).

[12] Cullen, W. C., Solar heating, radiative cooling, and thermal movement-their effects on built-up roofing, NBS Technical Note 231 (1963).

[13] Valore, R. C., Jr., Cellular concretes, Parts 1 and 2, Journal of the American Concrete Institute, (May and June, 1954).

[14] Pratt, A. W., Heat transfer in porous material, Research (May 1962).

[15] Sereda, P. J., and Hutcheon, N. B., Moisture equilibrium and migration in building materials, American Society for Testing and Materials Symposium on Material Behavior During a Fire Test, (1964).

[16] Whippo, H. M., and Arnberg, B. T., Survey and analysis of the vapor transmission properties of building materials, Final Report No. 1, Engineering Experiment Station, University of Colorado, (January 1955), also available as PB 131219, from the National Technical Information Service, U.S. Department of Commerce, Springfield, Virginia 22151.

[17] Johansson, C. H., and Persson, G., Moisture absorption curves for building materials, Byggmastaren, 17:311-314, Stockholm, Sweden (1946), available as Technical Translation 747 , by H. A. G. Nathan, National Research Council of Canada, Ottawa, (1958).

[18] Hansen, David, The process of drying, American Society for Testing and Materials Symposium on Material Behavior During a Fire Test (1964).

[19] Standard Method of Test for Thermal Conductivity of Materials By Means of the Guarded HotPlate: ASTM Designation C177.

[20] Standard Methods of Test For Water Vapor Transmission of Materials in Sheet Form: ASTM Designation E96-66T, Method A.

[21] Standard Methods of Test for Water-Vapor Transmission of Thick Materials: ASTM Designation C355-64 (Desiccant Method). 


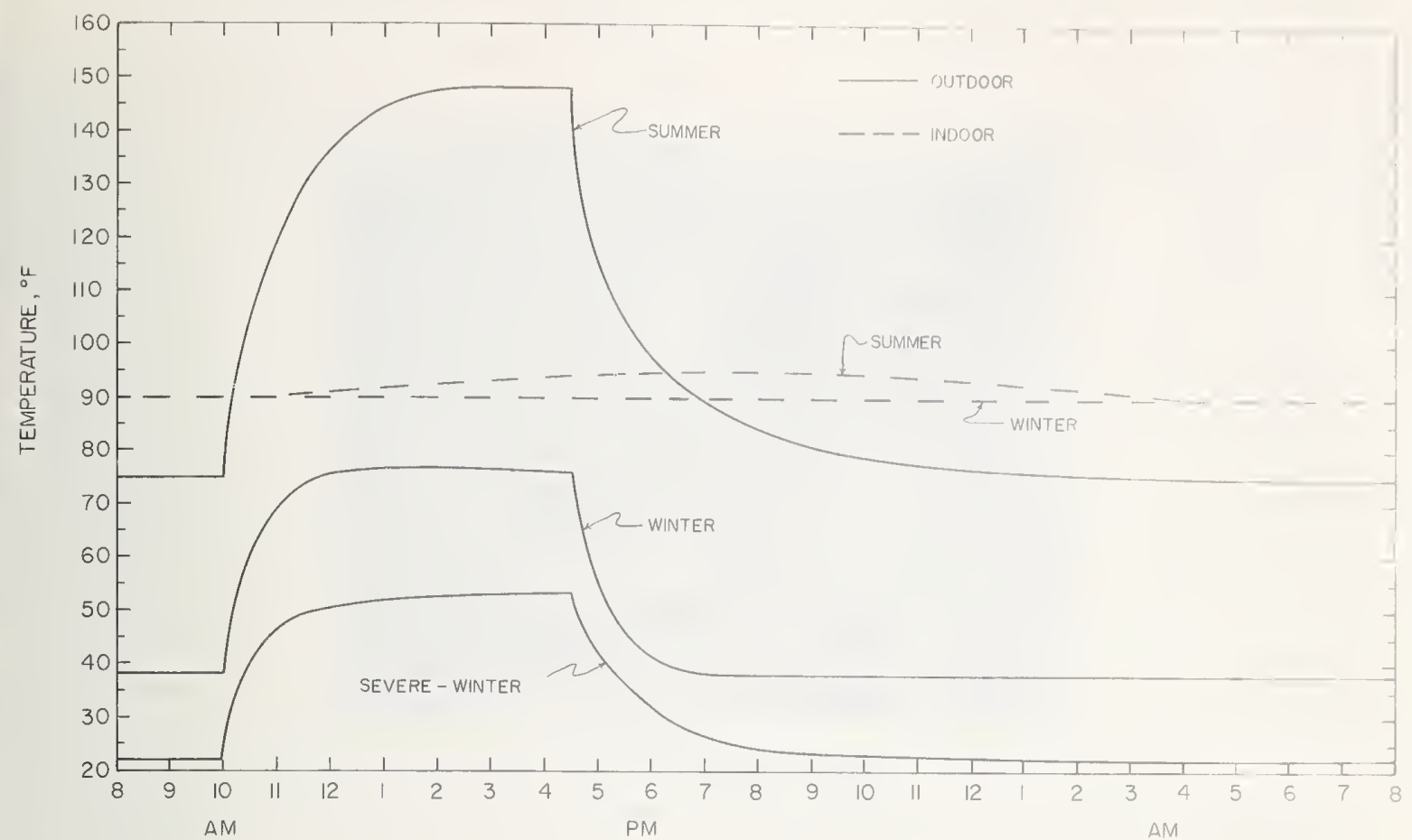

TIME OF DAY

FIGURE 1. Daily air temperature variations used to simulate winter and summer exposurc conditions, including solar heating period, for insulated flat-roof specimens.

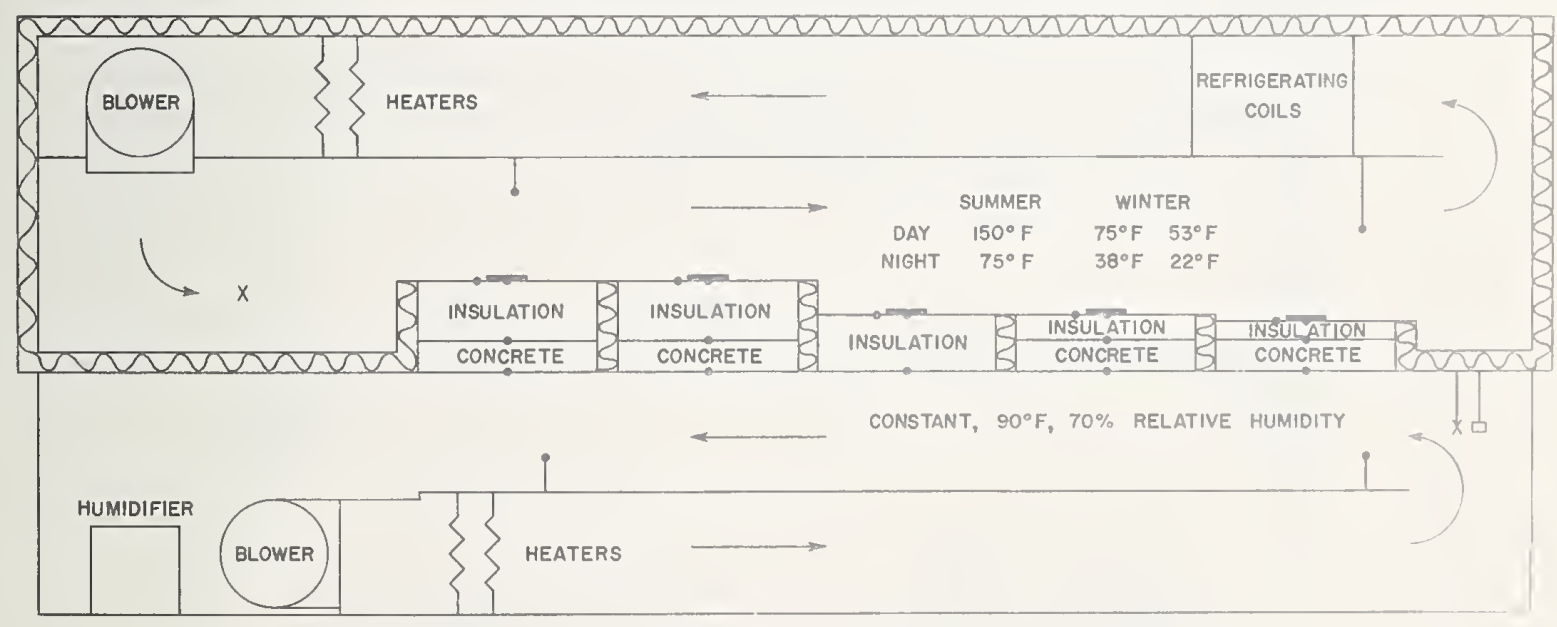

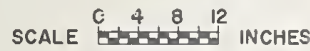

\section{LEGEND}

- THERMOCOUPI.E

$X$ temperature cuntrol

D HUMIDITY CONTROL

- HEAT FLOW METER

Figure 2. Apparatus for measuring the effect of moisture on heat transfer using the heat-floul-mete with th. 


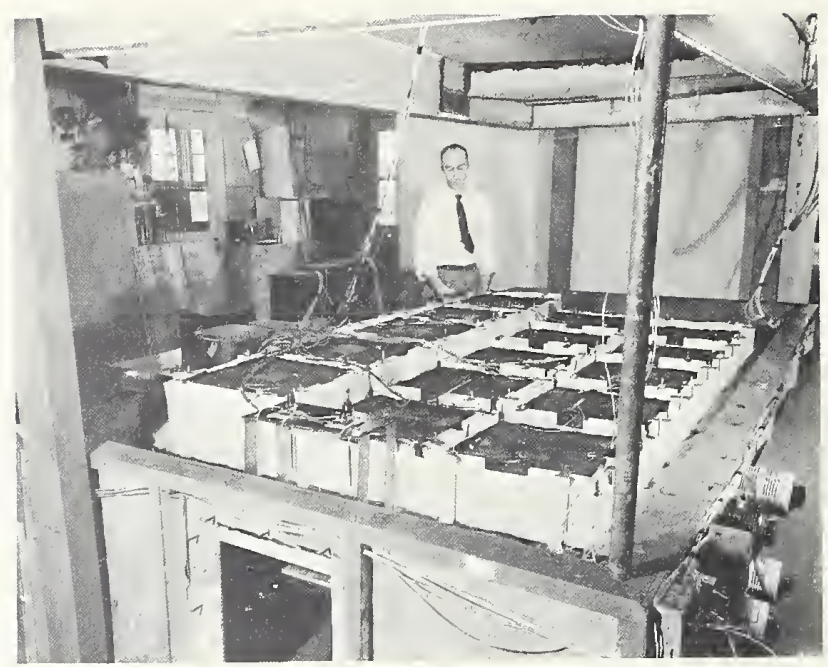

FIGURE 3. Apparatus for heat-flow-meter method with the top chamber in a raised position. Fifteen specimens are visible with their attached heat-flow meters.

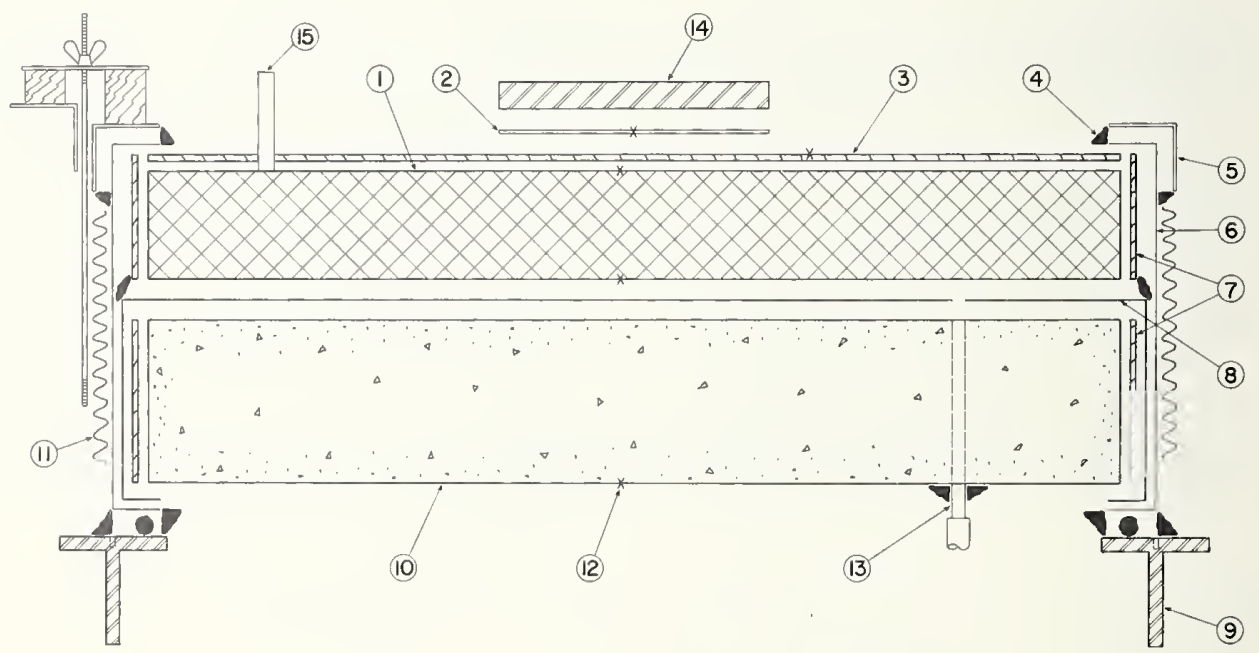

I. INSULATION SPECIMEN

2. HEAT FLOW METER

3. 5-PLY BUILT-UP MEMBRANE

4. MASTIC

5. ALUMINUM ANGLE ABOUT PERIPHERY

6. PLASTIC FILM WRAPPING

7. ASPHALT EDGE SEAL
8. VAPOR BARRIER

9. STEEL FRAME SUPPORT

10. DENSE CONCRETE, 145 pcf

II. EDGE INSULATION

12. THERMOCOUPLE

I3 TUBING INSERT

14. STEEL BLOCK

15. VENT TUBE

FIGURE 4. Construction and installation details of a typical specimen used with the heat-flow-meter method. 


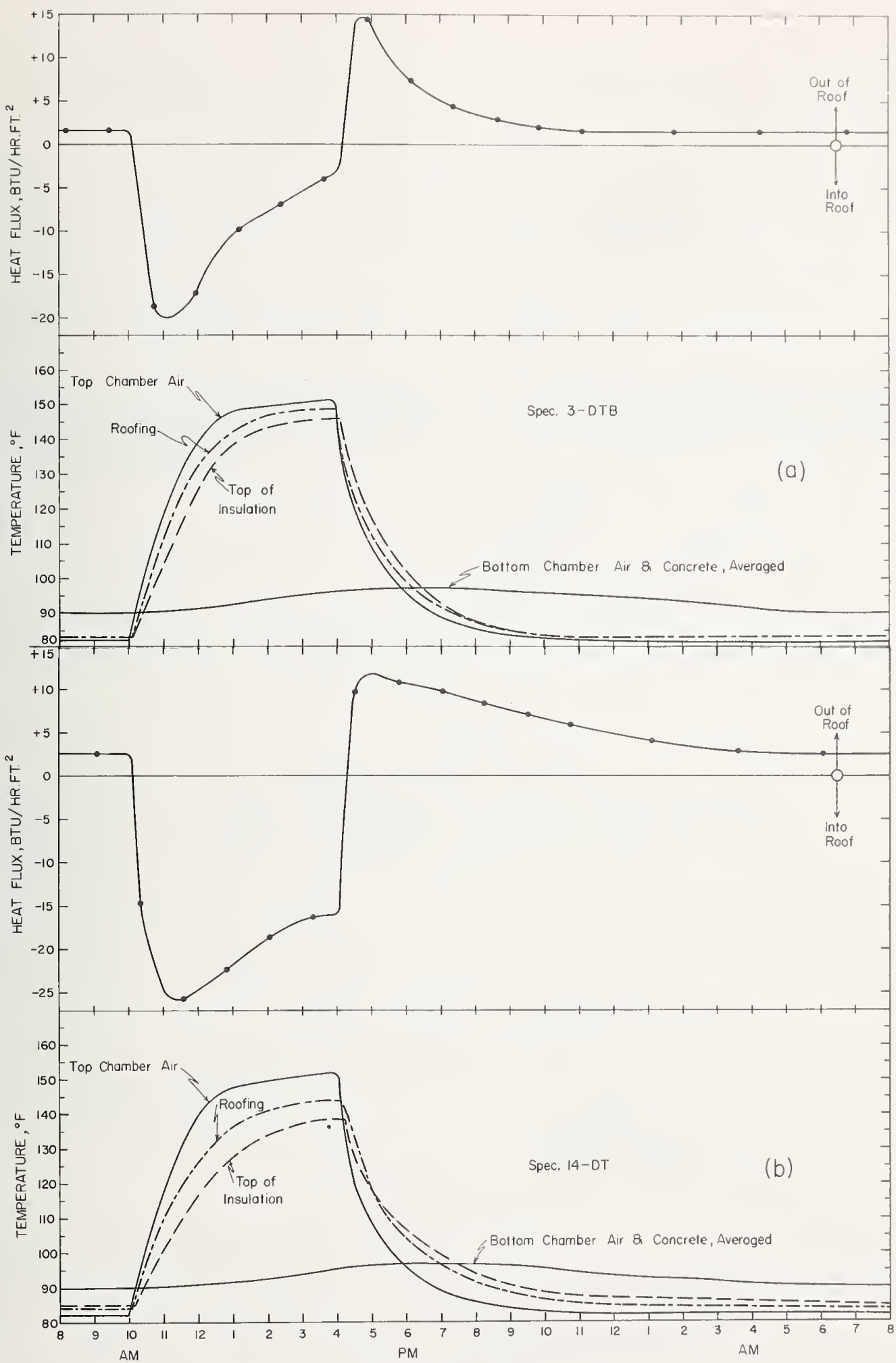

TIME OF DAY

FIGURE 5. Temperatures and top surface heat fux results for one day of a summer exposure.

(a) Specimen No 3-DTB was made from a 3 -inch-thick structural concrete deck over which was placed a vapor barrier and $13 / 4$-inch-thick glass-fiber roof insulation.

(b) Specimen No. 14-DT was made from a 3 -inch-thick structural concrete deck over which was placed a $5 \% / 4$-inch-thick cellular concrete insulation without a vapor barrier at the interface of the materials. 


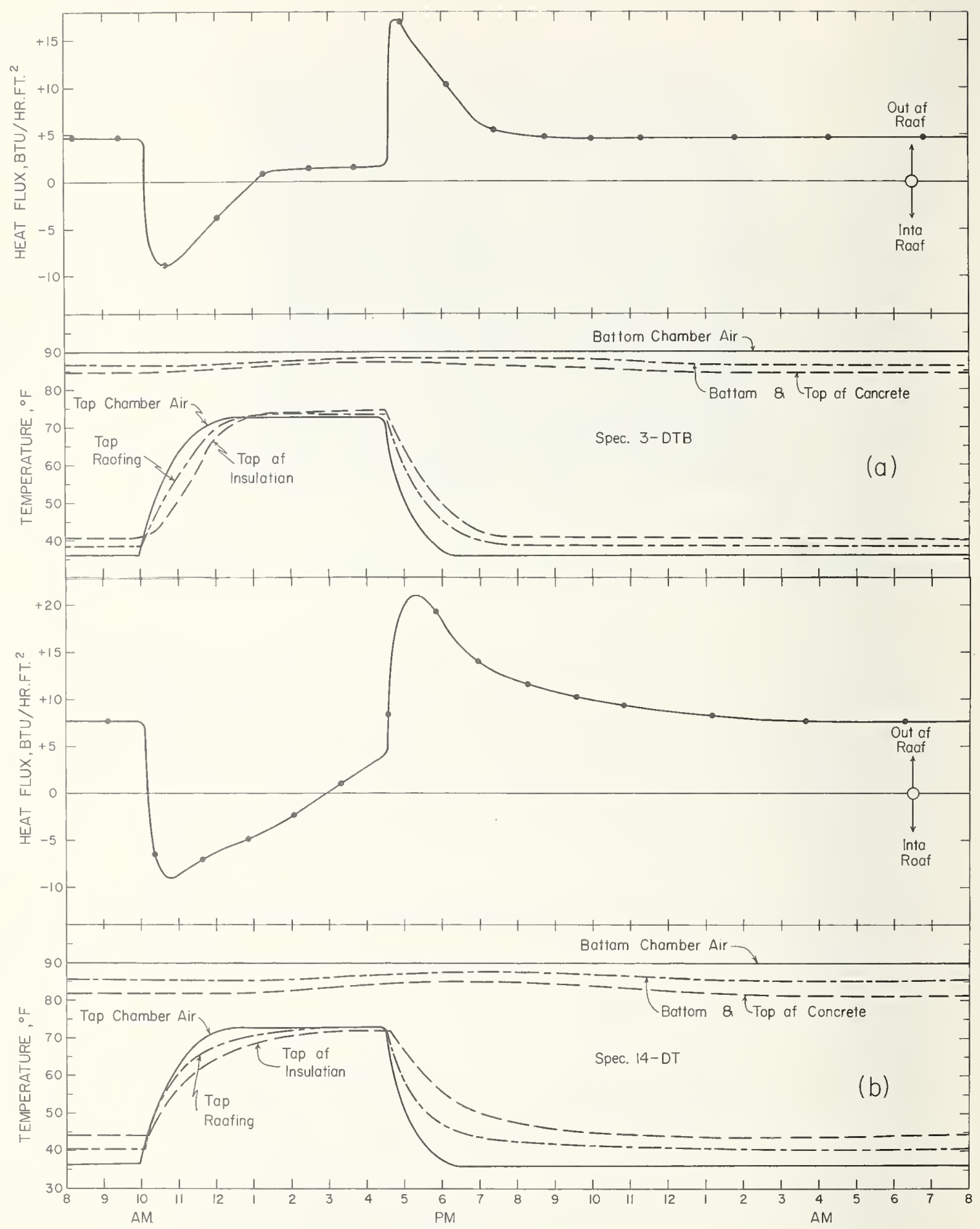

TIME OF DAY

FIGURE 6. Temperature and top surface heat flux results for one day of a winter exposure. (a) Specimen No. 3-DTB was made from a 3 -inch-thick structural concrete deck over which was placed a vapor barrier and $1 \% / 4$-inch-thick glass-fiber roof insulation.

(b) Specimen No. 14-DT was made from a 3 -inch-thick structural concrete deck over which was placed a 5-11/16-inch-thick cellular concrete insulation without a vapor barrier at the interface of the materials. 


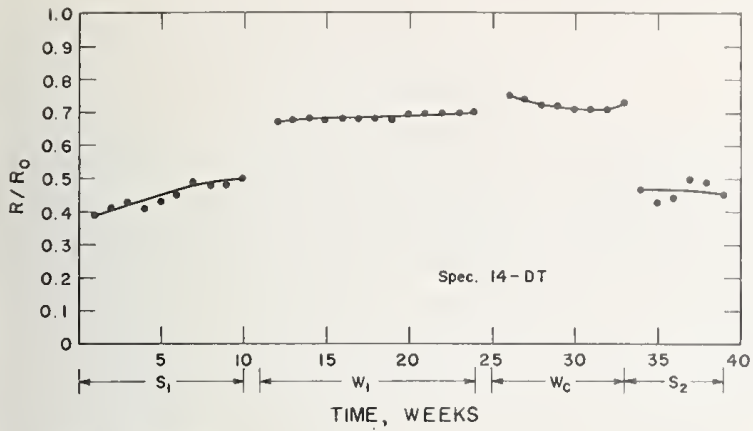

FIGURE 7. Effect of moisture and exposure conditions on the effective thermal resistance of the cellular concrete insulation of Specimen No. 14-DT during Phase 1.

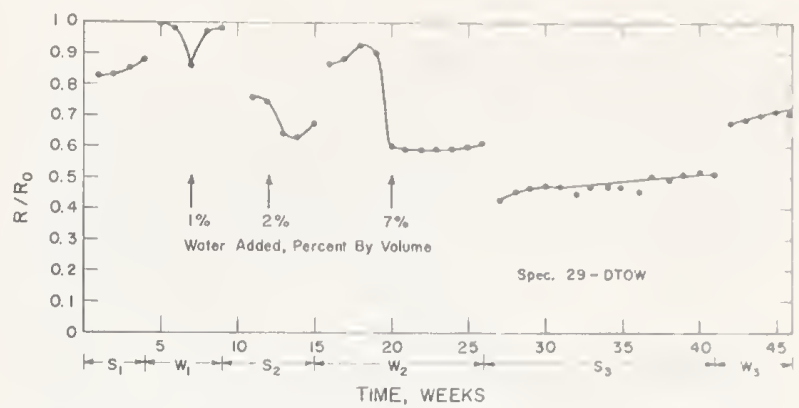

FIGURE 8. Effect of moisture and cxposure conditions on the effective thermal resistancc of the cellular concrete insulation of Spccimen 29-DTOW during Phase 2.

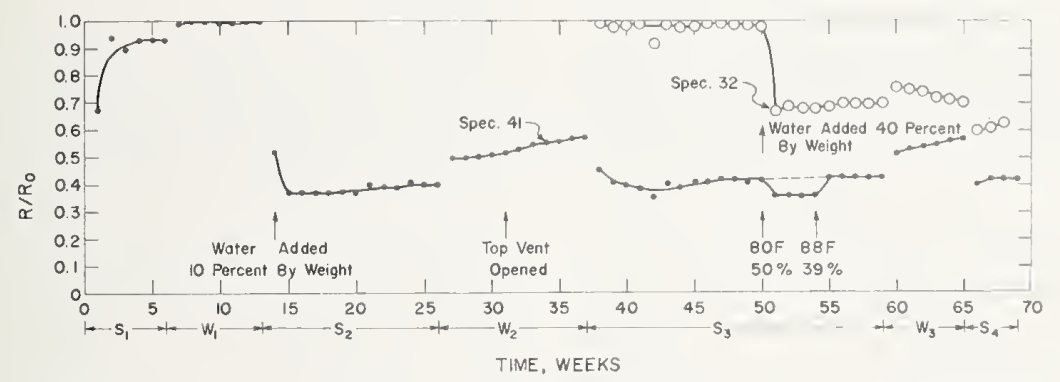

Figure 9. Effect of moisture and exposure conditions on the effective thermal resistance of the cellular concrete insulation of Specimen 41-DOWV and the perlite-asphalt insulation of Specimen 32-DOWV during Phase 3.

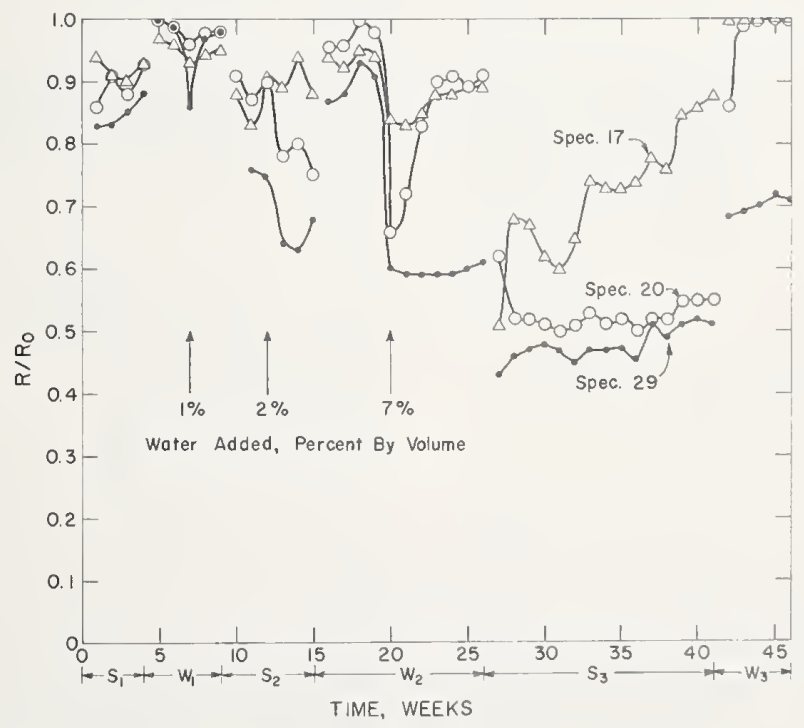

FIGURE 10. The effect of moisture and exposure conditions on the effective thermal resistance of the glass-fiber insulation of Specimen 1\%DTOW, and the wood-fiber insulation of Specimen 20-DTOW, during Phase 2. 


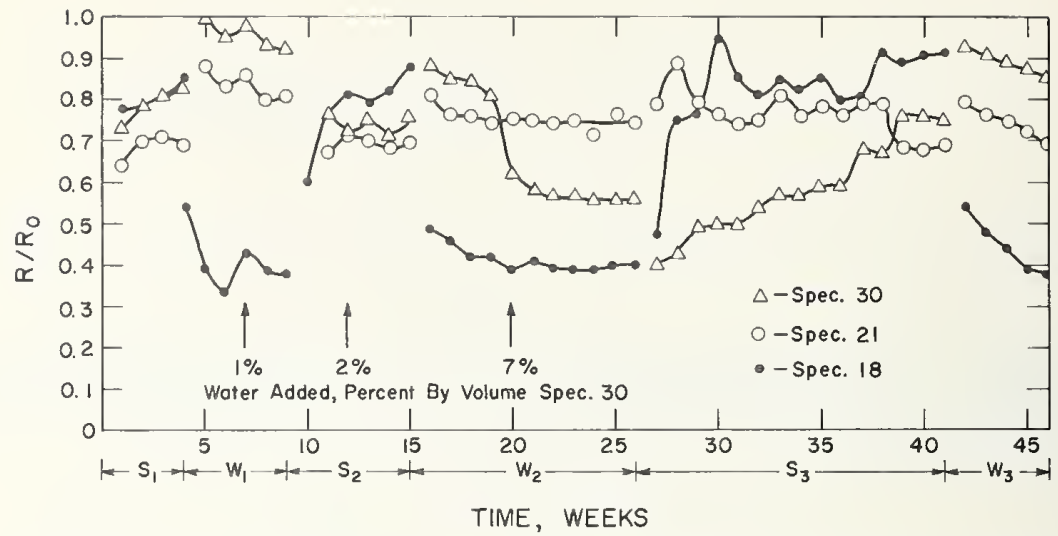

FIGURE 11. The effect of moisture and exposure conditions during Phase 2 on the effective thermal resistance, and the wetting and self-drying effects on specimens made without dense concrete decks. Specimen 18-0 contained glass-fiber insulation, Specimen 21-O wood-fiber insulation, and Specimen 30-OW cellular concrete insulation.

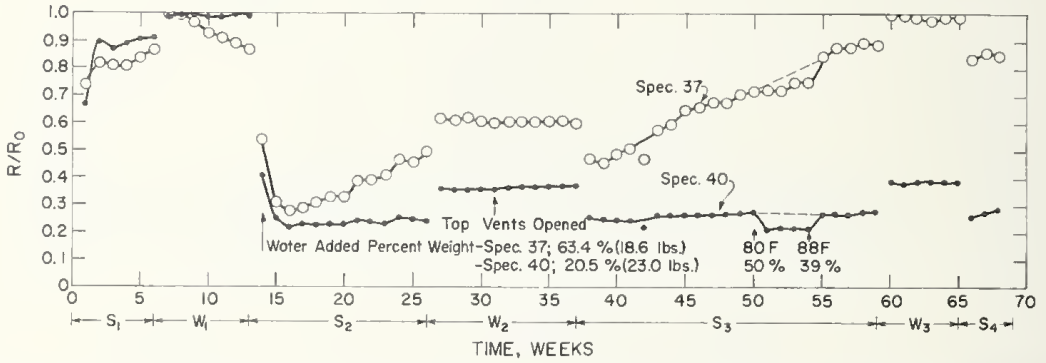

FIGURE 12. Comparison of the performance of vermiculite concrete insulation used with a dense concrete deck, Specimen 40DOWV; and without a dense concrete deck, Specimen 37$O W V$.

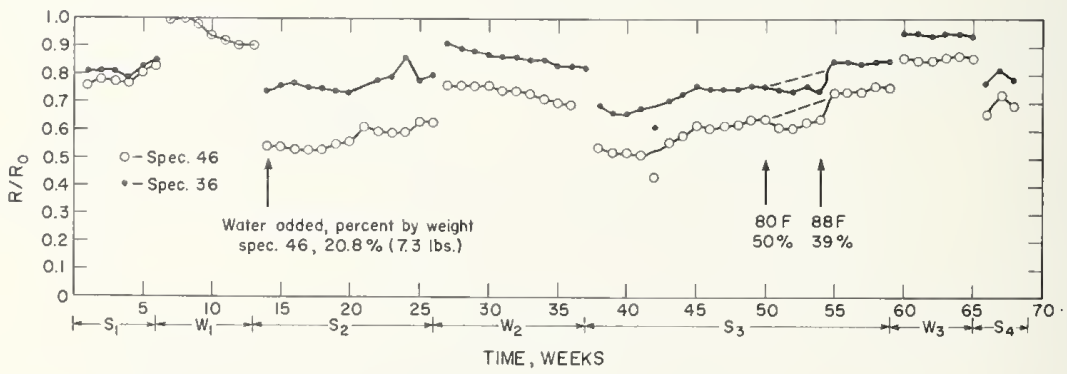

FIGURE 13. Comparison of the performance of cellular concrete insulation without a dense concrete deck. Specimen $36-0$ had no water added to the initially oven-dried insulation, while Specimen 46-OWV did. 


\section{Introduction}

In Part I it was found that roof specimens whose undersurfaces were of a moderately vapor-permeable nature tended to dry out significantly during simulated summer exposure conditions, and to recover nearly all of the insulating value expected of them in a dry condition, even if they had been excessively moist. Also, the moisture accumulated during winter exposure was reasonably low. On the basis of these findings, it was reasoned that the most practical and economical solution to the problems of moisture in insulated flat-roof constructions was to provide a design that would have in-service self-drying characteristics, should it become wetted for any reason. Since it is virtually impossible to keep moisture out of building constructions, the basic assumption was made that a construction will be wetted at some time during its service life; for example, from initial construction moisture or from a roofing leak. If the roofing leaks and the construction possesses self-drying characteristics, all that would seem necessary would be simple patching of the roofing, as compared to some designs that have required costly replacement of roofing and insulation with no assurance of non-recurrence in the future. Should the roofing remain water-tight for relatively long periods of time, as is probable, the construction should also be capable of absorbing and retaining without physical damage moisture that slowly accumulates over a winter. In the spring and summer the winter-gained moisture should be expelled by utilizing the heat of the sun on the roof. Thus, the insulating integrity of the roof construction could be maintained yearround.

In order to obtain information on the heat transfer and self-drying characteristics of selected types of insulated flat-roof constructions an experimental investigation was undertaken. The work was organized to provide a systematic method and procedure for experimental study of the factors that influence the in-service self-drying performance of particular types of insulated roof constructions. Designs that utilize formboards, precast channels, slabs, or tiles were selected because they allow considerable control in connection with insulating values and moisture passage through their undersurfaces. The factors that appeared to influence the wetting and drying rates and insulating value of an insulated roof construction were the exposure conditions of temperature and relative humidity, the arrangement and dimensions of the components of the construction, and physical properties such as thermal con- ductivity, vapor permeability and moisture absorbency. Materials for specimens were selected to provide as broad a range of each physical property as was available from commercially obtainable products. The designs of most specimens were chosen so that they could easily be adapted for use on buildings.

The method of measurement and apparatus used in Part I of this paper was considered inadequate for Part II because it did not allow weight measurements during the heat transfer tests. A new apparatus was designed and built that would allow simultaneous weight and heat transfer measurements on individual specimens during their exposures. The new equipment also provided better control, and increased flexibility and convenience of operations. A new calorimetric technique for measuring heat flux over the whole of the specimen area was devised and incorporated in the new apparatus.

Part II gives: the experimental exposure conditions used; a brief description and a reference for the method of measurement and apparatus; a tabulation of the specimens, materials, and their physical properties; the test procedures; results in graphical form; a discussion of meaningful results; proposed criteria for evaluating insulated self-drying designs for flat-roof constructions; and a summary. Exposure tests spanned a total of six years and in all 27 specimens were used, each $22 \times 23$ inches in plan. Specimens were subjected to successive periods of simulated summer and winter outdoor surface temperature conditions, each with simulated daily solar heating of the roof surface. In some cases simulated spring aná fall temperature conditions were used. The tests included exposures of specimens initially at a moisture content commensurate with that of a roof when roofing is normally applied and when wetted in simulation of a roofing leak.

\section{Experimental Exposure Conditions and Method of Test}

In Part I it was shown that use of temperatures that simulate in-service exposure is necessary for proper evaluation of insulating value, especially under summer conditions. In fact, many of the findings would not have been determined had steady-state temperature exposures been used. In the method of measurement used in Part II, a water-cooled metal calorimeter plate was used in place of roofing on a specimen. Steady water temperatures in the plate were adjusted to approximately the values observed at the underside of the rcofing in 
the tests using the method in Part I. The calorimeter plate was heated or cooled by water whose temperature was regulated in accordance with the daily cycles shown in figure 14 . Temperatures of 75 and $138^{\circ} \mathrm{F}$ were used for simulated summer night and day conditions, respectively, 56 and $106^{\circ} \mathrm{F}$ for simulated spring and fall season, and for simulated winter conditions temperatures of 38 and $75^{\circ} \mathrm{F}$ were used. Also indicated in figure 14 is the indoor air temperature used, $90^{\circ} \mathrm{F}$. The indoor air condition beneath the specimens was maintained at $90^{\circ} \mathrm{F}$ and 30 percent relative humidity (0.43 in. $\mathrm{Hg}$ water vapor pressure and $\mathbf{5 4 . 5}$ - F dewpoint), which corresponds in respect to water vapor pressure to an air-conditioned environment of about $75^{\circ} \mathrm{F}$ and 49 percent relative humidity, which is considered comfortable and typical for buildings of average occupancy. During the course of the program, the periodic time-temperature wave-forms, figure 14, were temporarily changed for several weeks to constant temperatures of $138^{\circ} \mathrm{F}$ for summer and $38^{\circ} \mathrm{F}$ for winter, for observing specimen performance under steady-state conditions.

For the calorimeter method of measurement, 8 specimens 22 by 23 inches in plan were placed in an insulated room, whose temperature and relative humidity were controlled. See figure 15 . Each specimen was mounted horizontally on a weighing scale, sensitive to 0.01 pound, for determination of changes in moisture content as the tests progressed. When desired during a test of a specimen, a measured amount of water could be admitted to the specimen through a small hole and tube in the center of each calorimeter plate. Heat gain to the calorimeter plate was determined by measuring the temperature change of the water as it passed through the plate and the mass flow rate. For this purpose a 10-fold differential thermocouple was used at the calorimeter plate inlet and outlet, and at the same time the water discharged from the plate was collected for one minute. The top and sides of each specimen and calorimeter plate assembly were moisture-sealed and surrounded with guarding insulation. The heat gain of the plate, during the substantially steady-state condition preceding the simulated solar heating part of the daily cycle, included both the heat flow through the specimen and that through the guarding insulation. To determine the latter and enable a correction for it to be made to the calorimetric measurement, a coefficient was dedetermined by separate experiments to express the heat transfer to the plate through the guarding insulation per unit of temperature difference between the plate and the top surface of the guarding insulation. The details and results of the two calibration procedures used are given in reference [6], of Part I. The effective thermal resistances of components of each specimen were obtained by dividing the appropriate observed temperature differences, as indicated by the thermocouples within the specimen, by the average specimen heat flux determined from the calorimetric measurement. Details of the apparatus are given in reference [6].

On two specimens heat flow meters were bonded to the underside of the specimen to determine the heat flux at these surfaces. Also, the electrical resistance across layers of component materials of several specimens was measured by means of a bridge connected to the copper leads of the thermocouples to indicate wetting or drying in the layers as the specimens were subjected to the various seasonal exposure conditions.

Upon completion of performance tests, samples of component materials from all specimens were used for physical property determinations. The dry thermal conductivity was determined using ASTM Method C177 [19], and the water vapor permeability was determined using ASTMI Method E96, [20]. Hygroscopic properties of some materials were determined by exposing the material to an environment of 75 ${ }^{\circ} \mathrm{F}$ and 90 percent relative humidity until the specimens achieved constant weight. The specimens were then oven-dried and weighed, enabling calculations of the percent hygroscopic moisture content by weight.

\section{Specimens and Procedures}

A schematic drawing of a typical specimen is shown in figure 16. Materials used in each specimen are listed in table 3 . Each specimen was 22 by 23 inches in plan. Most specimens were designed to provide a calculated thermal transmittance (U-value) of about $0.12 \mathrm{Btu} / \mathrm{hr}$ $\mathrm{ft}^{2} \operatorname{deg} \mathrm{F}$ on the basis of published values of the thermal conductivity or thermal resistance of the dry materials. Thermocouples were cemented or cast in place, as shown in figure 16 . The calorimeter plate was placed on the top of the specimen and edges were sealed with 1/32inch-thick neoprene rubber sheet bonded in place with a rubber adhesive. A thin, soft blanket of glass fiber insulation was used as a gasket between sections of the board-type expanded polystyrene guard insulation. The guard insulation was held in place by steel band strapping tensioned by wedges around the periphery of the specimen. All joints were sealed with mastic, covered with tape, and painted with a rubber-base paint paste. The water-feed hole through the center of the calorimeter plate was connected to plastic tubing that penetrated the top piece of guard insulation. Before assembly, a 1 -inch square hole $1 / 8$-inch deep was made in the center of the top surface of the specimen as a well for receiving water admitted through the drill hole. In table 3, specimens numbered 
16 and 22 contained three layers of an absorbent cotton muslin scrim placed between component materials and directly beneath the calorimeter to act as a water-distributing wick. Differential thermocouple wells were made from brass pipe nipples and tees and were insulated and vapor sealed. The assembled specimens were supported by slotted phenolic plastic tubes on the platform scales, and water connections to the calorimeter were made using flexible rubber tubing.

Specimens were designed for the most part to represent practical constructions thought likely to possess in-service self-drying characteristics when installed containing initial construction moisture, or when wetted during their service life. In general, most specimens were selected to be compatible with the construction technique of permanent formboards between steel subpurlins (bulb tees). The formboard or deck materials can be grouped as precast channel elements, slabs or tiles, and formboards.

The materials listed in table 3 include two types of concrete made with portland cement: structural concrete (Specimens 1, 2 and 3); and insulating concrete (Specimens 4 through 10 , 14 through 17 , and 19 through 24 ). Other materials were: gypsum concrete (Specimens 11, 12, 18 , and 25 through 27); formboards made from gypsum (Specimen 4), cement-asbestos (Specimen 6), wood-fiber (Specimens 8 through 13), glass-fiber (Specimens 14 through 18) ; and insulations made from mineral wool (Specimens $1,19,22,25$ and 26), wood fiber (Specimens $3,12,13,20$ and 27$)$, and expanded polystyrene plastic (Specimens 7 and 21). The expanded shale concrete slabs were cured in molds for one day, in a damp room for three days, and allowed to dry in the laboratory out of their molds for about two weeks before fabrication into specimens. These one-inch-thick specimens were intended to simulate the web portion of a prefabricated concrete channel roof deck. All insulating concretes were cast in a separate mold or directly on top of formboards in a mold and were allowed to cure for one day in the mold, three days in a damp room, and to dry in laboratory air for three days out of the mold before fabrication into a specimen and installation in the apparatus, except for Specimens 16 and 22, which were air-dried for several months before installation. Gypsum concrete for Specimens 25, 26, and 27 was obtained from a local contractor during the installation of this material in an insulated roof deck of a new building. The gypsum concrete was allowed to cure in a form for one day and was laboratory-air-dried for one day before installation in the apparatus. Other gypsum concretes were hand-mixed in the laboratory and cured in the same manner as the field-obtained material. Strength tests were made on cylinders or cubes of each concrete batch to assure that the specimens were representative of materials that would meet specifications for field use. All other materials and insulations used were taken directly from their cartons after storage in the laboratory for several weeks.

Specimens were installed with materials in a moisture condition similar to what might be expected shortly after roofing had been applied in the field. The investigation was conducted by subjecting specimens to alternations of periods of exposure simulating winter or summer temperature conditions as indicated on figures 17 through 43. In some cases exposure conditions of spring and fall were also used. Each period consisted of repeated 24-hour cycles of the appropriate daily temperatures to simulate nighttime and solar heating conditions, as indicated on figure 14. Heat-flow, temperature, and weight measurements of each specimen were recorded on working days within the two-hour period prior to the start of the simulated solar heating part of the daily cycle. At selected times data were taken for a full 24-hour period to observe the patterns of heat flow and temperature change and also several calorimeter calibration check tests were made using the specimens under test. The seasonal periods were of several weeks' duration each, varying in length as necessary to observe apparent trends in the insulating value and weight change of a majority of the simultaneously exposed specimens.

The exposure periods were aimed at different objectives. An initial summer exposure period was used to observe the insulating value and the ability of a specimen to self-dry when it contained construction moisture. A first winter exposure period was used to observe the change in heat transfer and the rate at which a specimen gained weight. Spring and fall exposure periods were used to determine whether dxying or wetting would occur in a specimen during these seasons. A second summer exposure was used to determine how rapidly the specimen would expel winter-gained moisture and after simulating a roofing leak, for observation of subsequent drying rates. At selected times indoor surfaces were spray painted to determine whether painting affected the rates of drying or wetting. Some thin formboards were removed during exposure to detelmine whether the drying or wetting rates would be significantly affected. The electrical resistance across layers of the component materials in ten of the specimens was measured daily as a part of each test to indicate the migration of moisture resulting from wetting or drying of the components.

At the conclusion of its exposure, each specimen was dismantled and the moisture content of its component materials was determined by drying to constant weight. Samples of exposed materials, 8 inches square and 1 inch thick were used for determining the thermal con- 


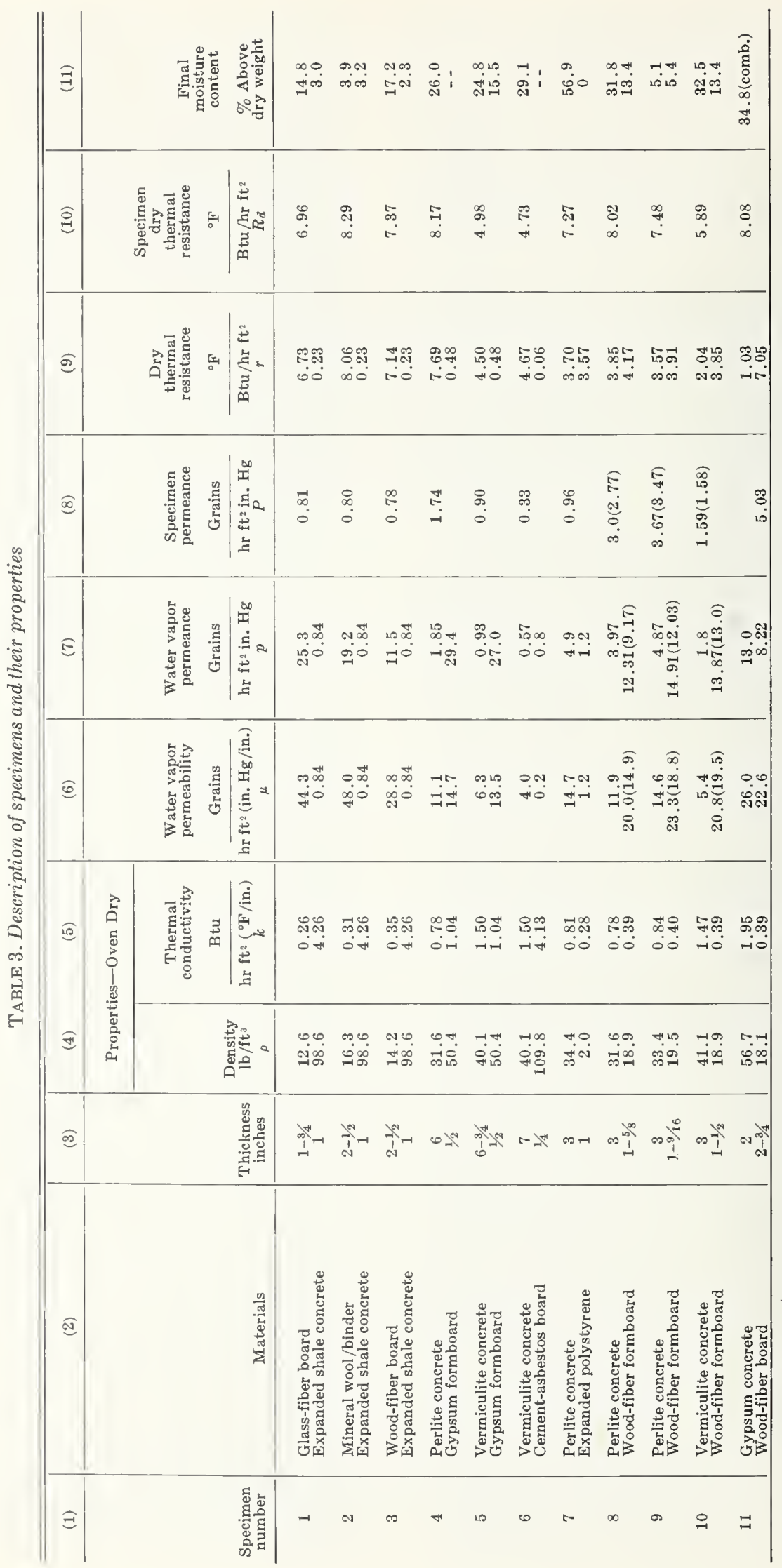




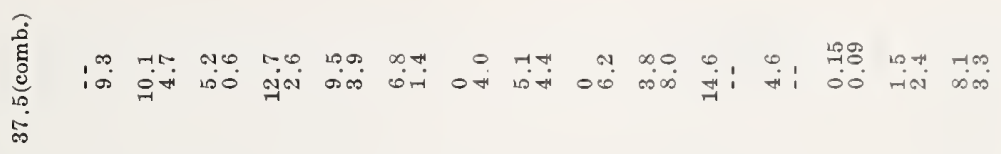

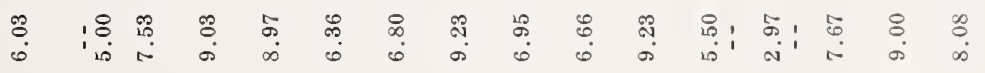

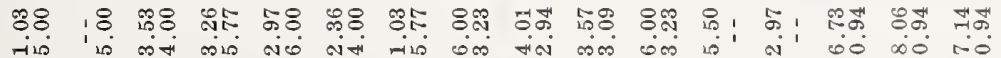

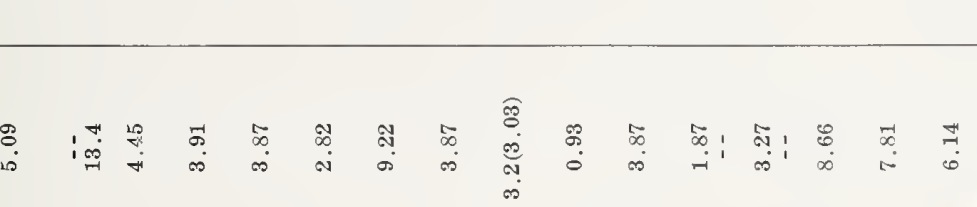

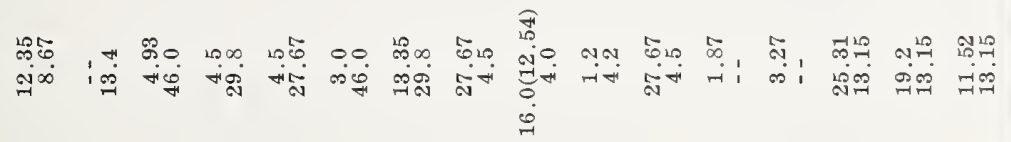

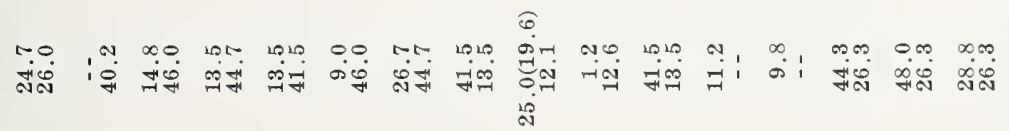

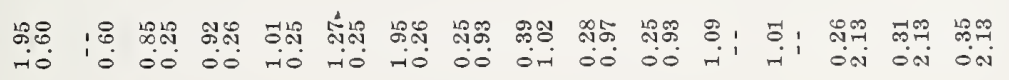

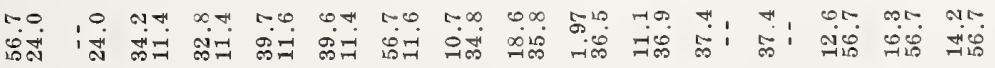

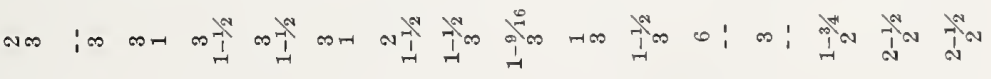

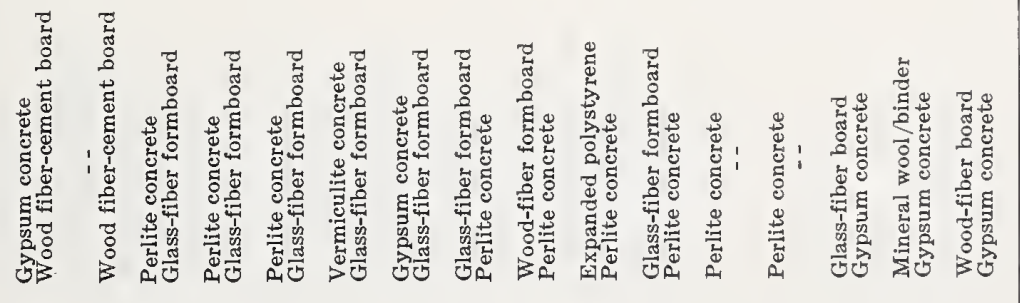

ม 


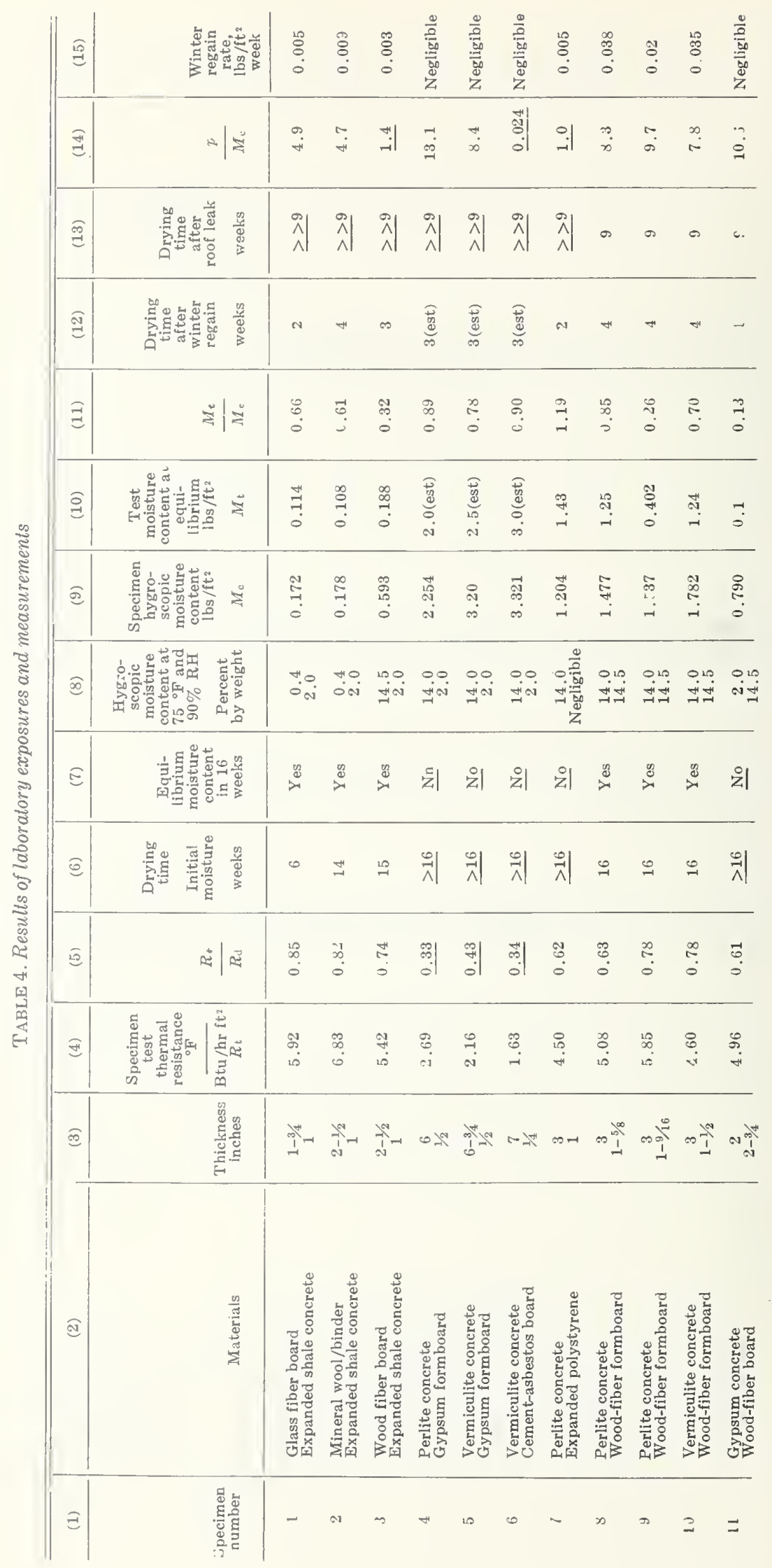




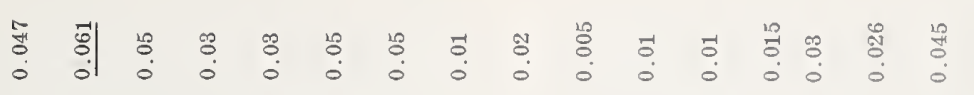

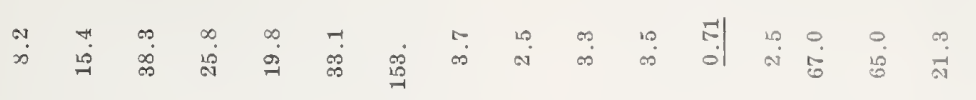

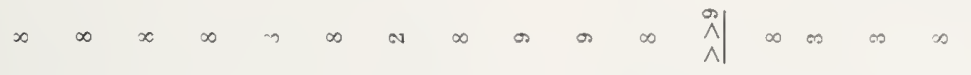

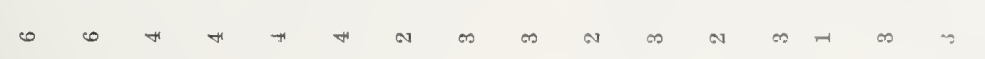

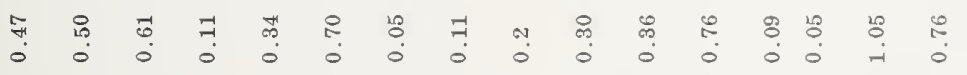

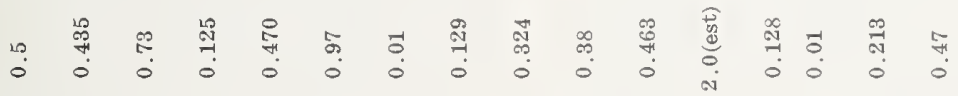

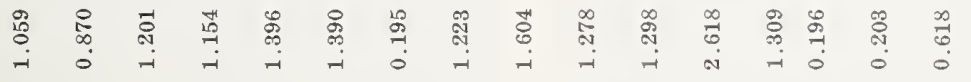

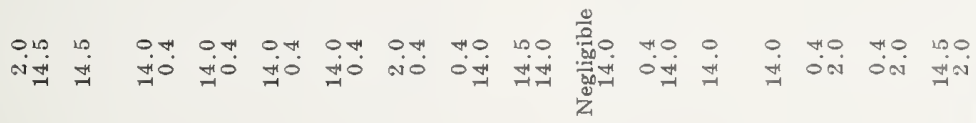

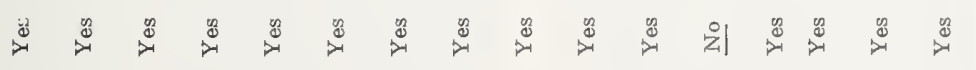

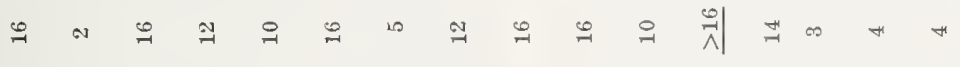

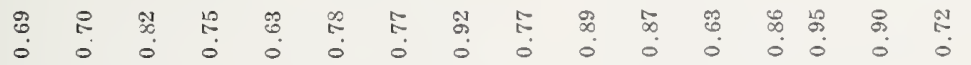

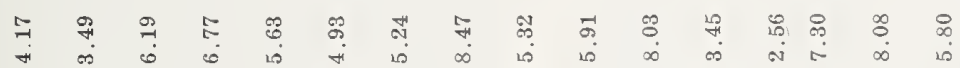

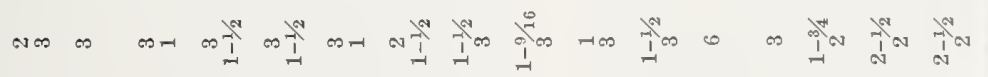

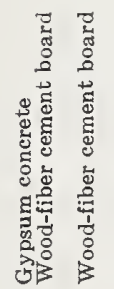
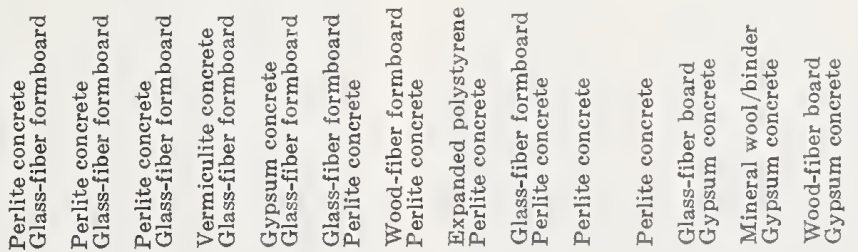

ก ๓ 
ductivity in an oven-dry condition, using the guarded hot-plate method (ASTM C177), and additional samples, 41/4 inches in diameter and $1 / 2$ inch thick, were used for measurement of water vapor permeability, using the dry cup method of ASTM C 355.

\section{Results}

Results of the investigation are presented in Figures 17 through 43 and in tables 3 and 4 . Several sets of curves showing the behavior of each specimen during selected 24-hour periods were obtained. These were similar in shape and magnitude to figures 4 and 6 (Part I) and a sample is shown as figure 44 .

Figures 17 through 43 show graphically the heat transfer, moisture content, and, for ten specimens, electrical resistance results. The heat transfer data are presented as thermal resistance values (reciprocal of thermal conductance) for the components of the specimen and the specimen as a whole. In some cases the thermal resistance of the air film from the indoor surface to the air beneath a specimen is also plotted. Thermal resistance is plotted against time in weeks for the duration of the tests. Also plotted against the same time scale are: the moisture content at the end of each week in terms of pounds per square foot of roof area and also as percent of specimen dry weight; and the electrical resistance of each layer for ten of the specimens. In the tests when the electrical resistance in ohms exceeded $10^{7}$, this value was plotted in the figures, since only values lower than this became meaningful in the investigation. Each value of thermal resistance plotted is the average of the daily values obtained during each week of the tests, usually five in number. In each of these figures, the thermal resistance of each specimen in a dry condition is indicated by a horizontal dashed line labeled "Design-R-Dry." This value of resistance was calculated using thermal conductivities determined by guarded-hot-plate tests on dry samples of the materials of each specimen obtained after their exposure in the apparatus. Thus, the figures show a comparison between the thermal resistance of the dry specimen and that of the specimen at various moisture contents observed experimentally during the several seasonal exposure periods. The electrical resistance indicates the location of the bulk of the moisture in the specimen and the downward or upward trend of the curve indicates whether the specimen was wetting or drying, respectively, as a result of its exposure.

Table 3 lists the specimens and their component materials and their thicknesses $(x)$ and the results of density $(\rho)$, thermal conductivity $(k)$, and water vapor permeability $(\mu)$ determinations on each component material of the specimens. From these determinations dry values of thermal resistance for each component material $(r)$ and each specimen $\left(R_{d}\right)$ and the water vapor permeance for each component $(p)$ and each specimen $(P)$ were calculated using the relationships $r=x / k, R_{d}=r_{1}+r_{2}$, $p=\mu / x$, and $1 / P=1 / p_{1}+1 / p_{2}$. Also listed in table 3 is the moisture content of each material as determined at the conclusion of its final exposure period by oven-drying the materials. In table 3 values of water vapor permeability and permeance given in parentheses for Specimens $8,9,10$, and 20 are values obtained for samples of the materials that contained an asphaltic binder for water resistance which were not used in the exposed specimens.

From the results obtained, tentative criteria were developed for evaluating the insulating and self-drying abilities of an insulated flatroof design. Table 4 lists for each specimen tested the results of the application of the criteria. Figure 45 illustrates in a general way typical performance characteristics of a selfdrying design and includes the items listed as column headings in table 4 . In table $4, R_{t}$ is the average thermal resistance of the specimen over the total test period obtained by averaging weekly test values of thermal resistance over a period totalling 37 weeks. $R_{d}$ is the dry thermal resistance as calculated on the basis of test results for the thermal conductivity of the dry components as given in table 3 . The fifth column in table 4 lists the ratio $R_{t} / R_{d}$. The sixth column lists the drying time, in weeks, that was required to expel initial construction moisture from the specimen by self-drying under summer exposure conditions while the seventh column states whether the specimen reached a defined moisture content equilibrium within 16 weeks. The eighth column gives the hygroscopic moisture content at $75^{\circ} \mathrm{F}$ and 90 percent relative humidity in percent by weight, as taken from the literature $[16,17]$ or estimated from tests on these materials at the National Bureau of Standards. Column nine gives the calculated quantity of hygroscopic moisture present, $M_{c}$, for each specimen in pounds per square foot. Column ten gives the quantity of moisture present, $M_{t}$, when the specimen was at a moisture content equilibrium during the tests. The ratio $M_{t} / M_{c}$ is given in column 11 . Column 12 gives the slimmer drying time in weeks to expel moisture accumulated during the specimen's previous winter exposure, Column 13 gives the summer drying time for expelling moisture after the specimen had been wetted in simulation of a roofing leak. Column 14 gives the ratio of the specimen permeance, $P$, from table 3 , to the specimen hygroscopic moisture content, $M_{c}$. Column 15 gives the average rate of moisture gain of the specimen during exposure under winter test conditions in lbs $/ \mathrm{ft}^{2}$ week. A discussion of the criteria is given in section 12.6 . 


\section{Discussion of Results}

In this section the principal findings are given separately as subsections and the performance of those specimens that illustrate the findings will be discussed, using the figures and tables. Other specimens that also illustrate the point will be mentioned but not discussed in detail.

As in Part I, daily determinations of thermal resistance of the specimens and their components were made just prior to the start of simulated solar heating. Several times during the investigation data were taken to show the heat flux and temperature history over a 24-hour period. The results of these several tests are similar to the curves shown in figure 44, and in figures 5 and 6 of Part I, and hence will not be presented in detail here. The curves show that all temperatures and the heat flux through the upper surface of the specimens were nearly constant for a period of two hours before the start of the simulated solar heating. Therefore, observations made during this time period yielded thermal resistance data for a condition approaching as nearly to an ideal steady-state condition as was possible within the restrictions of the imposed 24-hour periodic temperature cycle. Values of heat flux and temperature during the solar heating and the cooling portion of the daily cycle were clearly transient and would not have yielded a meaningful thermal resistance. The daily and weekly changes of thermal resistance were considered to be a measure of the effect of moisture on heat transfer through the insulated flat-roof specimens.

In order to maintain reasonably high thermal insulating values in summer and winter, the solution to the problems arising from the presence of moisture in insulated flat-roof construction, as proposed in the introduction, was to use a deck or formboard material that would allow passage of water vapor through it and thus foster self-drying of the wetted construction to the indoors as promoted by natural solar heating of the outdoor surface in summer. In winter the deck or formboard material must also inhibit the accumulation of moisture in the construction resulting from condensation of water vapor transferred from indoors. The results obtained indicate that the above solution can be considered feasible for several designs of practical insulated flat-roof decks provided the indoor vapor pressure is not excessive and is of the order of that found in normal-occupancy buildings $\left(75^{\circ} \mathrm{F}, 50 \%\right.$ humidity).

\subsection{Effect of Moisture on Insulating Value}

Appreciable amounts of moisture in insulated flat-roof constructions reduced their thermal insulating value under both winter and summer exposure conditions. The magnitude of the ef- fect of moisture on insulating value was influenced by the quantity of moisture present in the construction, its location, and the arrangement and volume of the component materials in the construction, as well as their properties of moisture hygroscopicity and absorbency, thermal conductivity and water-vapor permeability.

In figure 17 the thermal resistance during winter and summer exposure periods of Specimen No. 1, when it contained about $0.1 \mathrm{lb}$ per sq $\mathrm{ft}$ of moisture, was about equal to that of a dry specimen. The thermal resistance of the specimen and its insulation decreased markedly, to about 31 percent of their dry values, when water was added to the insulation, during week number 33, in simulation of a roofing leak. Resistances remained low as this summer exposure period continued. With continued exposure, the moisture content of the specimen gradually decreased from about $1.15 \mathrm{lb}$ per sq ft to an equilibrium moisture content of about $0.5 \mathrm{lb}$ per $\mathrm{sq}$ ft without a significant change in the specimen's insulating value. Also, during weeks 42 to 45 of this exposure period, the calorimeter plate was operated continuously at 138 ${ }^{\circ} \mathrm{F}$, causing a steady temperature gradient from the top to the bottom of the specimen. Such operation during this time period did not significantly affect the rate of drying of the specimen but did cause an increase in its thermal resistance to a value about 60 percent of that of a dry specimen. During the following winter exposure period, the thermal resistance of the specimen, when it contained about $0.5 \mathrm{lb}$ per sq ft of moisture, was about 91 percent of that of a dry specimen. The specimen gained little weight during its winter exposure periods, even when the calorimeter plate was operated continuously at $38^{\circ} \mathrm{F}$ for 9 weeks (weeks 52 to 61 ), demonstrating the resistance to watervapor transfer of the expanded shale aggregate concrete deck used for this test whose water vapor permeability was measured after the test and is given in table 3 as 0.84 . Water vapor permeance is expressed in a unit (perm) defined as the number of grains (7000 per pound) of water vapor transferred per hour over an area of one square foot with a water vapor pressure difference of one inch of mercury across the specimen.

The insulating performance of the insulation of Specimen No. 1, figure 17, was very similar to that of specimens numbered $1-\mathrm{DT}, 2-\mathrm{DT}$, 16-DT, and 17-DTOW, in table 2, Part I. The constructions of these specimens differed only in the type and thickness of their concrete decks. Also, the insulating performance of Specimens 2 and 3 was similar to that of Specimen 1 , where each specimen had in common a one-inch-thick expanded shale aggregate concrete deck but had different types and thicknesses of insulations over the deck. Further examination of the figures and table 3 shows 
that for most moist specimens whose overall permeance to water vapor was less than 2 perms a poor insulating value was evident for long periods of time. See figures 17 through 23 , and 39. For Specimens 1, 2, 3, 6, and 7 this can readily be attributed to the low permeance of the deck material. However, Specimens 4 and 5 contained a highly permeable deck material but poor insulating value resulted because of the high moisture content of the thick concrete over the deck, as was the case for Specimen 23 that had no deck at all, although a trend of slowly increasing insulating value with time is evident. It is interesting to note that for moist specimens containing a low permeance deck material, and a permeable low conductivity insulation over it, Specimens 1, 2, and 3, there were relatively large changes between the summer and winter values of specimen thermal resistance while those specimens that had comparatively high moisture contents, Specimens $4,5,6$, and 23 showed relatively little change between summer and winter thermal resistance regardless of the permeance of the deck material.

The long-term impairment of insulating value of the above specimens, when wet, was attributed to the high resistance to moisture passage of the over-all specimens and especially their decks. During summer exposure, moisture in the specimens and especially in the permeable insulations was free to migrate in response to the twice-daily reversal of temperature gradient and thus was kept distributed and available for latent heat transfer. In the winter exposure condition there was no daily reversal of temperature gradient and highly permeable insulating components allowed moisture to migrate to the cooler regions of the insulation, which resulted in improved specimen insulating value. For hygroscopic and moisture absorbing materials the migration was not as complete resulting in a thicker layer of wetted material that allowed the specimen insulating value to remain relatively low. When a nonreversing temperature gradient was applied (steady-state) during both winter and summer exposure conditions, moisture tended to migrate and accumulate in the cooler regions of the insulation, resulting in a higher over-all specimen thermal resistance and a greater insulating effect.

The construction of Specimen 19, figure 35, was such that the deck material, perlite aggregate concrete, was moderately permeable to water vapor, 4.5 perm, as compared to the denser concrete decks of Specimens 1, 2 and 3, 0.84 perm, and the 3 -inch-thick structural concrete decks used in Part I. The perlite concrete constituted about one-third of the specimen's dry thermal resistance. The top-layer material, glass-fiber insulating board, was relatively high in permeance and thermal resistance but low in hygroscopicity and moisture absorbency and of lesser thickness than the deck material. The initial moisture contents of Specimen 1, figure 17 , and Specimen 19, figure 35, were approximately the same, about $0.5 \mathrm{lb} / \mathrm{sq} \mathrm{ft}$, but the moisture content of Specimen 19 was greater after water had been added in simulation of a roofing leak, about 1.15 and $1.8 \mathrm{lb} / \mathrm{sq} \mathrm{ft}$, respectively.

The thermal resistances of both Specimens 1 and 19 were about equal to the dry values for all exposure periods when their moisture contents were less than about $0.5 \mathrm{lb}$ per sq ft. After water had been admitted to both specimens in simulation of a roofing leak their thermal resistances decreased considerably. Specimen 19 also showed a rapid decrease in moisture content even though it was first subjected to spring season roof-side temperatures of only $106^{\circ} \mathrm{F}$ before its summer exposure, and its thermal resistance gradually increased until insulating value was fully recovered, while the resistance of Specimen 1 exposed at steady roof-side temperatures of $138^{\circ} \mathrm{F}$ remained low and did not show a trend toward recovery. This finding is considered to have major practical value even though the more rapid expulsion of moisture from Specimen 19 would constitute a considerable short-term latent heat load to the room beneath the roof construction which would have to be dissipated by ventilation or an air-conditioning system. The recovery of insulating value of Specimen 19 was attributed to the increased permeance of the perlite concrete deck, which allowed drying of the wetted specimen.

Results similar to those of Specimen 19 were obtained for Specimen 20, figure 36; Specimen 21, figure 37; Specimen 22, figure 38; Specimen 23 , figure 39 ; and Specimen 24, figure 40 ; all containing a perlite concrete deck. The insulation of Specimen 20, wood-fiber board, was hygroscopic and showed a lesser depression of thermal resistance with approximately the same time to recover its insulating value. The insulation of Specimen 21 was nonabsorptive to water and the large amount of water added was contained chiefly in the perlite concrete. The construction of Specimen 22 was the same as for Specimen 19 except that a cotton muslin scrim was used between the materials and beneath the calorimeter plate in Specimen 22 to assure uniform lateral distribution of added water. The rate at which the insulation recovered its insulating value was more rapid and uniform initially for Specimen 19 and was almost sudden for Specimen 22 after several weeks at low insulating value while wet. The reason for delay in recovering insulating value in Specimen 22 was attributed to the wetted scrim on each surface of the glass-fiber insulation which caused a smaller temperature difference across the insulation as water was evaporating from the scrims. When the scrims were dried suffi- 
ciently, especially the scrim at the interface, the insulating value of the glass-fiber insulation rapidly rose to dry values.

Specimens 23 and 24 were made from perlite concrete only. Note that Specimen 23 was a six-inch-thick layer of perlite concrete that had a high moisture content, about $3.3 \mathrm{lb} / \mathrm{sq} \mathrm{ft}$, when its test began. The distribution of the moisture in the specimen is indicated by the electrical resistance curves for each 2 -inch-thick layer of its total thickness as shown at the top of figure 39. The bottom layer of the specimen had less moisture than the middle or top layer but as drying proceeded during the first spring and summer exposure periods the electrical resistance of the top layer increased, indicating that it too was relatively much more dry when compared with the middle layer. In fact, the electrical resistance of the middle layer did not increase substantially during all exposure periods, indicating that the middle layer of the specimen remained moist regardless of exposure.

Evidence of a moisture band in the middle is further indicated because its thermal resistance values are lower as compared with the values for the top and bottom layers of the specimen. In figure 39 during the second winter exposure period, week numbers 28 through 34 , moisture was migrating from the middle layer to the top layer as indicated by a decrease in electrical resistance for the top layer as shown. When water was added during the second spring exposure period the electrical resistance decreased to a low value for the top and middle layers but decreased only slightly, and temporarily, in the bottom layer. These changes were accompanied by similar decreases in thermal resistance for each respective layer. The specimen gradually recovered its thermal resistance and showed a considerable reduction in moisture content during the second spring and summer exposure periods. The value of the thermal resistance of the specimen when it was most dry during the tests was about $4^{\circ} \mathrm{F} /\left(\mathrm{Btu} / \mathrm{hr} \mathrm{ft}^{2}\right)$.

A similar history of exposure was obtained for Specimen 24, figure 40, but note that a central wet band was not as apparent when compared with the performance of Specimen 23. The thermal resistance of the three-inch-thick Specimen 24 at its lowest moisture content was about $2.6^{\circ} \mathrm{F} /\left(\mathrm{Btu} / \mathrm{hr} \mathrm{ft}^{2}\right)$. Doubling the thickness of insulation apparently did not double the thermal resistance for this material because of the considerable additional amount of moisture present in the thick specimen. Specimen 23 achieved as a maximum approximately 73 percent of its dry insulating value while Specimen 24 achieved a maximum of about 90 percent.

The construction of Specimen 9, figure 25, was such that the deck material, wood-fiber insulating board, was permeable to water va- por, 14.91 perm, and constituted about half of the specimen's thermal resistance when dry. The top layer of the specimen was perlite aggregate concrete. The permeance of the insulating concrete layer was lower, 4.87 perm, than that of the wood-fiber formboard but its thermal conductivity, thickness, and waterholding capacity were higher. Thermal resistances, as plotted in figure 25 , changed relatively little with changes of exposure conditions from winter to summer or with substantial changes in specimen moisture content, when compared with other specimens tested. In view of the greatly reduced insulating values observed over long periods of time for specimens tested under summer conditions containing wetted insulation over relatively impermeable decks, the stability of the insulating performance of Specimen 9 was a definite practical improvement.

Figure 25 shows that Specimen 9 was drying and at the same time providing a reasonabiy fair insulating value, although not as much as expected for dry materials. The insulating values shown in figure 25 were lower than dry values because the specimen contained some moisture throughout the tests. A sudden increase in moisture content, when water was added at week number 36 to simulate a roof leak, caused a considerable percentage decrease, about 60 percent, in the insulating value of the perlite concrete but little percentage change, about 3 percent, in the thermal resistance of the wood-fiber formboard. The performance of the wetted specimen, from week 57 onward, appeared substantially similar to its performance during weeks 6 to 15 , when its moisture content was about the same. The electrical resistance plots indicate that most of the moisture present in the specimen was contained in the perlite insulating concrete.

Similar results were obtained for Specimen 8 , figure 24, and Specimen 10, figure 26. For Specimen 11 the wood-fiber insulation was $23 / 4$ inches thick and constituted about 87 percent of the specimen's insulating value. Figure 27 shows that the insulating board was more sensitive to change when wetted during exposure as compared to Specimens 8,9 , and 10 , but it too was remarkably stable when subjected to changes of seasonal exposure conditions. The performances of Specimen 12, figure 28 and Specimen 13, figure 29, were, in general, similar to that of others that employed a wood-fiber insulation as a formboard.

The construction of Specimen 15, figure 31, was such that the deck material was very permeable to water vapor as compared to the decks of other specimens, and the deck constituted the major portion of the thermal resistance. The top layer of material, perlite aggregate concrete, was of moderate permeance to water. vapor, and had a higher thermal conductivity and moisture absorptancy, and a greater thick- 
ness, than the deck material. Specimen thermal resistance decreased but not seriously during the first spring-summer-fall exposure conditions when compared with the first winter exposure, with initial distributed moisture present. The thermal resistance decreased rapidly when the specimen was wetted in simulation of a roofing leak during the second spring exposure period, but the loss of insulating value was regained rapidly. When wetted the specimen thermal resistance decreased from a value of about $7^{\circ} \mathrm{F} /$ $\left(\mathrm{Btu} / \mathrm{hr} \mathrm{ft}^{2}\right)$ to about 3.2 and then increased to about 6 within a week's time and remained stationary while the specirnen was gradually drying. The value of the thermal resistance again reached $7^{\circ} \mathrm{F} /\left(\mathrm{Btu} / \mathrm{hr} \mathrm{ft}^{2}\right)$ when exposure to the second summer condition commenced. The moisture content and electrical resistance performance curves also indicated rapid drying during these time periods. The drying curve shows large changes in specimen moisture content from about 4 to about 1.75 $\mathrm{lb} / \mathrm{ft}^{2}$ with relatively little change in specimen thermal resistance during the spring exposure condition when roofing-side temperatures reached only $106^{\circ} \mathrm{F}$ during the simulated solar heating portion of the daily temperature cycle. An explanation for this desirable result is that the glass-fiber formboard was quite permeable to water vapor and of low conductivity.

Due to its comparatively low thermal resistance, the entire volume of the insulating concrete top layer during exposure to simulated solar heating was raised substantially in temperature. The concomitantly increased water vapor pressure in the moist permeable concrete promoted vapor escape through the permeable deck material, and thus effected rapid drying of the specimen. During the early morning hours, when the near steady-state heat flow and temperature measurements were made, the moisture in the concrete was distributed in the specimen as a result of the daily reversals of temperature gradient. The temperature at the interface of the materials was initially near the temperature of the calorimeter $\left(75\right.$ or $56^{\circ} \mathrm{F}$ ) because of the lowered thermal resistance of the moist concrete. Thus, initially the concrete had a small temperature difference across it, while the glass-fiber formboard had a higher temperature difference across it. Heat flowed from the undersurface of the specimen through the formboard to the underside of the insulating concrete, which at that stage was relatively moist, and there a part of it went to evaporate moisture, which passed freely from the specimen through the permeable formboard to the indoor air. Only a part of the heat reaching the insulating concrete remained to be conducted through it to the calorimeter plate and measured. As the vaporization and drying progressed, the temperature at the interface of the materials increased, yielding a gradual in- crease in the temperature difference and thermal resistance of the concrete. The thermal resistance of the glass-fiber decreased slightly, because its temperature difference decreased as the interface temperature increased. The total temperature difference across the specimen remained relatively unchanged, as was the heat flow at the calorimeter. Thus, the specimen was able to maintain its insulating integrity while expelling a considerable amount of moisture. Similar results and behavior are shown in figures $30,32,33$, and 34 for glass-fiber formboard of different thicknesses and for other insulating-type concretes.

During summer exposure periods, especially when water was added in simulation of a roofing leak and the specimen was drying rapidly (notably Specimens 17 and 18, figures 33 and $34)$, the observed temperature drop across the insulating concrete approached and became substantially zero, and the whole temperature drop at the time of observation occurred across the formboard. At the same time the heat flow to the calorimeter through the specimen decreased to practically zero. Thus, the concrete appeared to have an indeterminate thermal resistance (calculated as $R=\Delta t / q$ ), and the formboard an apparent large resistance approaching infinity. This type of result is indicated in figure 34 by a broken line symbol and is attributed to the latent heat transfer effect. That is, most or all of the heat entering the bottom face of the specimen was used to evaporate moisture from the concrete. The apparent thermal resistance of the glass-fiber formboard decreased from a near-infinite value to a measurable value as the heat flow reaching the calorimeter increased. The total temperature difference across the specimen from the room to the calorimeter remained relatively unchanged. The latent heat effect is also shown in figure 33 but is much less pronounced as compared with figure 34.

The constructions of Specimens 25, 26, and 27 consisted of a 2-inch-thick gypsum concrete deck which was permeable to water vapor, and much higher in thermal conductivity as compared to the three types of insulation used over the deck. When Specimens 25, 26, and 27, figures 41,42 , and 43 , respectively, were subjected to their initial summer exposure period, each rapidly lost weight and reached a moisture content equilibrium within a two-week time period and thereafter during this exposure period remained at a constant moisture content, as shown. The thermal resistance of Specimen 25 was near its dry value, since during this time it contained little moisture, but the thermal resistances of Specimens 26 and 27 were about 89 and 75 percent of their dry values when they contained 0.2 and $0.5 \mathrm{lb} / \mathrm{ft}^{2}$ moisture, respectively. The lowered thermal resistances of the latter two specimens were attributed to the 
moisture held in equilibrium within them. The insulations of these specimens were of greater thickness and density, and less porous, than that of Specimen 25, and thus were able to retain moisture in equilibrium, especially Specimen 27, whose insulation is hygroscopic. The retained moisture would tend to migrate back and forth within these specimens in response to the twice-daily reversal of temperature gradient, thus remaining distributed and available for latent heat transfer.

Specimens 25, 26, and 27 gained weight and increased in moisture content with relatively little change in insulating values during their second winter exposure period after each had been dried to an equilibrium moisture content during its first summer exposure period. The moisture gained was easily expelled from the specimens within the first two weeks of the following second summer exposure period. Their performances during subsequent summer exposure periods show that the maximum time required for expulsion of added moisture was seven weeks for Specimen 27 when a maximum of about $1.58 \mathrm{lb} / \mathrm{ft}^{2}$ of moisture was expelled.

During the second summer exposure period, water amounting to 10 percent of specimen volume was added to Specimens 25-27 in simulation of a roofing leak. The quantity of water added to Specimen 25 was restricted to a total of 7.4 percent of specimen volume, because the indoor face of the gypsum concrete became wet during the water addition process and droplets of water began forming on it. Further addition of water to this specimen would have resulted in free water dripping from the indoor face, which would cause a weight loss not attributable to self-drying of the specimen. Water added to Specimens 25, 26, and 27 penetrated to the indoor face of the gypsum concrete, visibly wetting a circular area around the center of the specimens. This sudden increase in moisture content of all three specimens was accompanied by a sharp decrease in thermal resistance. The thermal resistance decreased because the temperature at the interfaces of the materials and at the indoor surface decreased and approached the calorimeter temperature, resulting in a much reduced temperature difference across the insulating materials. Also, the heat flux at the wet indoor face of the gypsum concrete, at the time the measurements were made, was largely used to evaporate moisture from the gypsum to the room, causing a reduced flow of heat into the calorimeter. As the exposure continued, the specimens dried and their thermal resistance increased. Specimens 25 and 26 were easily wetted and upon continued exposure dried rapidly, quickly recovering their insulating value. Specimen 27 did not wet or dry as easily or as quickly and its loss of insulating value was considerably less because it was able to maintain a greater temperature difference and heat flow across the materials during its longer evaporative process. It should be noted that rapid self-drying of these specimens and others would not occur if a vapor barrier were used at the interface of the materials.

\subsection{Summer Self-Drying, Initial Construction Moisture}

The quantity of moisture present in a roof construction when initially placed determines the immediate insulating effectiveness of the construction. Factory-made board types of insulation when installed contain only hygroscopic moisture if protected from the veather during installation. Water-mixed materials contain a considerable quantity of free water even when their surfaces are dry enough to apply roll-roofing. Normally contractors apply roofing as soon as practicable to protect the construction from rain or snow. The specimens used in this investigation, as shown in table 3 , range from those having materials practically dry when installed to constructions that contain considerable free water distributed throughout the specimen. For example, Specimen 1, figure 17 , when installed had about $0.4 \mathrm{lb} / \mathrm{ft}^{2}$ of free moisture, most of which was contained in the 1-inch-thick expanded shale concrete deck. This deck was intended to simulate the web-portion of a prefabricated channel-shaped slab. In contrast, Specimen No. 23, figure 39, contained about $3.3 \mathrm{lb} / \mathrm{ft}^{2}$ of moisture, all of which was contained in the 6-inch-thick perlite aggregate insulating concrete. Obviously some means must be provided to dissipate the large quantity of moisture in the latter specimen after the roofing has been applied. The self-drying concept emphasizes the omission of a vapor barrier and the importance of the vapor-transfer properties of the deck material and of the specimen itself. It becomes important that the design of the roof construction permit the escape of initial construction moisture. To illustrate: Specimens 7 and 21 were alike in construction except for arrangement. In Specimen 7 the expanded polystyrene was used as a formboard deck with insulating concrete over it, while Specimen 21 had the expanded polystyrene insulation on top of the insulating concrete. Examination of figures 23 and 37 show that when exposed to the first spring, summer, and fall exposure periods, Specimen 21 dried to a moisture content equilibrium of about $0.4 \mathrm{lb} / \mathrm{ft}^{2}$, while Specimen 7 showed comparatively little tendency to dry and had a moisture content of about $1.4 \mathrm{lb} / \mathrm{ft}^{2}$ after being exposed for the same time periods.

The different performances of these two specimens clearly indicate the importance of arrangement of the components when one of them is resistive to vapor transfer. Specimen 
represents a good self-drying construction; pecimen 7 does not.

Most of the specimens tested that contained initial construction moisture were able to dry an equilibrium moisture content and yield od insulating values in a suitable time, proded the specimen and deck were reasonably ermeable to water vapor. However, some specmens even with permeable undersurfaces dried comparatively slowly when exposed to summer exposure conditions and insulating values were for long periods. In the latter cases the quantity of moisture that had to be evaporated and the thickness of the specimen was large. ramples are Specimens 4, 5, 6, figures 20, 21, 22, respectively. Note in figures 20 and 22 that the average drying rate under summer onditions was not materially improved when the 1/2-inch-thick gypsum formboard (29.4 perm) was removed while the specimen was being tested, but removal of the $1 / 4$-inch-thick cement asbestos formboard $(0.8$ perm) of pecimen 6 produced an immediate change of ying rate. Also, Specimen 24, figure 40, whose ickness was 3 inches, did dry to a moisture ontent equilibrium while Specimen 23, figure whose thickness of the same type of matewas 6 inches, did not dry to a moisture content equilibrium over the identical time of sure.

The rate and time of drying appeared to be controlled by the quantity of free moisture sent, the severity of the exposure conditions, thickness or volume of the specimen, the ter vapor permeance of the specimen and its k material, the hygroscopic moisture capacthe water absorbency, the thermal conducand the arrangement of the materials thin a specimen. An attempt was made to relate these variables and formulate simple, ctical engineering expressions that would be ful in predicting thermal insulating and dryperformance on the basis of geometry and sical properties. Such a formulation was not sible and it appears necessary to rely upon oratory or field tests of the performance of poposed constructions. Constructions consistof deck materials of moderate to high pereance to water vapor and also of moderate to h thermal resistance covered with materials high moisture absorbency and moderate permeance appear to possess promising self-drying thermal insulating characteristics even if identally wetted in service.

\subsection{Winter Gain of Moisture}

has been shown that initial construction ture can be dissipated through a permeable material by utilizing solar heat on the However, under winter exposure condithe saturated water vapor pressure just eneath the cold roofing at night is lower than that of indoor air. This causes vapor to transfer into and through the materials to condense on the undersurface of the roofing because the temperature of the roofing is below the dewpoint of the indoor air. Therefore, in winter it becomes desirable to restrict the flow of vapor into the roof or provide sufficient moisture absorption capacity beneath the roofing to accommodate reasonable amounts of condensate that may accumulate over the winter.

Inspection of the figures for all the specimens reveals that except for Specimen 13 the rate of gain of moisture and the total weight of accumulation during winter exposure periods were small and the moisture capacity was more than sufficient to accommodate accumulated moisture. Generally, the figures show that higher values of specimen permeance, especially that of the deck, allowed faster rates of moisture gain. Insulating values were not significantly lowered unless a very considerable degree of wetting of the specimen thickness occurred. In winter under cyclic temperature exposure conditions the rate of moisture gain decreased as the exposure time and quantity of moisture accumulated increased. For example, Specimen 17 , figure 33 , shows similar rates of moisture gain during the second and third winter exposure periods. When the temperature of the calorimeter was held constant during the third winter and not cycled, the rate of moisture gain increased; but when changed again to a cyclic temperature procedure, the rate of moisture gain decreased considerably and was less than it was at the start of the third winter period when its moisture content was lower. See the winter condition moisture gains for Specimen 25, figure 41. Also, it can be shown, for moist, thick, permeable specimens, that the daily night-time gain of moisture under cyclic temperature conditions was offiset by a daily daytime loss of moisture, resulting in little net change of specimen weight, hence a nearly-zero rate of moisture gain. See Specimens 4, 5, 8, 10, 11,12 , figures $20,21,24,26,27,28$, respectively.

In most specimens of comparatively high permeance winter-gained moisture was easily and rapidly dissipated through the deck to the room beneath by subsequent exposure to a summer condition.

Whether a particular design will dry, wet, or remain static under winter exposure conditions appears to depend upon the quantity of moisture present in the specimen, the degree of daytime solar heating on the roof, the temperature of the roof and indoor space, and the indoor water vapor pressure. Some information is available for analysis from this investigation but it is felt that further research in regard to these points is needed.

Also, the question of the deteriorating effects of freezing and thawing of moisture in the construction, and concomitant dimensional 
changes, requires consideration in cold climates. This problem is probably greater for a roof that does not dry in service than for one that does.

\subsection{Self-Drying From Roof Leaks}

Roofing leaks are probable sooner or later. Even newly-laid roofing may accidentally be made to leak by operations such as installation of airconditioning or other equipment on the roof. Eventually most roofing materials will degrade, causing leaks. One can design against entry of water to the occupied space from a roofing leak by using a waterproof deck such as monolithic structural concrete. The disadvantages of this are that the insulation or the crack-space between slabs of insulation can become wetted often for a long time without the building occupant knowing it and a serious loss of insulating value results and eventually the insulation and roofing must be replaced, at a very considerable expenditure. An alternative is to use a moderately vapor-permeable and water-absorptive construction. Should a leak in the roofing occur with this type of construction, a wet spot or dripping of water from the ceiling immediately affords detection of the roofing leak. Simple patching of the roofing corrects the leak and, if the construction possesses good self-drying characteristics, it will dry to the indoors. Redecorating of the affected interior area is all that would be necessary, resulting in a large saving of maintenance costs as compared with replacing the roofing and wet insulation over a large area of the roof.

Generally the performance results show that the higher the permeance of the specimen and especially of the deck the faster the roof will dry after being subjected to a simulated roof leak. It appears advantageous to provide some moisture absorption capacity to prevent inundation of the occupied space should the roofing leak during a hard rain storm. Also, some moisture absorption capacity appears advantageous to retain the much smaller quantity of vapor transferred and condensed during the winter. The permeances of the decks of Specimens 1 through 7 , and 23 , or the overall permeances of these specimens, apparently were too low to allow sufficient drying to cause recovery of insulating value in a reasonably short time period such as a calendar summer. Given more time or several summer seasons, these specimens probably eventually would dry, since their decks and materials are not impermeable and because their resistance to winter gain of moisture is high. All other specimens dried reasonably rapidly and maintained or recovered their insulating value after being subjected to a simulated roof leak. In some cases, to simulate a roofing leak, a fixed amount of water was added, such as 10 percent of specimen volume; in other cases the amount of water added was determined by the ability of the specimen to absor water to the point where droplets formed the undersurface.

Pertinent observations noted during the ter-addition operation for the quantities water added as given in the figures include: wet spots visible on the undersurface of Spec mens 1 through 4, 6 through 10, and 20 through 23 ; circular-shaped wet spot not covering full area of interior surface, Specimens 11 through 17, 26 and 27; circular-shaped spots to the point of water dripping, Specimens $12,18,19,24$, and 25 ; and water flowed through specimen with little resistance, Specimen Specimen 5 had no water added to it during exposure. During wetting it was observed that wood-fiber board tended to expand when and shrink as it dried.

Most specimens when removed from the paratus showed little change in appearan except for water-stain markings. However, specimens containing gypsum concrete revealed that leaching or cavitation had occurred in the upper surfaces of the gypsum concrete, espe cially in areas immediately under the waterfeed hole in the calorimeter through which water leak was simulated. It is probable that cavities formed as the result of the solution of gypsum and its deposition elsewhere in the pore space of the specimen as drying progressed. The summer cycle of the specimens probably carried the temperature of the gypsum above the point at which gypsum is in its stable phase, and under these conditions it could be expected dissolve and re-precipitate as anhydrite, with a higher density and hence a smaller specific volume. From the practical point of view, cavitation as a result of a roofing leak was not considered serious because it would tend to reveal a roof leak and repairing gypsum concrete is relatively simple chore.

It was mentioned earlier that wetting of materials beneath roofing as a result of a roofing leak is an imponderable. Questions as to hor far laterally the materials will become wetted or whether water will soak uniformly througlh the thickness of the construction depend largely on the quantity of water available to pass through the leak in the roofing and the ability of the materials themselves to absorb water. Some materials are very difficult to wet and are designed to be so, while others by their very nature are highly absorptive. The heat transfer performance becomes very much dependent upon how the moisture is distributed within the materials and the time for drying is dependent upon the quantity of water to be vaporized. The criterion used in this investigation was to add a fixed quantity of water ( $10 \%$ by volume) to the specimens and for later additions of water the quantity used was determined by the absorptive capacity of the speci- 
men. In an actual roof the amount of water absorbed will depend upon the rainfall or puddling on the roof and the absorptive capacity of the materials.

Specimens 15, figure 31, and 16. figure 32 , were made the same way except that Specimen 16 had a cotton scrim on each surface of its perlite concrete. About the same auantity of water was added in simulation of a roofing leak. For each specimen the thermal resistance dropped sharply but quickly increased as the moisture became distributed in the concrete. Specimen 16, with the scrim, took longer to dry, probably because most of its moisture was contained more uniformly in its concrete and scrim where Specimen 15 probably had more of a concentration of moisture in its central area. Specimen 19, figure 35, and Specimen 22, figure 38 . were made the same way, excent that Specimen 22 had a cotton scrim on each surface of its glass-fiber board. Approximatelv the same ruantity of water was added to each specimen in simulation of a roofing leak. The thermal resistance of Specimen 19 decreased rapidly and gradually increased while drying: but for Specimen 22, the thermal resistance decreased and remained depressed for several weeks before suddenly increasing as it dried and it took this specimen a little longer to drv from its roofing leak. Latent heat effects kept the thermal resistance depressed in Specimen 22 and it. was concluded that the use of a scrim to provide for more uniform distribution of moisture during testing was not indicative of what would occur on an actual roof where the lateral distribution of moisture would be controlled by the materials of the construction and other factors such as local roof slope.

It would be desirable to be able to accurately predict the long-term simultaneous insulating and self-drying or wetting performance of any combination of materials used in constructing flat roofs from a knowledge of the geometric and physical properties of the materials and their exposure temperatures and relative humidities. However, such factors as variable moisture contents of materials when installed in a roof, the degree of wetting from a possible roofing leak, temperatures of the roofing as influenced by the weather, the stacking arrangements of several different materials and other imponderables, preclude accurate prediction of field performance. Also, little theoretical information is available to support formulation of a useful mathematical model. A qualitative picture of the processes can be deduced from the results of pertinent researches and empiric equations can be written to describe laboratory results. A mathematical model for quantitative prediction of simultaneous heat and mass transfer performance in porous materials under transient temperature conditions was attempted in connection with this work but a correlation of variables suitable for quantitative prediction was not obtained. This type of problem is very complex and Hansen [18] states that preparation of a quantitative analytical analysis which would permit accurate a priori prediction of drying behavior from a knowledge of characteristics of the solid, the liquid, and external conditions is not yet possible. Sereda and Hutcheon [15] state that there is a serious limit to the prediction of moisture migration and there is a similar restriction on the prediction of heat flow in moist materials because the two flow mechanisms of heat and moisture are so thoroughly interrelated that one cannot deal with one without the other.

As an example of possible field imponderables, consider the following situation: A roof construction consisted of poured gypsum concrete over glass-fiber formboard insulation on bar joists with built-up roofing and aggregate surfacing installed on the gypsum concrete. Laboratory results as given in this paper for this type of construction show rapid self-drying characteristics. However, in the spring of the year the insulation of the subject construction had a layer of water near its lower surface. It was learned that the gypsum concrete was placed during the previous winter and also that portable combustion-type heaters were used in the weather-closed building while the interior finishing operations were completed. Apparently the initial moisture plus moisture generated in the indoor space at a high rate under conditions where an indoor-to-outdoor vapor pressure gradient existed served to retain an accumulation of moisture in the construction until sufficient solar heating in the spring caused a migration to the lower surfaces of the formboard. Areas containing unventilated hung ceilings were similarly affected with water damage to the ceilings. Ventilation of the indoors in combination with solar heating of the roof soon dissipated the accumulated moisture. Simple ventilation of the indoors in winter and spring would have prevented moisture damage in this case.

\subsection{Arrangement and Physical Properties of Components}

Discussion, thus far, concerning the insulating and moisture performance of roof construction has identified materials properties of hygroscopicity, water absorbency, water vapor permeability, and thermal conductivity as properties of major importance. Other factors, such as temperature and relative humidity exposure conditions, the quantity and location of moisture present in the materials, and the thicknesses of the materials were also shown to exert considerable influence on performance. The arrangement of materials in a roof construction was thought to have a bearing on its performance. 
Certain pairs of specimens listed in table 3 were sufficiently alike and were exposed simultaneously to enable comparisons in respect to arrangement of materials within a specimen. These pairs of specimens were 7 and 21,9 and 20, and 15 and 19.

For Specimens 7 and 21, figures 23 and 37, respectively, arrangement was of major importance. Here the location of the expanded polystyrene insulation, whose water vapor permeance was low compared with that of the perlite concrete, controlled the self-drying characteristics. The best performance was obtained with the polystyrene insulation board located above the perlite concrete, Specimen 21, figure 37 . With the polystyrene board located beneath moist perlite concrete, relatively little drying of the perlite concrete to the room beneath occurred because of the high resistance of the polystyrene to the flow of water vapor through it, as shown for Specimen 7 in figure 23.

The performance characteristics for Specimens 9 and 20, figures 25 and 36 respectively, show that it made little difference whether the wood-fiber insulating board was located above or below the perlite concrete. Each specimen provided about the same insulating value and was able to dry to an equilibrium moisture content when wetted. Their insulating values were lower than dry values because both component materials in the specimens are hygroscopic and in use always contain some moisture.

The performance characteristics of Specimens 15 and 19 , figures 31 and 35 respectively, show that a higher average insulating value was obtained for Specimen 19 when the glassfiber insulation was located above the perlite concrete but it took a longer period of time for this specimen to recover insulating value when wetted as compared with Specimen 15.

From these comparisons it was concluded that the performance of a specimen cannot be reliably predicted on the basis of any one physical property of the materials. To evaluate the insulating and self-drying performance, one must consider the thermal and moisture properties of the materials simultaneously as well as the factor of their location within the construction. Also, a general rule stating that insulation should be placed either above or below concrete in a construction was not considered to be feasible.

The thermal resistance values shown in figure 35 for Specimen 19 were approximately what would be expected for the nearly dry component materials of perlite concrete and glass-fiber insulation, but for the same component materials as used in Specimen 15, figure 31, comparable resistance values were considerably lower. Lower resistances occurred in Specimen 15 because of a higher rate of heat flow through the specimen as compared with that of Specimen 19 when each had approximately the same speci- men surface-to-surface temperature difference across it during exposure. During the second winter exposure period, week No. 34, figure 31 , an in-place calibration of the calorimeter over Specimen 15 was completed using Procedure A in Reference [6]. Results of the calibration showed that a slightly higher heat flow through the guarding insulation was occurring as compared to the value of heat flow allowed on the basis of the original calibration determined using dry specimen materials. However, allowance of a slightly increased guard insulation heat flow did not increase the specimen thermal resistances to dry values. The presence of moisture in the perlite concrete when used over insulation was considered to be the primary cause of the observed increase in heat flow in Specimen 15 because of absorption by the calorimeter of latent heat from condensation occurring in the perlite concrete in winter at the time of the calorimeter measurement and the original calibration factor obtained using dry materials was considered to be valid.

Additional calibrations were performed as indicated in figures 31 and 35 and later on similar Specimens 16 and 22, as indicated in figures 32 and 38 , respectively. Results in general indicated that the heat flow in specimens with glass-fiber insulation over perlite concrete was comparable to that to be expected for dry materials, while that for concrete over insulation was consistently higher. Also, throughout the exposure history of Specimens 16 and 22, extra heat-flow data were obtained using heat flow meters attached to the indoor surfaces of the specimens. For Specimen 22, insulation over concrete, reasonably good agreement was obtained between the heat flows determined using the calorimeter and the heat flow meter, and the calculated heat flow based on the thermal conductivity of the dry component materials of the specimen during the periods when the specimen was fairly dry (week 90 to 113). For Specimen 16 , insulation beneath concrete, reasonably good agreement was obtained between the heatHow meter and the heat flow based on the conductivity for dry materials. The heat flow as indicated by the calorimeter was greater. A reasonably good agreement of the heat flows of Specimens 16 and 22 was obtained when the heat-flow meter and calculated data were compared. The reason for the higher heat flow of Specimens 16 and 15 when using the calorimeter technique was attributed to latent heat effects as mentioned above. It is postulated that a heat-flow meter attached to the indoor surface measures the heat flux across the meter but does not account for latent heat of condensation that would be absorbed by the calorimeter, as used, on the outdoor surface of the specimen. It can be noted from the performance characteristics of all of the figures shown here that all specimens that are made with moist concrete above 
insulation consistently show decreased thermal resistance when compared with dry values of thermal resistance as calculated from the thermal conductivity of the component materials.

During the course of the test series investigating arrangement of the same materials in test specimens, temperature and heat-flow data were taken during twenty-four-hour periods at several times in the exposure periods of some specimens as indicated in figures $23,25,31,32$, 35 to 37 , and 38. Figure 44 shows typical sample lesults for Specimens 19 and 15 during summer and winter exposure periods when the specimens were near their equilibrium moisture content. Similar results were obtained for all specimens in the arrangement-test series. Figure 44 shows, for the summer exposure period, that the average temperature of the 3-inch-thick perlite concrete when placed over the $1 \frac{1}{2}$-inch-thick glass-fiber formboard of Specimen 15 reached a maximum of about $125^{\circ} \mathrm{F}$ about 6 hours after the start of simulated solar heating. If liquid water were present in the concrete at this temperature, its saturated water vapor pressure would be about 4.0 inches of mercury and with the room beneath held constant at a vapor pressure of about 0.43 in. of mercury a vapor pressure difference of 3.57 in. of mercury would be available for drying at this time. The vaporpressure-difference potential for drying would increase and decrease as the specimen heats and cools with a net tendency towards drving to a moisture content equilibrium as is indicated by the moisture content curves of the performance characteristics. The same process would apply in Specimen 19 if liquid water were present in the glass-fiber formboard over perlite concrete. After the specimens reach a moisture content equilibrium, presumably as much vapor leaves the indoor face during the heating phase as enters the specimen during the cooling phase over a 24-hour period.

The average temperature of the perlite concrete, when located under the glass-fiber insulation in Specimen 19 reached a maximum of $98^{\circ} \mathrm{F}$ when subjected to simulated summer solar heating as shown in figure 44. As previously discussed, the near steady-state heat flow observed just prior to simulated solar heating was greater in Specimen 15 than in Specimen 19. In summer, condensation of indoor water vapor in the specimen was not probable, as in winter, because temperatures in the specimen were all above the dewpoint of the indoor air. The reason for greater heat flow in Specimen 15 in summer has not been fully accounted for. In winter, the increased heat flow was probably due to the latent heat of condensation in the perlite concrete. An estimate of the quantity of heat given up by vapor condensation using the rate of weight gain of the specimen indicated that this most probably was the cause, especially since the temperature within the perlite concrete of Specimen 15 fell to values lower than the dewpoint of the indoor air $\left(54.5^{\circ} \mathrm{F}\right)$ for several hours of the night period of the winter exposure condition as shown in figure 44 .

In Specimen 19, the perlite concrete did not at any time reach temperatures during the winter exposure conditions as low as the indoor air dewpoint. This difference between the two specimens explains why Specimen 15 gained weight during its first and later winter exposures, while Specimen 19 lost, or gained little weight. Similarly, consideration of the average daily temperature of the perlite concrete during the summer exposure condition indicates that Specimen 15 should dry faster than Specimen 19, as was in fact the case.

The results and discussion presented indicate that a design of an insulated flat roof that omits a vapor barrier, has some moisture absorption capacity, and is not used over indoor environments of very high relative humidity, will provide reasonably good insulating value year-round and will self-dry by sun heat if wetted from a roofing leak once the roofing leak or source of accidental moisture is corrected. However, results obtained were observed under carefully controlled laboratory conditions and the question arises as to whether a particular design would perform similarly in an actual building in the field. Such factors as variable moisture contents of materials when installed in a roof, difficulties in obtaining consistent high-quality workmanship on the job, changing weather, and the ever-present possibility of roofing leaks being accidentally created, preclude prediction of field performance. The authors recommend that field tests of promising self-drying-type designs be performed for comparison with the laboratory results presented here.

\subsection{Design Criteria}

Design criteria were prepared to allow a designer of insulated flat-roof constructions much freedom of choice as to commercially available insulations and building materials and to provide a means to judge and evaluate these designs, particularly those that utilize newlydeveloped materials. The basic rules in designing self-drying insulated flat-roof constructions as developed in this paper, are: omit conventional sheet or mop type vapor barrier; use at least one material in the layer that has water absorptive capacity; if more than one material is used, locate the material of lowest water vapor permeance just under the roofing, though this may not be necessary if the permeance values of the materials are reasonably close; do not use alone an insulation of high watervapor permeance; avoid thicknesses in excess of 3 to 4 inches of highly absorptive materials; arrange materials so that water vapor is readily transferred indoors from the material should 
there be moisture present (e.g. as from a roofing leak); provide edge venting and/or roofdeck venting to avoid a rapid increase of pressure in any layer of the composite roof; and do not allow the dewpoint of the indoor air to exceed $60^{\circ} \mathrm{F}$ in winter.

Simple formulas for general design purposes that would predict simultaneously the thermal insulating and wetting or drying performances were not feasible on the basis of only the physical properties of the materials. Instead, certain criteria for performance, as determined by laboratory tests, were prepared and are listed as column headings in table 4, and are shown schematically in figure 45 . The tentative criteria require that designs be tested in the laboratory to determine if performance is within the suggested limits. Laboratory performance testing is considered to be imperative for new designs of roof construction. Observation of field performance would be even better, considering our national climatic variations, but this is slow, might be expensive, and is subject to difficulties of effective feedback of crucial evaluation and utilization of information. Table 4 lists values calculated from the laboratory performance tests and physical property determinations for the 27 specimens used in this investigation. In the table values underlined with a solid line do not meet the suggested performance criteria. A discussion is given below of each limiting factor, with suggestions for numerical values to assure good performance.

\subsubsection{Scope}

This discussion covers suggested insulating and self-drying performance requirements of insulated flat-roof constructions intended for normal occupancy buildings. Normal occupancy spaces in buildings are defined here as those in which the dewpoint temperature does not exceed $60^{\circ} \mathrm{F}$, which corresponds to a relative humidity of 50 percent at $80^{\circ} \mathrm{F}$ dry bulb. Laboratory tests are required for simultaneously determining insulating value and moisture content. The testing procedure requires exposure of a sample of the proposed construction to repeated daily cycles of simulated in-service environmental conditions of temperature and relative humidity, starting with the specimen containing normal construction moisture. The tests required cover the determination of: (a) the time required for the specimen to expel initial construction moisture by a process of self-drying to an approximate moisture content equilibrium when exposed to a simulated summer exposure condition; (b) rate of moisture gain during an immediately following winter exposure condition; (c) duration of a second summer exposure condition required to expel the winter-gained moisture; (d) self-drying performance of the specimen during a summer ex- posure condition after it was wetted with water in simulation of a roof leak. The tests include making daily measurements of insulating effect during these exposures. Adjunct laboratory tests to determine particular physical properties of the component materials are also included.

The discussion of each factor, given below, suggests limits for the performance of an acceptable construction. These are illustrated and indicated in figure 45, and are also given as suggested at the bottom of Table 4.

\subsubsection{Thermal Insulating Value}

The criterion for insulating performance of the construction is a thermal resistance ratio, $R_{t} / R_{d} . R_{t}$ is the average thermal resistance of the specimen over the total test period, evaluated as described below. $R_{d}$ is the dry thermal resistance as calculated on the basis of test results for the thermal conductivity of the dry components. The suggested minimum acceptable value of $R_{t} / R_{d}$ is 0.6 . In this ratio the thermal resistance of the construction is reckoned from its underside (indoor) surface to the top surface of the construction underneath the roofing.

The thermal resistance of the construction as tested, $R_{t}$, is determined daily (usually 5 days per week) by using the National Bureau of Standards Calorimeter Plate Method of test described in reference [6]. The individual daily measured values of thermal resistance of the construction are averaged for each week. The average of the weekly averages, over a period totalling 37 weeks (the 29th week is excluded from this average) constitutes the thermal resistance, $R_{t}$, of the construction as tested. The total test time is 38 calendar weeks. See figure 45 .

The thermal conductivities of the dry materials used in the specimen are determined at $75^{\circ} \mathrm{F}$ mean temperature using the method of test ASTM C 177, reference [19]. The thermal resistance, $R_{n}$ of each component shall be calculated using the formula $R_{n}=X_{n} / k_{n}$, where $X_{n}$ is the thickness of the component in inches and $k_{n}$ is its thermal conductivity in Btu/hr $\mathrm{ft}^{2}$ (deg $\mathrm{F} / \mathrm{in})$. The thermal resistances of the tandem components shall be summed $\left(R_{1}+R_{2}\right.$

etc.) to determine the total calculated dry thermal resistance, $R_{d}$, of the construction.

For any component material the value of its thermal resistance, $R_{n}$, can be firmly fixed because the thermal conductivity of a dry specimen is determined by a standardized methodASTM C 177. The value of the test thermal resistance of a construction or a component varies with time, moisture content, arrangement of the components of the specimen, and exposure conditions. The suggested requirement that the average test specimen resistance achieve a minimum of 60 percent of its dry value may at first appear to be easily accom- 
plished. However, the procedure for calculating $R_{t}$ consists of numerically averaging values that are obtained by exposure under moist conditions during simulated summer and winter seasons. For some specimens that are wet a weekly value of $R_{t}$ may be as little as 25 percent of the dry value. Also, limits of time of exposure are suggested. Thus, the average value $R_{t}$ includes values obtained with the specimen both neardry and moist, as well as values for two seasonal exposures. From laboratory data obtained on specimens that demonstrated good ability to dry in place the value of 0.6 for the ratio $R_{t} / R_{d}$ was selected as a minimum to assure a reasonably efficiently-insulated construction year round. For many constructions that are installed with only normal hygroscopic moisture in them, the weekly value of the ratio $R_{t} / R_{d}$ should be mostly in the range from 0.8 to 1.0 . Further, some constructions that have decks that are relatively quite permeable to water vapor may indicate high values of $R_{t}$ when covered with a wet material of high water absorptive capacity. This occurs because the heat entering the bottom face of the specimen during measurement can largely be used as latent heat of evaporation and the quantity of heat remaining to be absorbed by the calorimeter is small. The apparent weekly thermal resistance of the specimen thus indicated may exceed the dry value and in such cases the maximum value that should be used to obtain $R_{t}$ is the dry value $R_{d}$. Such exceptional results were obtained only with rapidlydrying specimens having quite permeable decks, so the procedure of using the dry value for an obviously wet construction occurs for only a small fraction of the total time of averaging.

\subsubsection{Self-Drying Time for Initial Construction} Moisture and Equilibrium Moisture Content

The maximum testing time suggested under the first summer exposure condition for the construction to expel initial construction moisture by self-drying to a moisture content equilibrium is 16 calendar weeks. Specimen weight loss is determined from daily weighing, using scales sensitive to $0.01 \mathrm{lb}$, made simultaneously with the daily thermal resistance measurements. The average of the daily weight observations for each week constitutes the average gross specimen weight, $G_{t}$, for that calendar week. The gross weight, $G_{t}$, is the sum of the actual net specimen weight $N_{t}$ and a tare.

Weight measurements and thermal exposure and testing should begin immediately upon fabrication and installation of the test specimen. The start is in no case to be later than one week after cast-in-place components are poured. When installed, component materials should be in a moisture condition similar to that to be expected when roll roofing would be applied over such a construction in the field; that is, materials are to be not more than air-dry, and cast-in-place components should not have been subjected to air-drying for longer than one week after placing.

The specimen is considered to be at an approximate moisture content equilibrium during exposure testing when its change of weight, $\Delta G_{t}$, does not exceed $0.05 \mathrm{lb} / \mathrm{ft}^{2}$ (week) for 2 consecutive weeks.

The quantity of moisture present initially will vary widely with various types of constructions. Manufactured insulation normally will contain only hygroscopic moisture. Green concrete will contain a relatively high percentage of free moisture by weight.

Those constructions that are placed in the field with all materials nearly dry will, under laboratory exposure conditions for the first summer exposure condition, reach a moisture content equilibrium rapidly and the values of $R_{t}$ should be high and stable. For these cases it may be permissible to reduce the time of testing to less than the maximum of 16 weeks suggested. However, when averaging weekly values of $R_{t}$ over the aggregate of 37 weeks the appropriate values of $R_{t}$ should be included for the full time period of 16 weeks.

For those specimens containing relatively much moisture, the maximum of 16 weeks for the first summer exposure condition will probably be needed to establish a moisture content equilibrium. It is important that the weight and heat transfer measurements begin within one week after concrete is poured because prolonged laboratory air drying can reduce the moisture content considerably and this would not be compatible with field installation where roofing is usually applied as soon as possible to prevent rain-wetting.

\subsubsection{Equilibrium Moisture Content}

The value of the approximate equilibrium moisture content of the construction achieved as a result of self-drying at the conclusion of the first summer exposure period is evaluated by means of the ratio $M_{t} / M_{c}$, where $M_{t}$ is the average specimen moisture content at the end of the first 16-week summer exposure period. $M_{t}$ is evaluated as $\left.(1 / A)\left[G_{t}-G_{f}\right)+\left(N_{f}-N_{d}\right)\right]$, where $A$ is the plan area of the specimen, $G_{t}$ is defined above, $G_{f}$ is the gross specimen weight after week 38 and just before determining $\left(N_{f}-N_{d}\right)$, which is the loss of total weight of the net specimen on oven-drying its components to constant weight. $M_{c}$ is the calculated moisture content based on equilibrium hygroscopic moisture content determinations of the component materials, and is defined below. The maximum acceptable value for the ratio $M_{t} / M_{c}$ is suggested to be 2.0 .

The equilibrium hygroscopic moisture absorption of each component material is deter- 
mined by exposing a conveniently-sized sample having a thickness of at least 1 inch and an exposed surface area of about $1 / 2 \mathrm{ft}^{2}$ to a uniform temperature of $75^{\circ} \mathrm{F} \pm 2^{\circ}$ and a relative humidity of 90 percent \pm 3 percent until the sample shows no further change of weight. The dry weight of the sample is then determined by oven-drying it to constant weight at a temperature commensurate with the use limit of the material. For drying most building materials an oven temperature of $215^{\circ} \mathrm{F}$ can be used, but for some materials the softening point temperature or other factors must be observed. The equilibrium hygroscopic moisture content, $M_{c}$, in $\mathrm{lb} / \mathrm{ft}^{2}$, is calculated as follows :

$$
\mathrm{M}_{c}=\frac{\rho_{1} x_{1}}{12}\left(\frac{\mathrm{W}_{h_{1}}-\mathrm{W}_{d_{1}}}{\mathrm{~W}_{d_{1}}}\right)+\frac{\rho_{2} x_{2}}{12}\left(\frac{\mathrm{W}_{h_{2}}-\mathrm{W}_{d_{2}}}{\mathrm{~W}_{d_{2}}}\right)+\ldots
$$

where $\rho=$ dry density of each component material, $\mathrm{lb} / \mathrm{ft}^{3}$

$x=$ thickness of each component material, in.

$W_{h}=$ constant weight of each component of the specimen at $75^{\circ} \pm$ $2^{\circ}$ and $90 \% \pm 3 \%$ relative humidity

$W_{d}=$ constant weight of each component of the specimen after ovendrying

Evaluation of the approximate equilibrium moisture content at the conclusion of the first summer exposure condition is required to assure that the quantity of moisture present is not excessive.

Laboratory results on specimens have shown that for two-component constructions, after several weeks of the summer exposure condition, the evaporable moisture present in the construction is widely distributed throughout it. To set a limit on the amount of evaporable moisture an allowable construction may contain after 16 weeks of summer-condition exposure, a maximum value of 2 for the ratio $M_{t} / M_{c}$ was suggested, where $M_{t}$ is the average evaporable moisture content of the specimen at that time, and $M_{c}$ is the hygroscopic moisture content of the total specimen if each of its components has the moisture content corresponding to its hygroscopic equilibrium at a condition of $75^{\circ} \mathrm{F}$ and 90 percent relative humidity. It has been found that for most constructions the latter quantity of moisture does not markedly affect the insulating value under the winter exposure conditions.

The value of $M_{c}$ differs considerably among constructions of different kinds, depending both on their weight and on the hygroscopicity of their materials. Information on hygroscopicity at this condition available in the literature is sparse, and what is available indicates considerable variation for ostensibly the same mate- rial, and also shows variation with specimen size. Hence, it appears necessary to require test measurements to ascertain $M_{c}$ for a construction. The quantity of hygroscopic data obtained as an adjunct to the NBS tests on roof constructions is small. It is felt that as more information becomes available it may be possible in the future in some cases to omit specific measurements to obtain $M_{c}$. It may also be desirable in the future to change the present limiting value of the ratio $M_{t} / M_{c}$.

\subsubsection{Regain of Moisture-Winter Exposure Conditions}

The maximum permissible average rate of moisture regain under winter test exposure conditions is suggested as $0.05 \mathrm{lb} / \mathrm{ft}^{2}$ (week). The time of exposure to determine the average rate is six calendar weeks immediately following the first summer exposure period at the conclusion of which an approximate moisture content equilibrium was established.

\subsubsection{Summer Self-Drying Time for Winter Regain Moisture}

The maximum permissible testing time under the second summer exposure period for expulsion by self-drying of moisture gained under the first winter exposure period ( 12.6 .5 above) is suggested to be six calendar weeks. The second summer exposure test immediately follows the first winter exposure period. The specimen should dry to a moisture content not greater than that at the end of the first summer exposure period.

\subsubsection{Summer Self-Drying Time for a Simulated Roofing Leak}

During the second summer exposure period and following 12.6.6 above, a roof leak is simulated by adding water to the center of the upper surface of the top component material of the specimen in an amount equal to 10 percent of the total specimen volume.

In order to facilitate water admission and its lateral distribution, a small well $1 / 8$-inch deep and 1 inch in diameter may be made if necessary in the upper surface of the top component of the specimen, directly beneath the water feed tube through the calorimeter plate. For admission, the head of water over the calorimeter plate should not be more than 6 inches. The maximum time allowable for admission of water is one week. If the full 10 percent by volume cannot be introduced in this time, the amount actually introduced should be noted. If dripping of water from the undersurface of the specimen occurs, the rate of admission must be slowed to prevent dripping, if possible. Thermal resistance values obtained during this week are 
not to be used when averaging to determine the test thermal resistance, $R_{t}$.

The maximum allowable exposure time for expulsion of added water by self-drying during the second summer exposure period to a moisture content equilibrium should not exceed 9 calendar weeks. During this time period ( 9 weeks) the insulating value of the specimen should return to approximately the same value as that observed before water was added.

After the test is completed the amount of moisture in each component is determined by oven-drying to constant weight.

\subsubsection{Water Vapor Permeance and Hygroscopic Moisture Capacity}

The ability of the construction to self-dry in service is also evaluated by the ratio $p_{t} / M_{c}$, where $p_{t}$ is the permeance in perms (grains/hr $\mathrm{ft}^{2}$ in. $\mathrm{Hg}$ ) of the room-side component of the construction calculated from water vapor permeability determinations, and $M_{c}$ is the calculated moisture content in $\mathrm{lb} / \mathrm{ft}^{2}$ of the total construction based on equilibrium hygroscopic moisture content determinations of the component materials. The calculated value of the ratio $p_{t} / M_{c}$ numerically should be between 2 and 200 .

The water vapor permeance, $p_{t}$, is calculated from the values of water vapor permeability and thickness as follows:

$$
p_{t}=\frac{\mu}{x}
$$

where $\mu$ is the water vapor permeability in perm-inch units [grains/ $\mathrm{hr}_{\mathrm{ft}}{ }^{2}$ (in. $\left.\mathrm{Hg} / \mathrm{in}.\right)$ ] determined by either ASTM E96, Procedure A, or ASTM C355, Desiccant Method [20, 21$].$

The hygroscopic moisture capacity, $M_{c}$, is calculated and determined as described in 12.6.4, Equilibrium Moisture Content.

The ratio $p_{t} / M_{c}$ is included to assure that the construction and especially its deck component has a permeance in a range suitable for adequate self-drying without excessive moisture accumulation in winter. Permeability measurements to determine $p_{t}$ are sometimes variable on the same type of material. The value of the ratio $p_{t} / M_{c}$ is also subject to variations of $M_{c}$ as discussed above. Therefore the suggested interval of 2 to 200 should also be subject to future adjustment as more data become available.

\subsubsection{Exposure Conditions}

During exposure the atmosphere beneath the specimen should be maintained constant at $90^{\circ} \mathrm{F}$ and 30 percent relative humidity.

The temperature of the calorimeter covering the upper surface of the top specimen component material should be programmed to repeat daily the following (24-hour) cycle:

\begin{tabular}{|c|c|c|}
\hline & \multicolumn{2}{|c|}{$\begin{array}{l}\text { Calorimeter plate } \\
\text { temperature, }{ }^{\circ} \mathrm{F}\end{array}$} \\
\hline & Winter & Summer \\
\hline 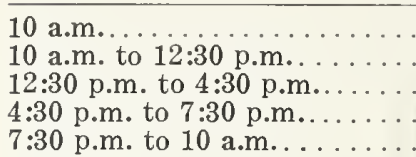 & $\begin{array}{r}38 \\
38 \rightarrow 75 \\
75 \\
75 \rightarrow 38 \\
38\end{array}$ & $\begin{array}{r}75 \\
75 \rightarrow 138 \\
138 \\
138 \rightarrow 75 \\
75\end{array}$ \\
\hline
\end{tabular}

Measurements of the heat flux, and the temperatures at the surfaces of all component materials, and of the specimen gross weight should be made each working day between the cyclic hours of 7:00 and 10:00 a.m. For convenience in testing, the 24-hour cycle of test time can be shifted to enable observations at a preferred time of day.

\section{Summary}

The simultaneous thermal insulating and selfdrying performances of 27 specimens are given. The specimens, $22 \times 23$ inches in plan, were exposed in the laboratory to successive periods of simulated summer and winter temperature conditions on their outdoor surfaces, each with simulated daily solar heating, and with the moisture content of the materials ranging from a near-dry to a wet condition that simulated the results of a roofing leak. The dewpoint of the indoor air was held constant at $54.5^{\circ} \mathrm{F}$.

Results for three of the specimens indicated that a construction consisting of an air-dried one-inch thick structural concrete deck under each of three near-dry board types of thermal insulation without a vapor barrier between materials allowed the insulation to remain dry in winter and summer and resulted in good insulating values. However, when the insulations were wetted in summer to simulate a roofing leak, the concrete decks opposed the escape of vapor from the moist insulations to the room beneath and caused specimen insulating values to decrease to as little as $1 / 3$ of that observed for near-dry materials. These results were very similar to results given in Part I for similarly made specimens with concrete decks 3 inches thick.

The thermal resistance of several specimens was high when they were made without vapor barriers using materials of moderately high water-vapor permeance and were dried to a hygroscopic moisture content equilibrium. These constructions when wetted were reduced in insulating value but during simulated summer conditions self-dried to the indoors within a few weeks time and recovered their insulating value. The quantity of moisture gained by these specimens during winter exposure conditions was not great enough to seriously reduce their 
insulating value or prevent rapid expulsion of winter-accumulated moisture downward through the deck as vapor during a subsequent summer exposure, especially if the deck was covered by a moisture-absorbent material.

Reductions in insulating value were not proportional to changes in moisture content. The ability of an insulated flat-roof deck to yield good year-round insulating value and self-dry in service if wetted was dictated by the outdoor surface temperature conditions, the indoor dewpoint temperature, the arrangement of materials in the construction, the thickness of highlyabsorptive materials, the avoidance of a vapor barrier on or between materials, and the physical properties of thermal conductivity, water vapor permeance, and liquid-water and hygroscopic-moisture absorption of the materials.

Criteria for design of self-drying insulated flat-roof constructions were developed and limits of performance as obtained by laboratory tests were suggested.

The authors recommend field tests on fullscale buildings to compare results with labora- tory results on relatively small specimens as presented here.

This work was conducted at the National Bureau of Standards with partial sponsorship by the Office of the Chief of Engineers, U.S. Army; the Bureau of Yards and Docks, U. S. Navy; and the Office of Civil Engineering, U.S. Air Force.

The authors acknowledge with appreciation the services of L. S. Crockett and D. R. Showalter, who constructed the apparatus, made the majority of the test specimen installations, and recorded the data. They also thank T. W. Reichard for making the concrete specimens and determining their compressive strengths; $\mathrm{T}$. W. Watson for determining the thermal conductivity of all materials by the guarded hot plate method; and W. C. Cullen for measuring water vapor permeances.

Acknowledgment is made to the several associations, institutes, and manufacturers who freely contributed information and materials for this investigation.

Table of Conversion Factors to Metric (S.I.) Units

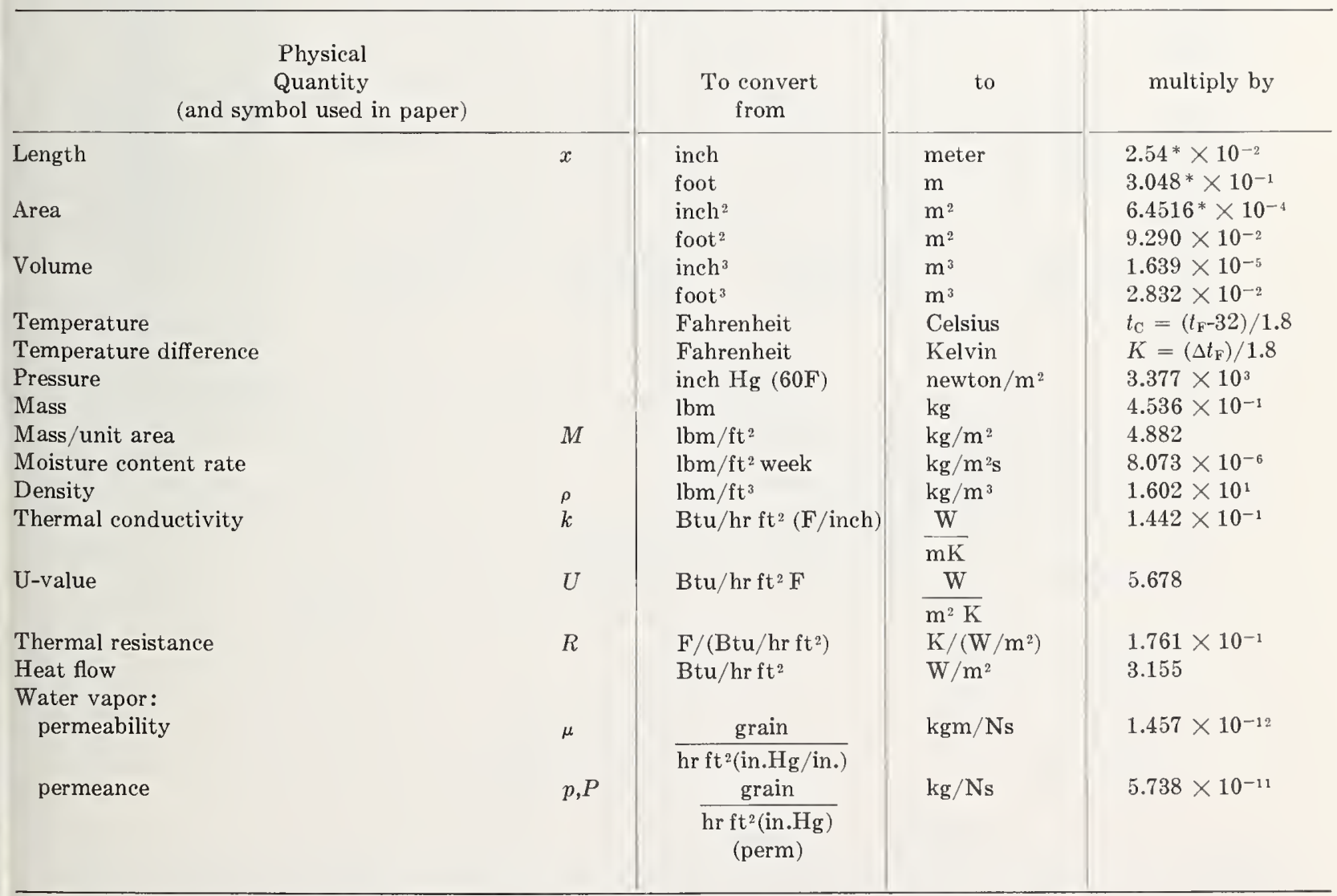




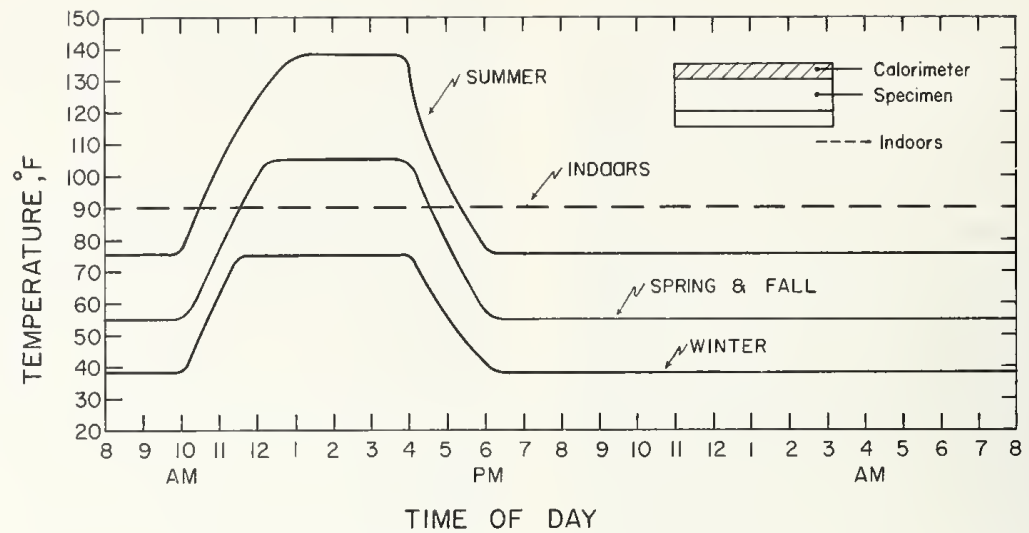

FIGURE 14. Daily temperature wave forms used to simulate winter, spring, fall, and summer exposure conditions on the insulated flat-roof specimens for the calorimeter method of measurement.

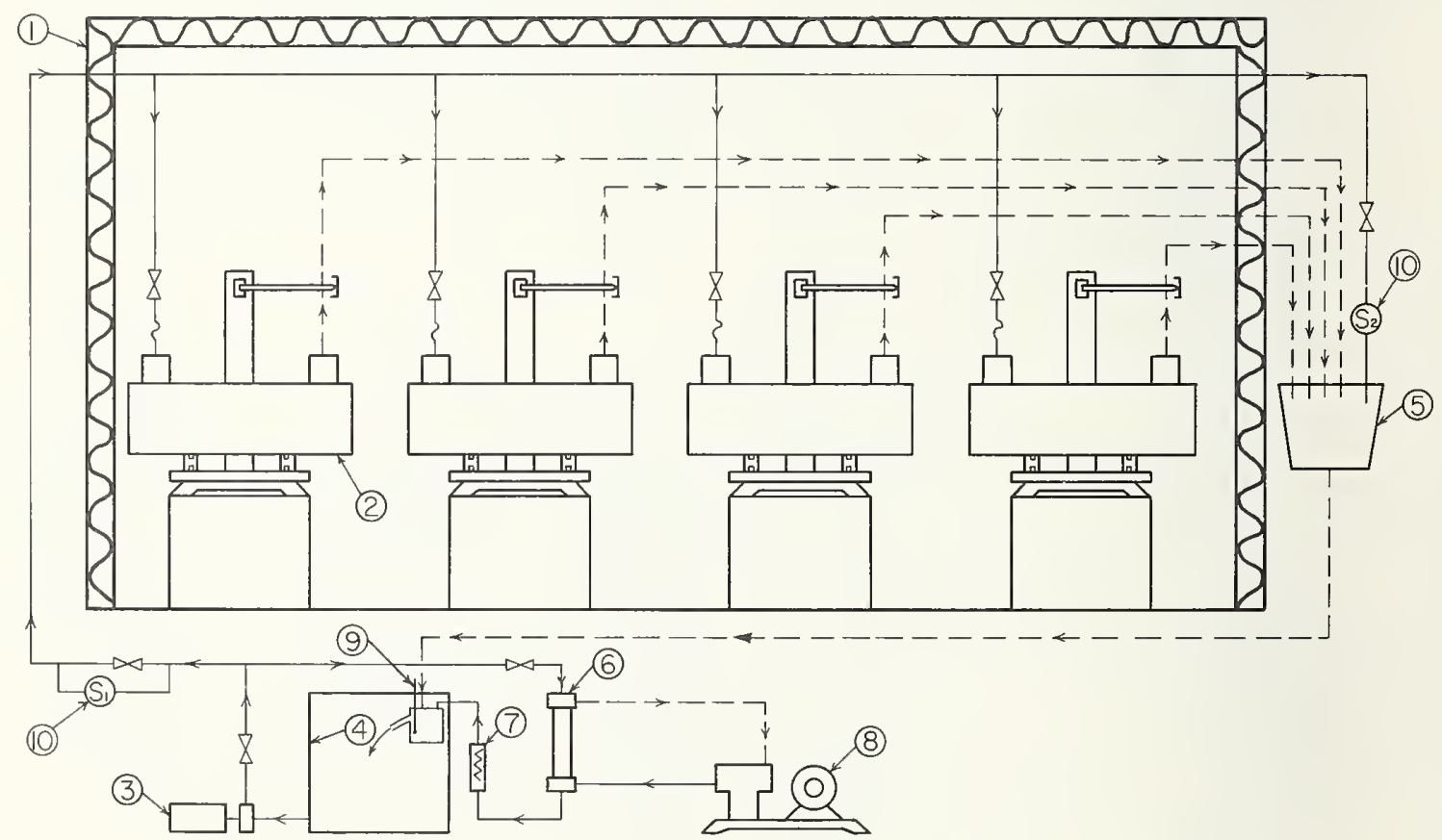

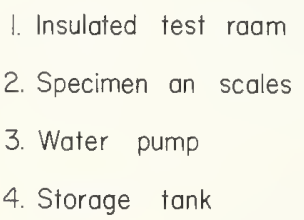

9. Thermastat
5. Sink

6. Heat exchanger

7. Immersian heaters

8. Air caoled refrigeratian

\section{Solenaid valve}

FIGURE 15. Apparatus for measuring the effect of moisture on heat transfer, using the calorimeter method. 


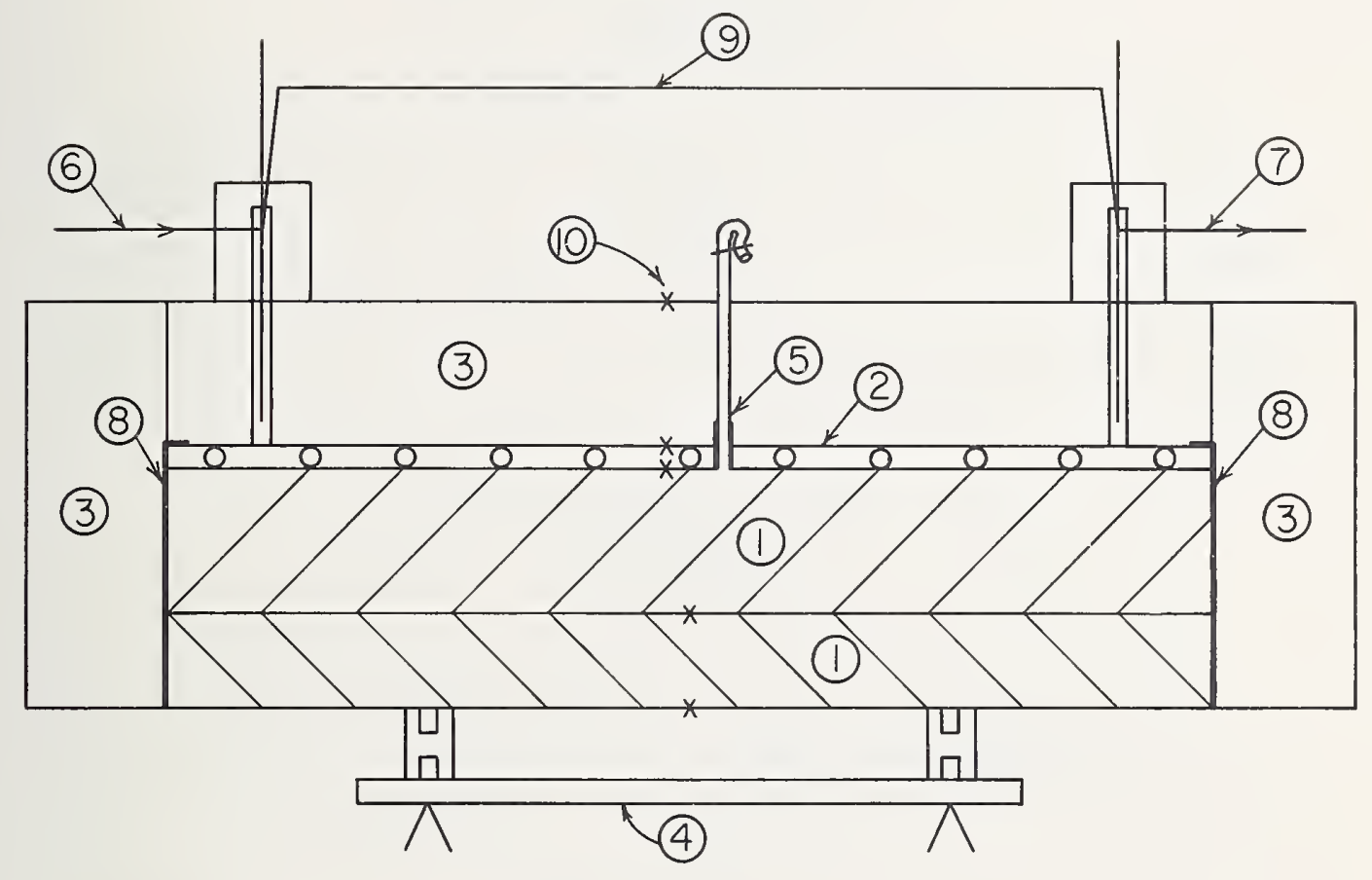

I. Specimen

2. Calorimeter plate

3. Guard insulation

4. Platform scale

5. Tubing to drill-hole
6. Water in

7. Water out

8. Vapor and water proofing

9. Ten differential thermocouples

10. Thermocouple

FIGURE 16. Construction and installation details of a typical specimen used with the calorimeter method. 


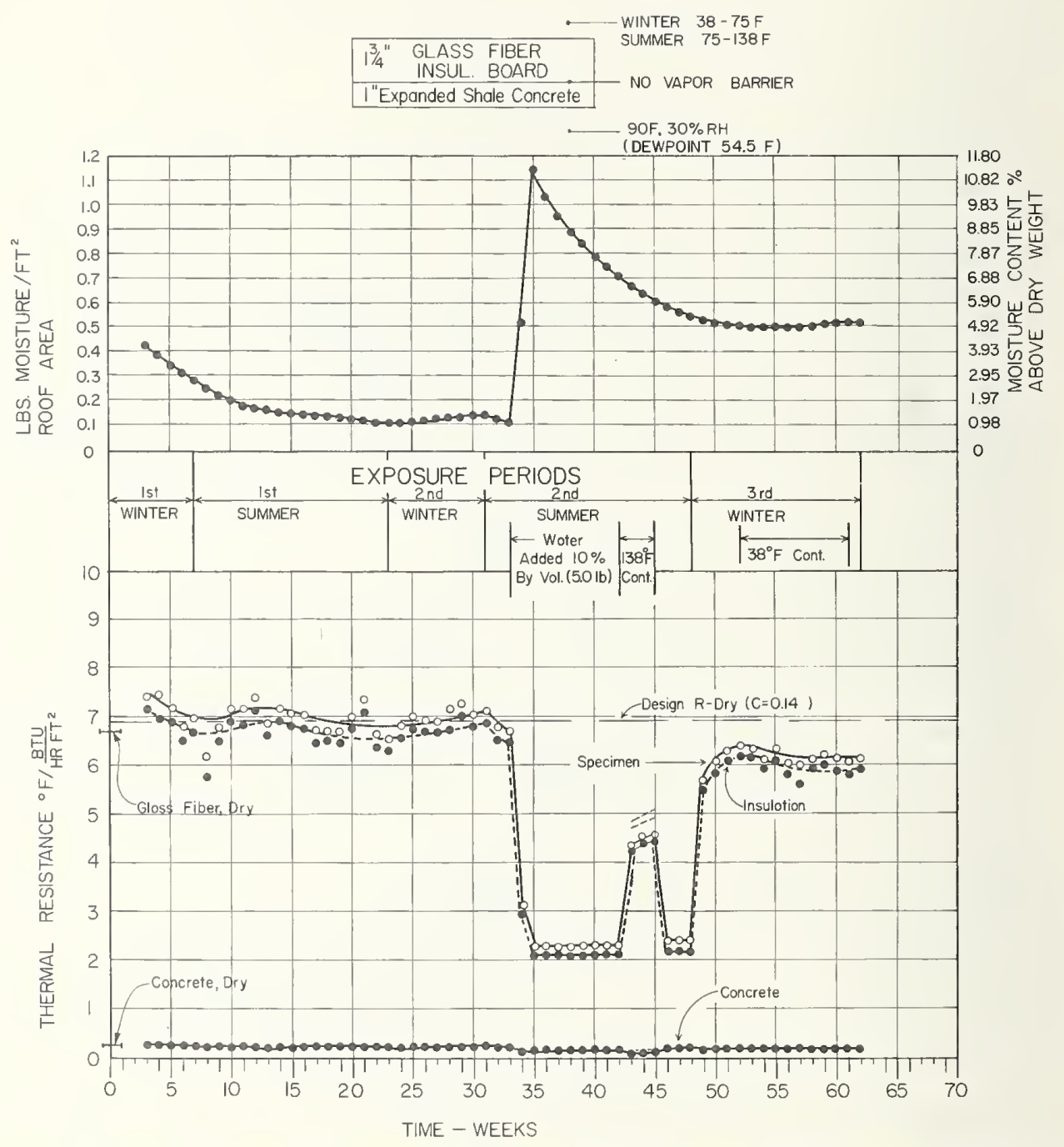

FIGURE 17. Effect of moisture and exposure conditions on the thermal resistance of Specimen 1. 


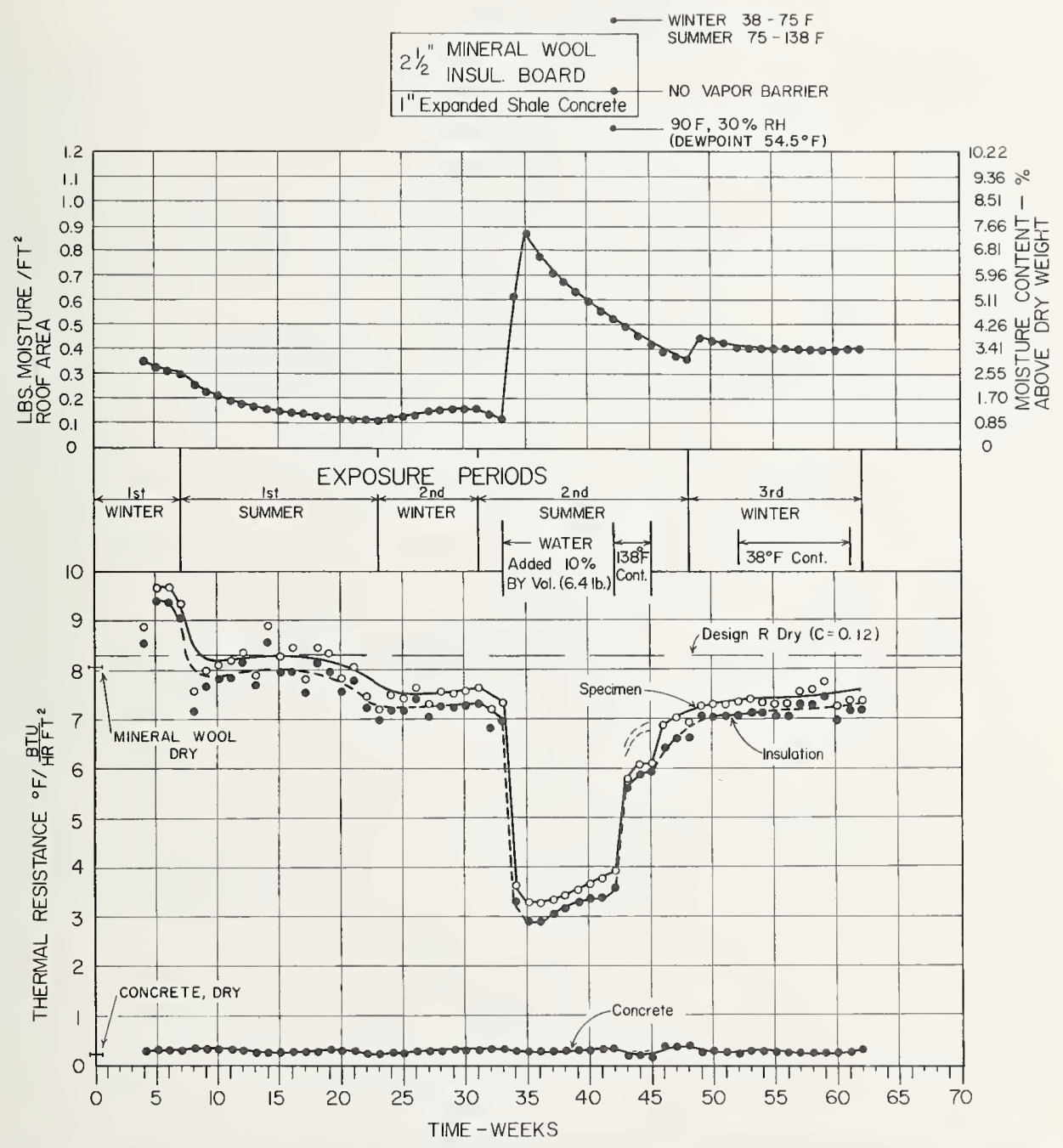

FIGURE 18. Effect of moisture and exposure conditions on the thermal resistance of Specimen 2. 


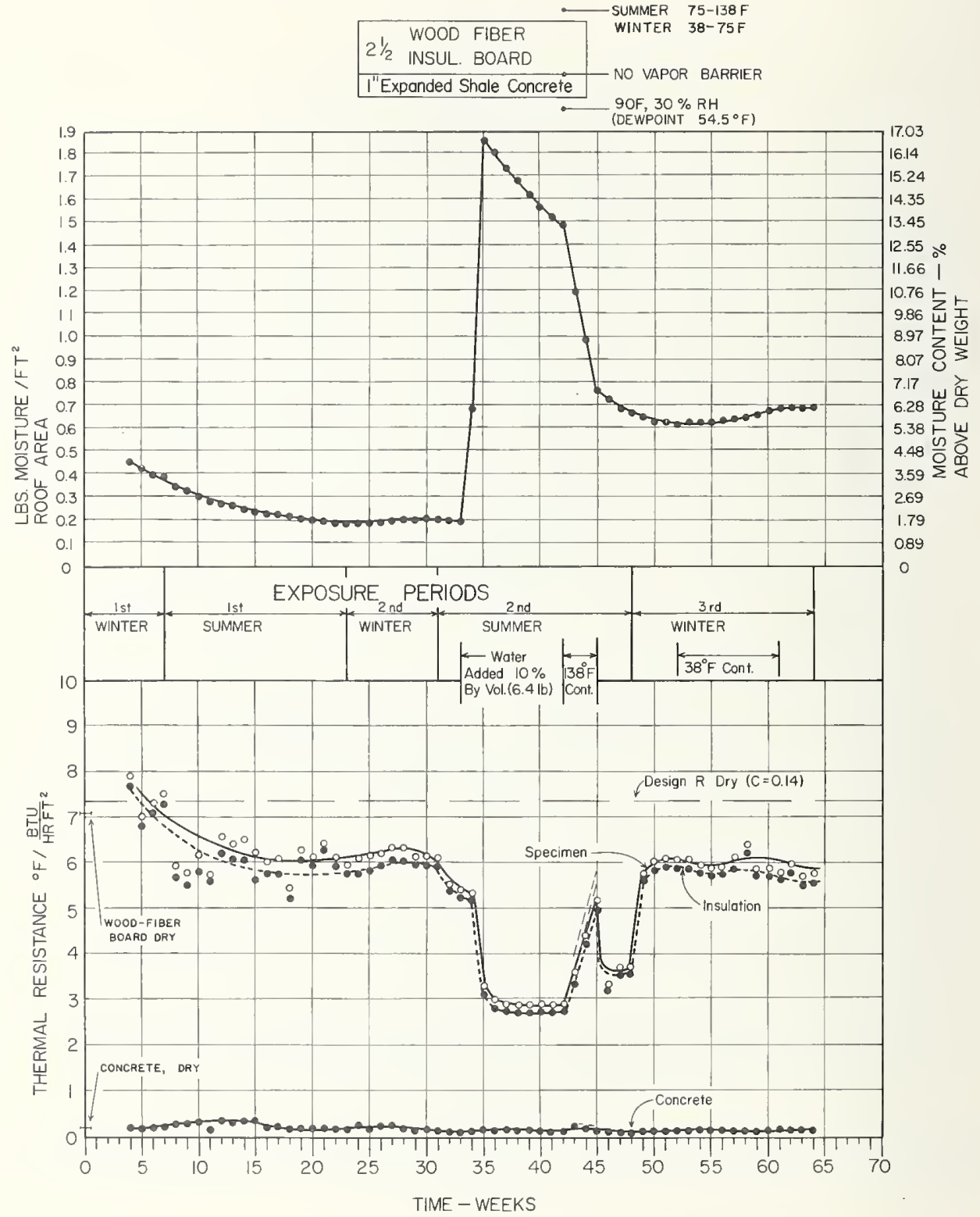

FIGURE 19. Effect of moisture and exposure conditions on the thermal resistance of Specimen 3. 


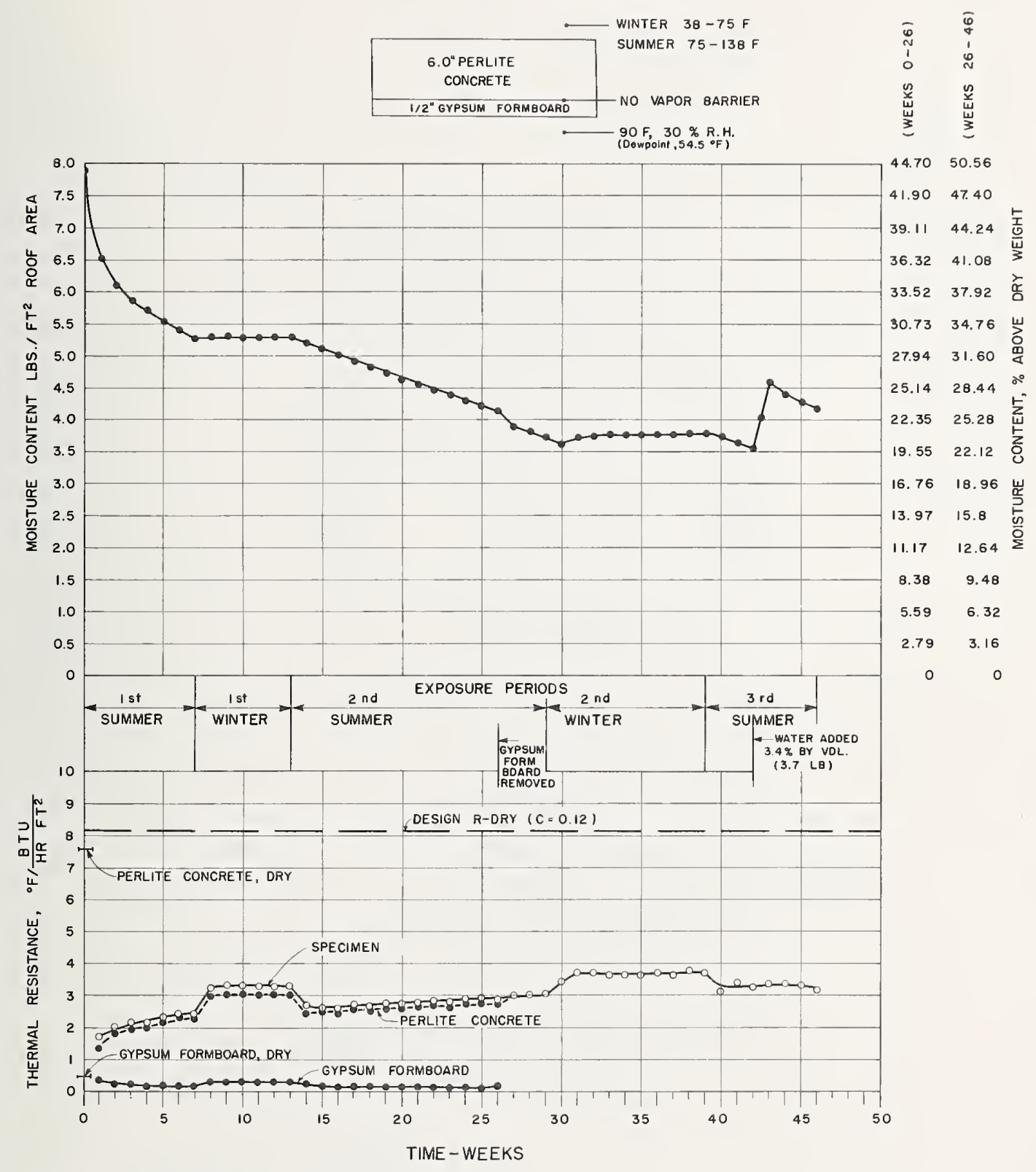

FIGURE 20. Effect of moisture and exposure conditions on the thermal resistance of Specimen 4. 


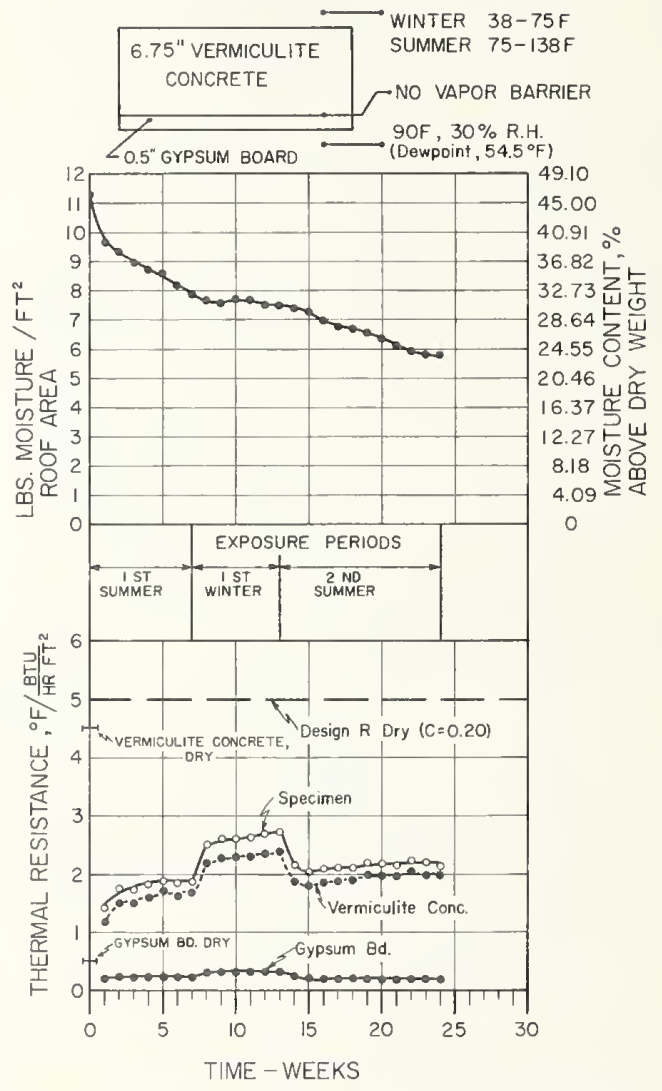

FIGURE 21. Effect of moisture and exposure conditions on the thermal resistance of Specimen 5. 


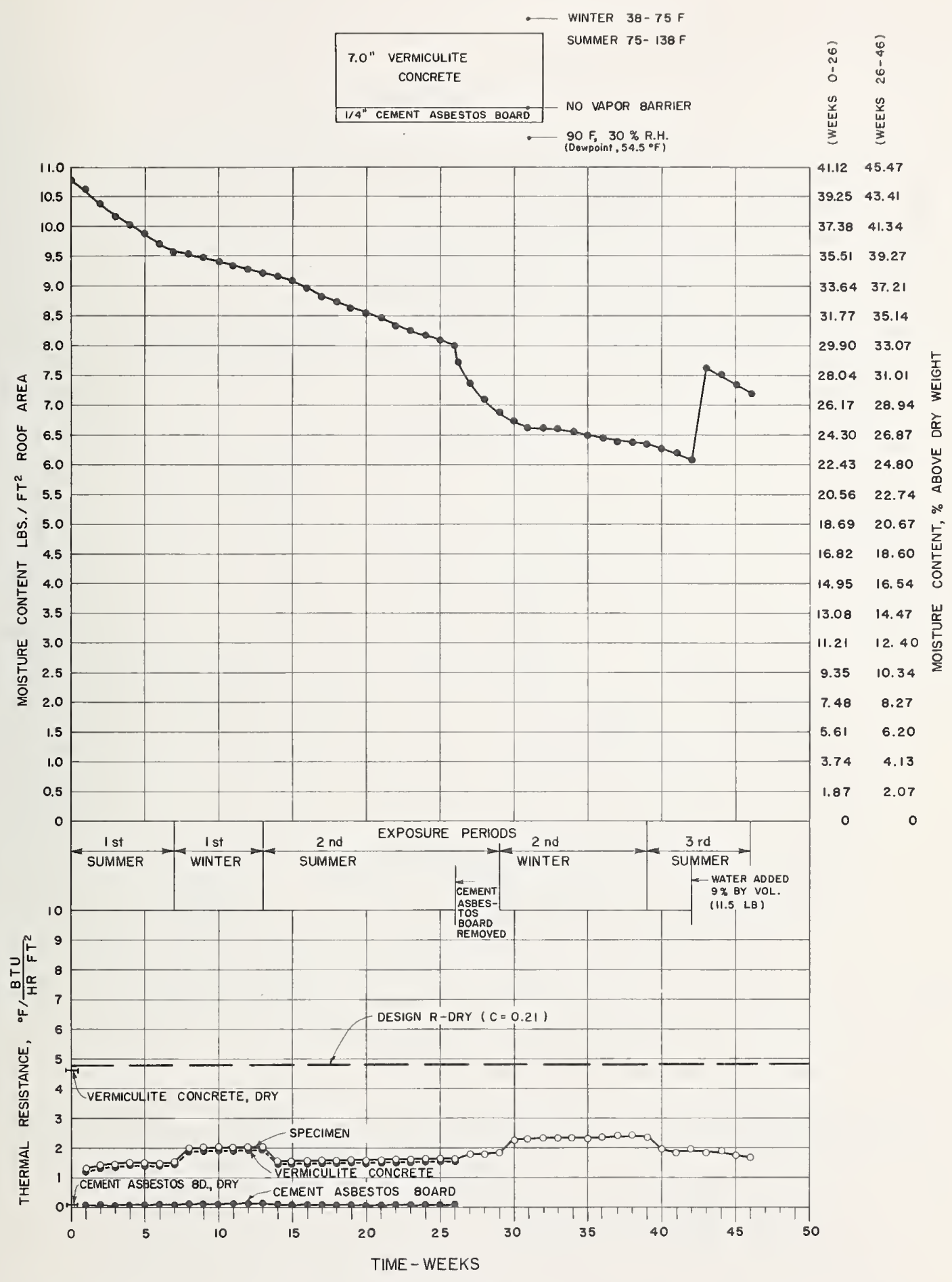

FIGURE 22. Effect of moisture and exposure conditions on the thermal resistance of Specimen 6. 

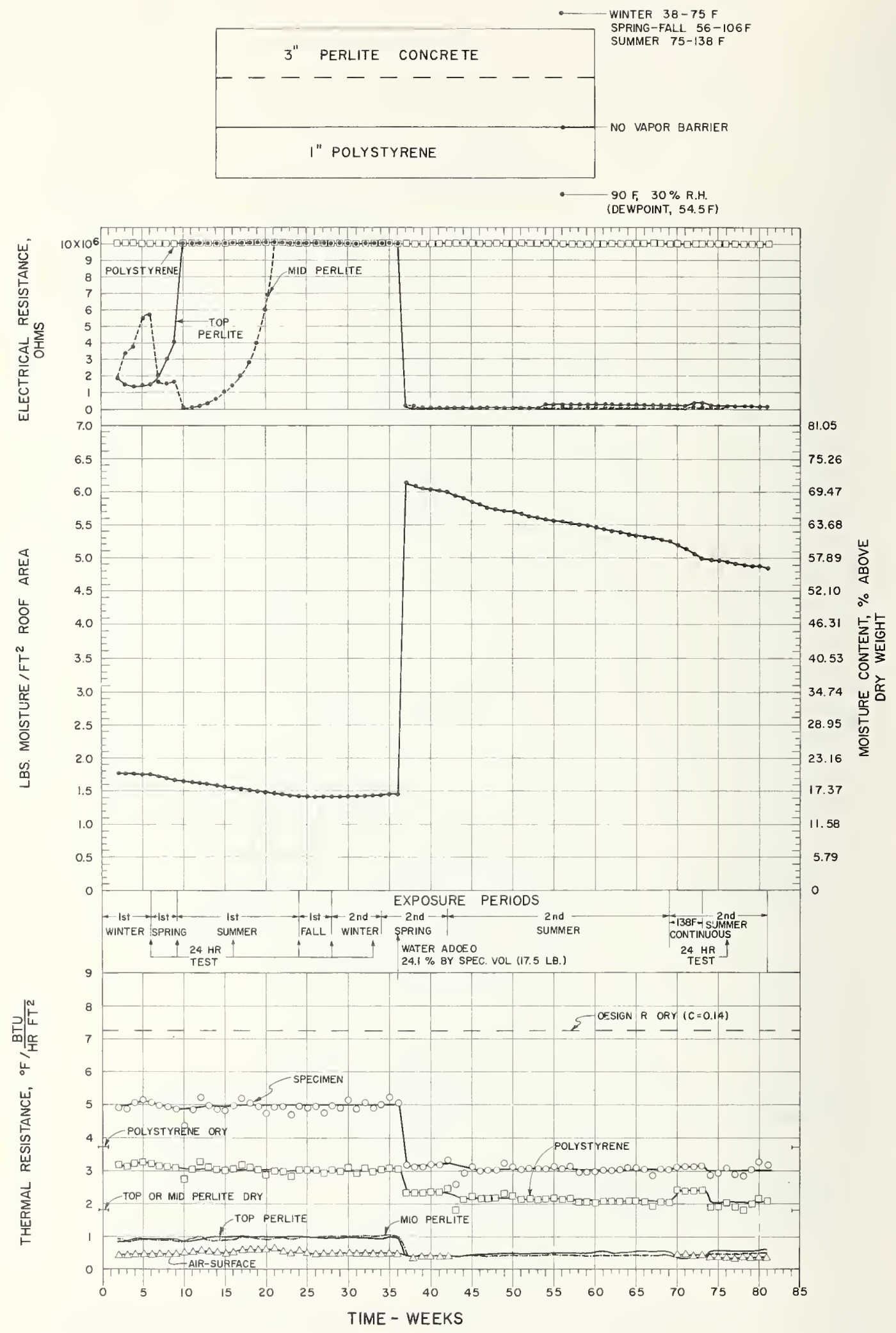

FIGURE 23. Effect of moisture and exposure conditions on the thermal resistance of Specimen $\%$. 


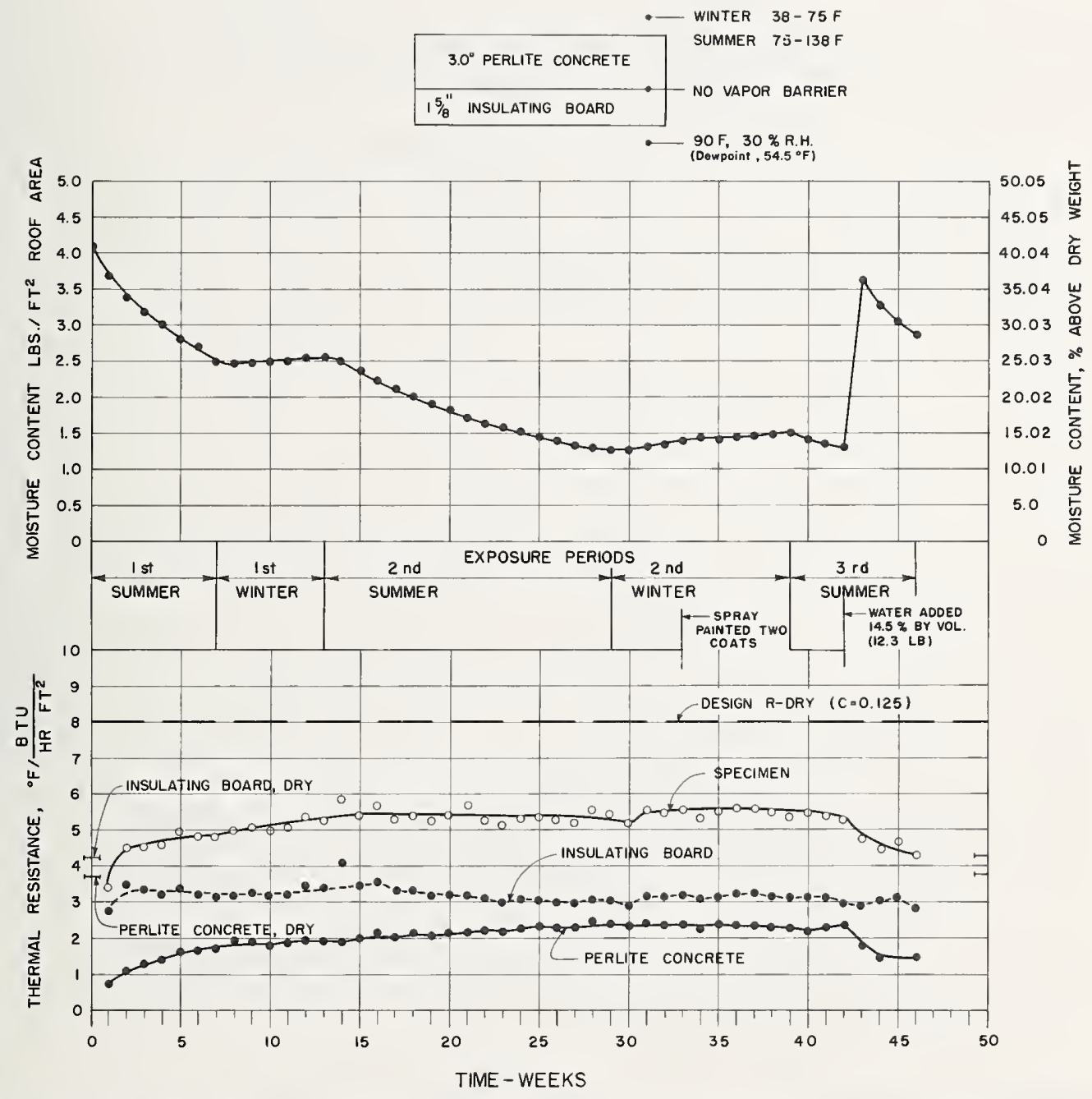

FIGURE 24. Effect of moisture and exposure conditions on the thermal resistance of Specimen 8. 
WINTER $38-75 \quad F$

SPRING-FALL 56-106 F

SUMMER $75-138 \quad F$

3" PERLITE CONCRETE

NO VAPOR BARRIER

I $19^{\prime \prime}$ WOOD FIBER INSULATING BOARD

90 F, $30 \%$ R. H

(DEWPOINT, 54.5 F)
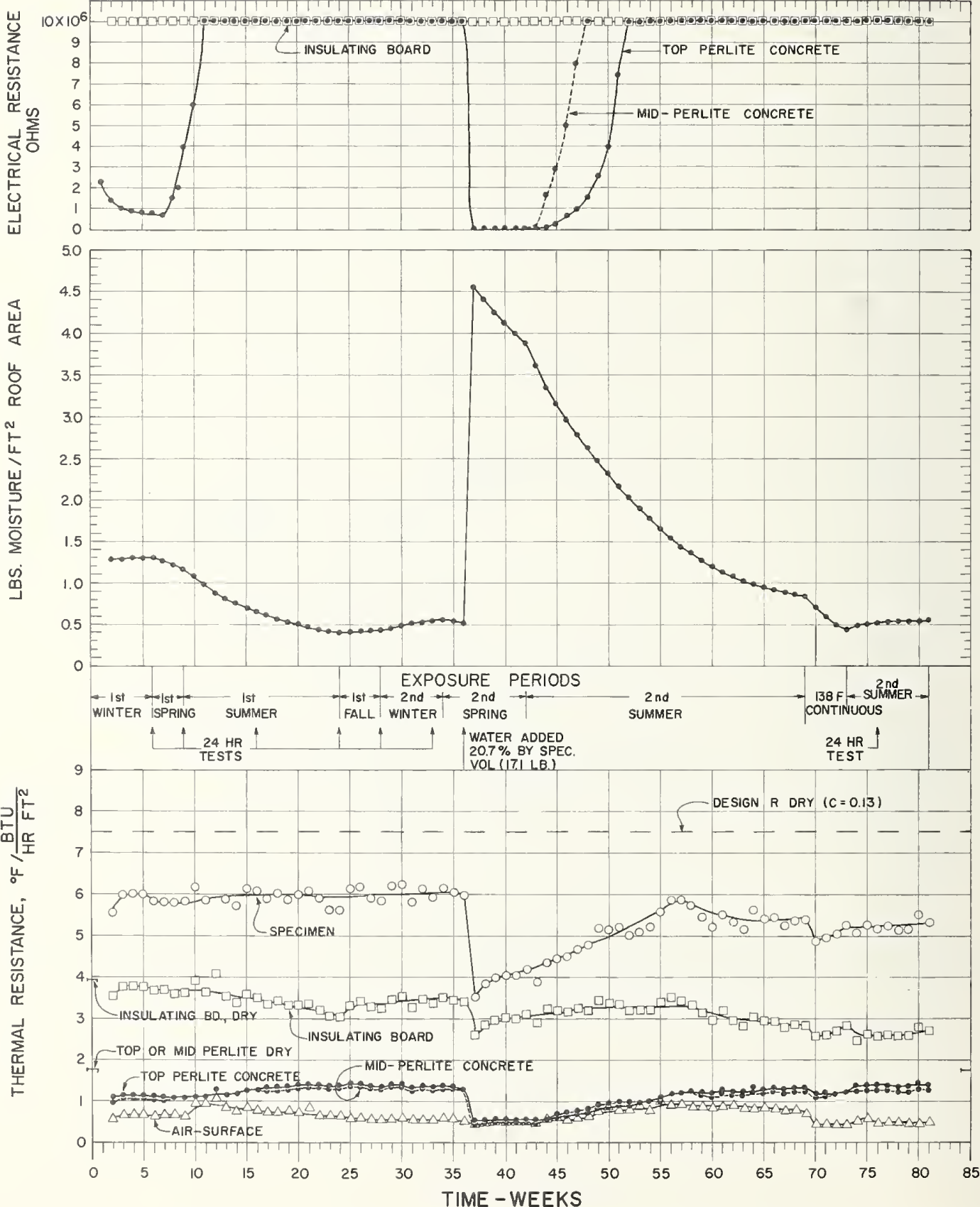

FIGURE 25. Effect of moisture and exposure conditions on the thermal resistance of Specimen 9. 


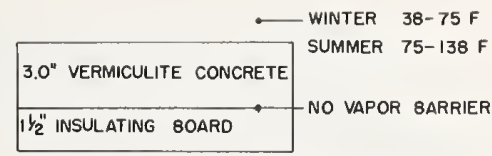

$90 \mathrm{~F}, 30 \%$ R.H.
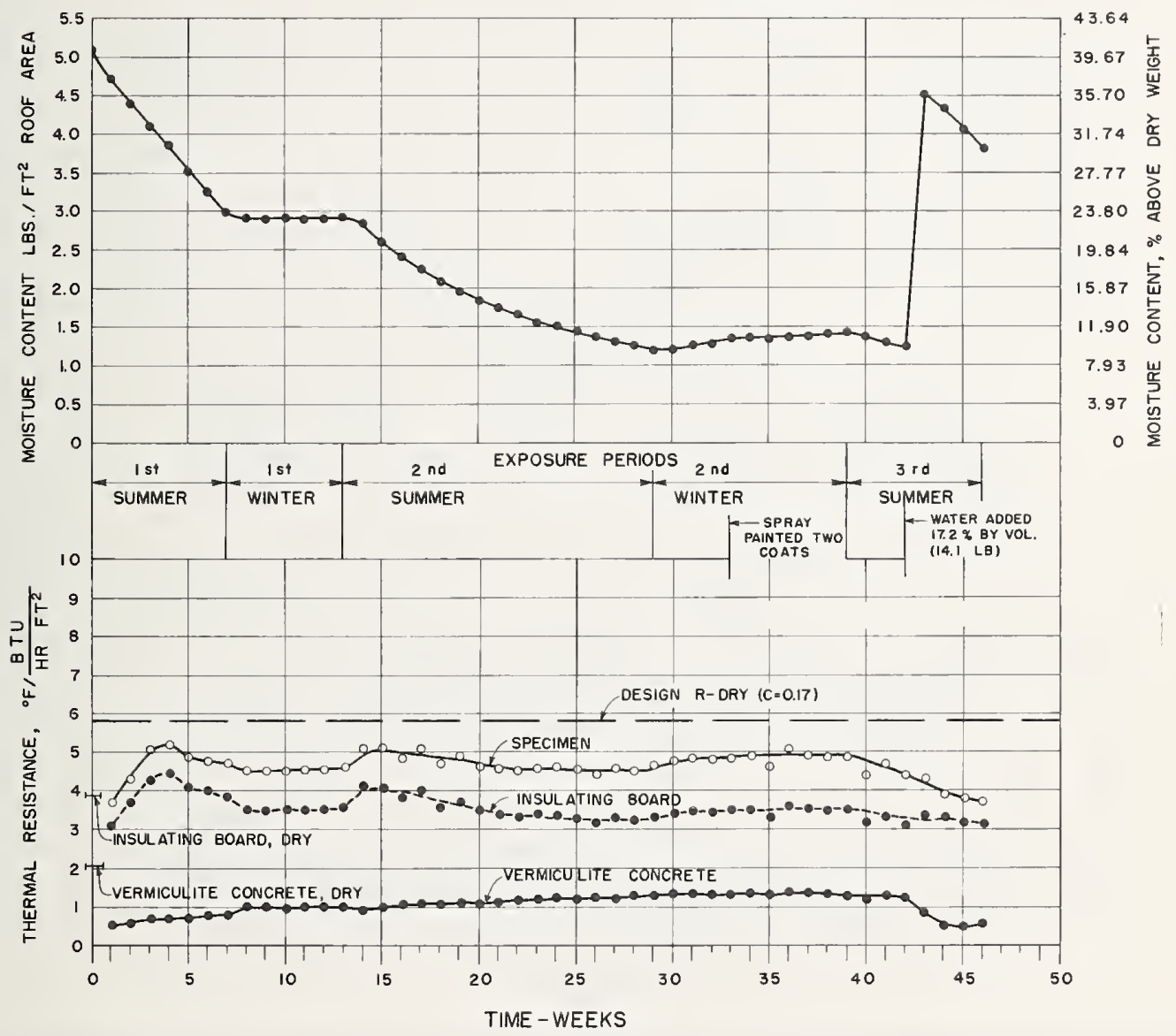

FIGURE 26. Effect of moisture and exposure conditions on the thermal resistance of Specimen 10. 


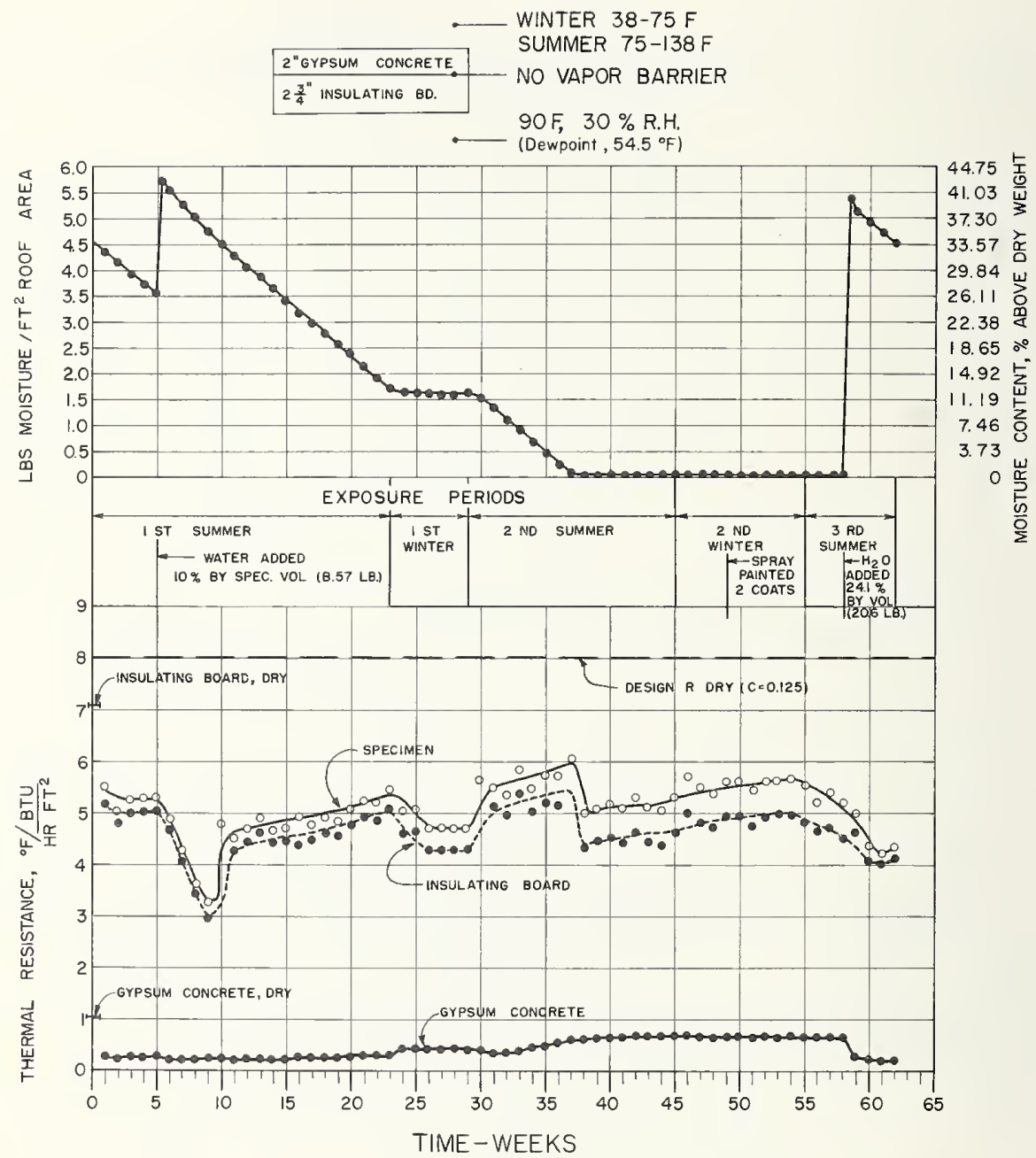

FIGURE 27. Effect of moisture and exposure conditions on the thermal resistance of Specimen 1 


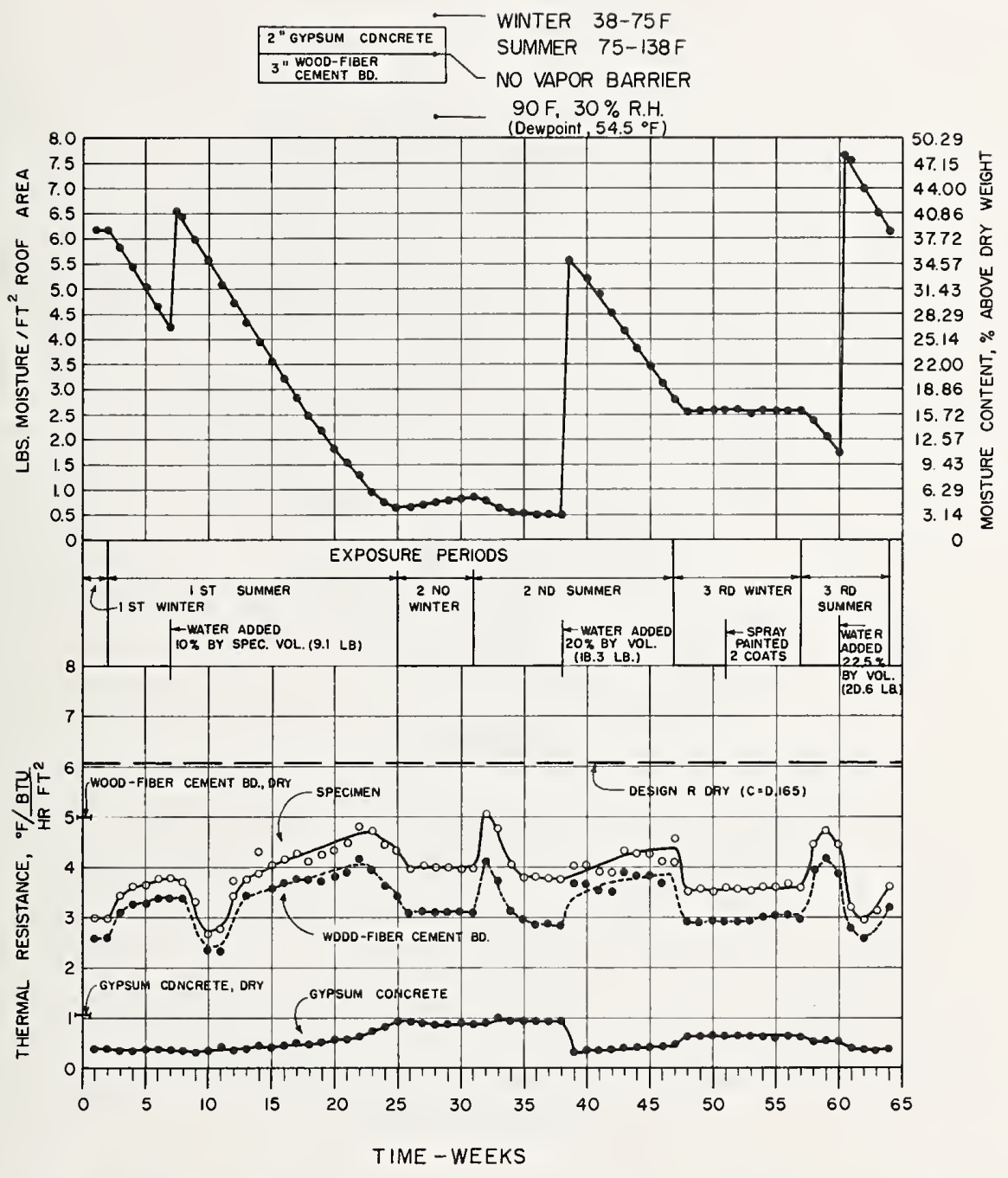

FIGURE 28. Effect of moisture and exposure conditions on the thermal resistance of Specimen 12. 


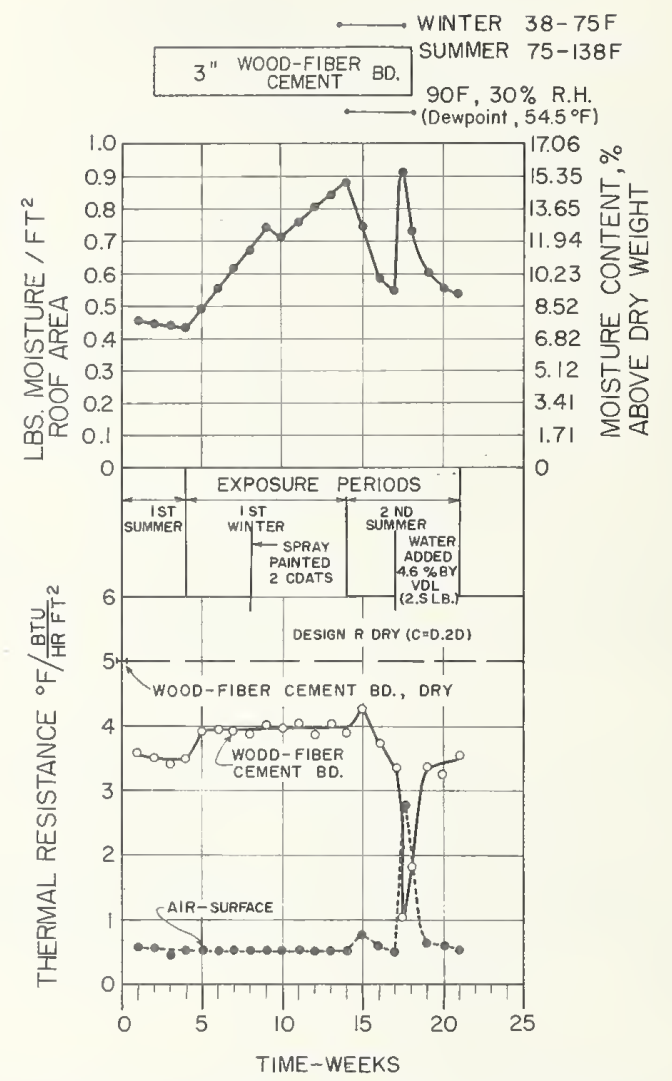

FIGURE 29. Effect of moisture and exposure conditions on the thermal resistance of Specimen 13. 


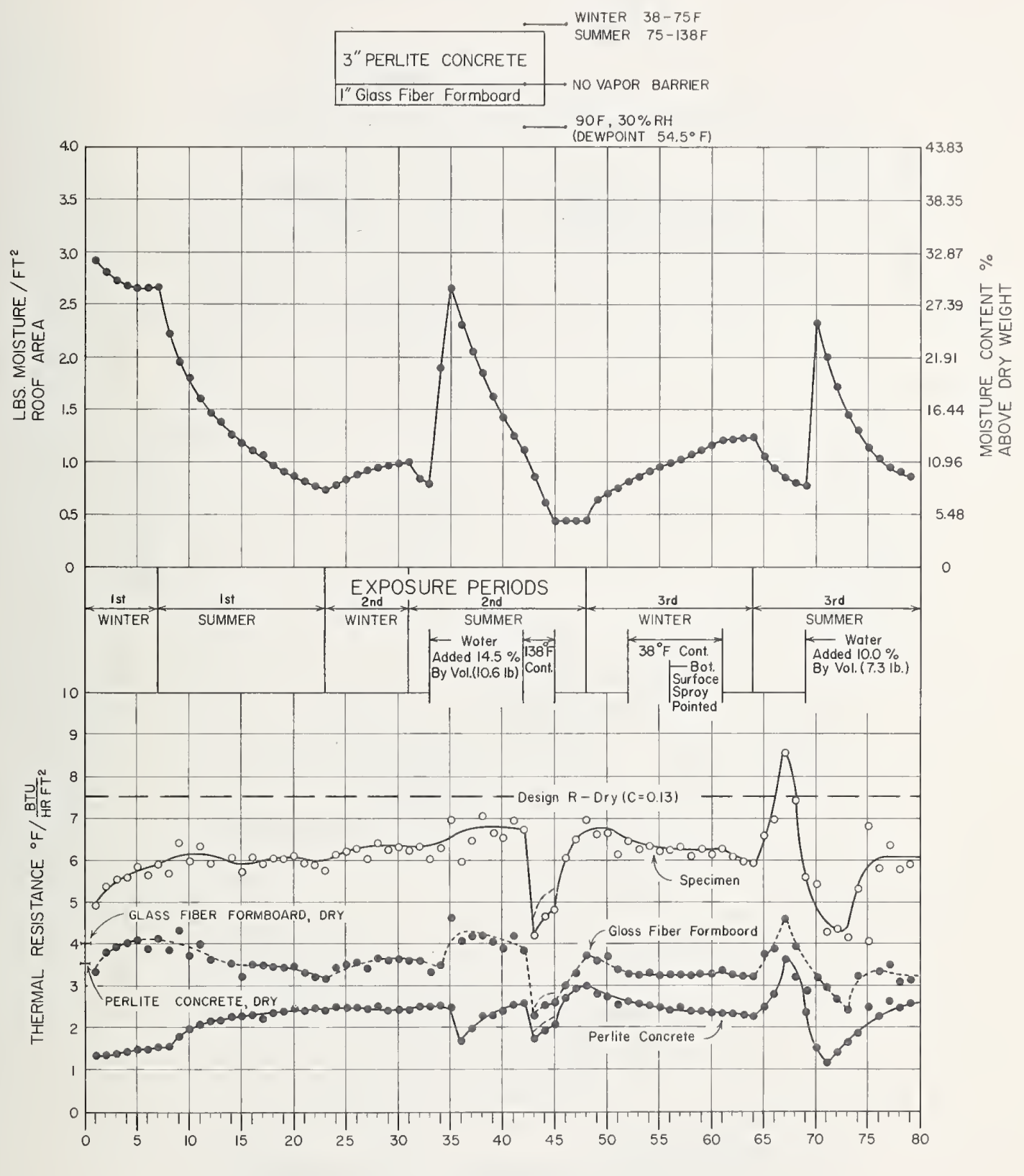

TIME - WEEKS

FIGURE 30. Effect of moisture and exposure conditions on the thermal resistance of Specimen 14. 


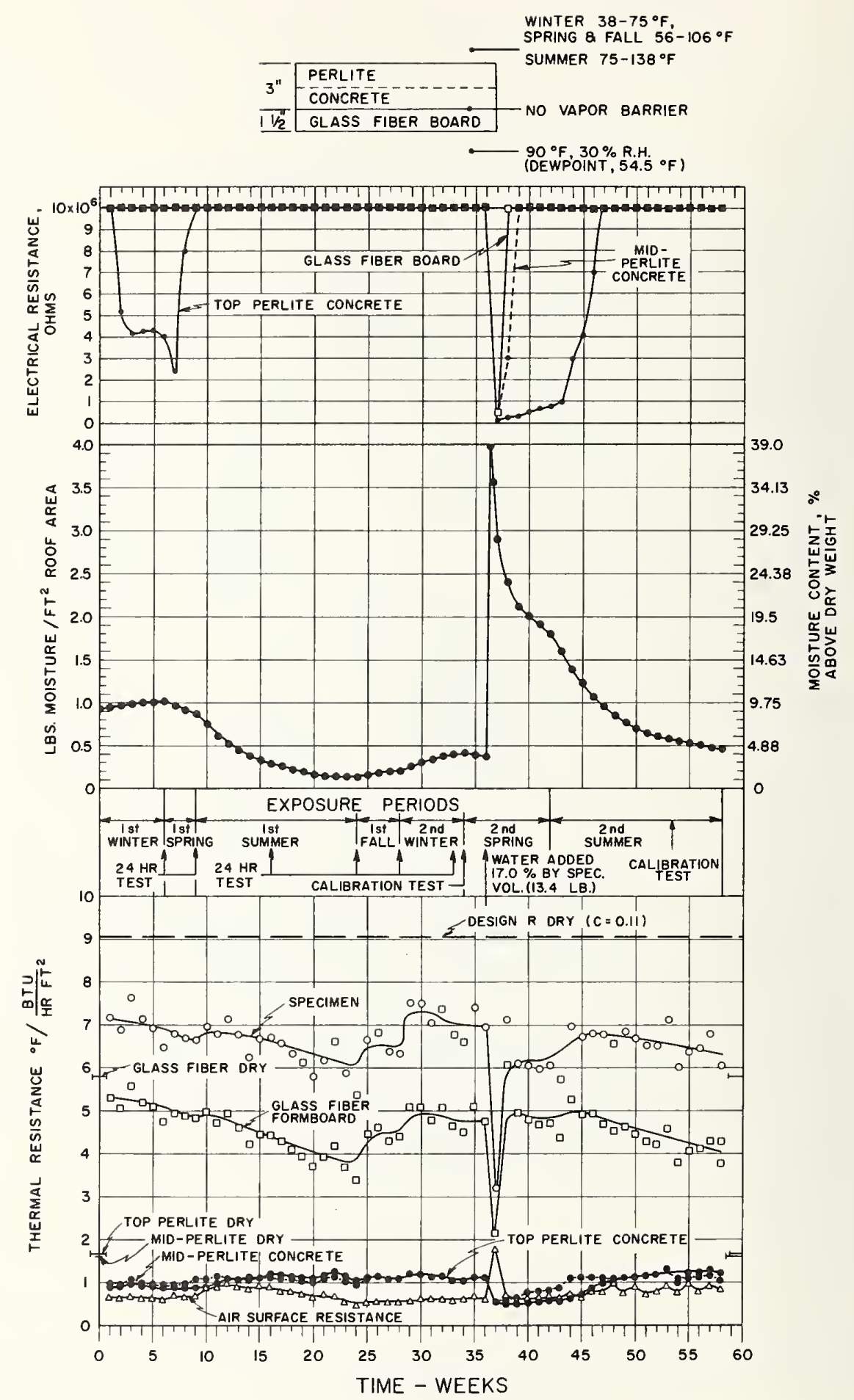

FIGURE 31. Effect of moisture and exposure conditions on the thermal resistance of Specimen 15. 


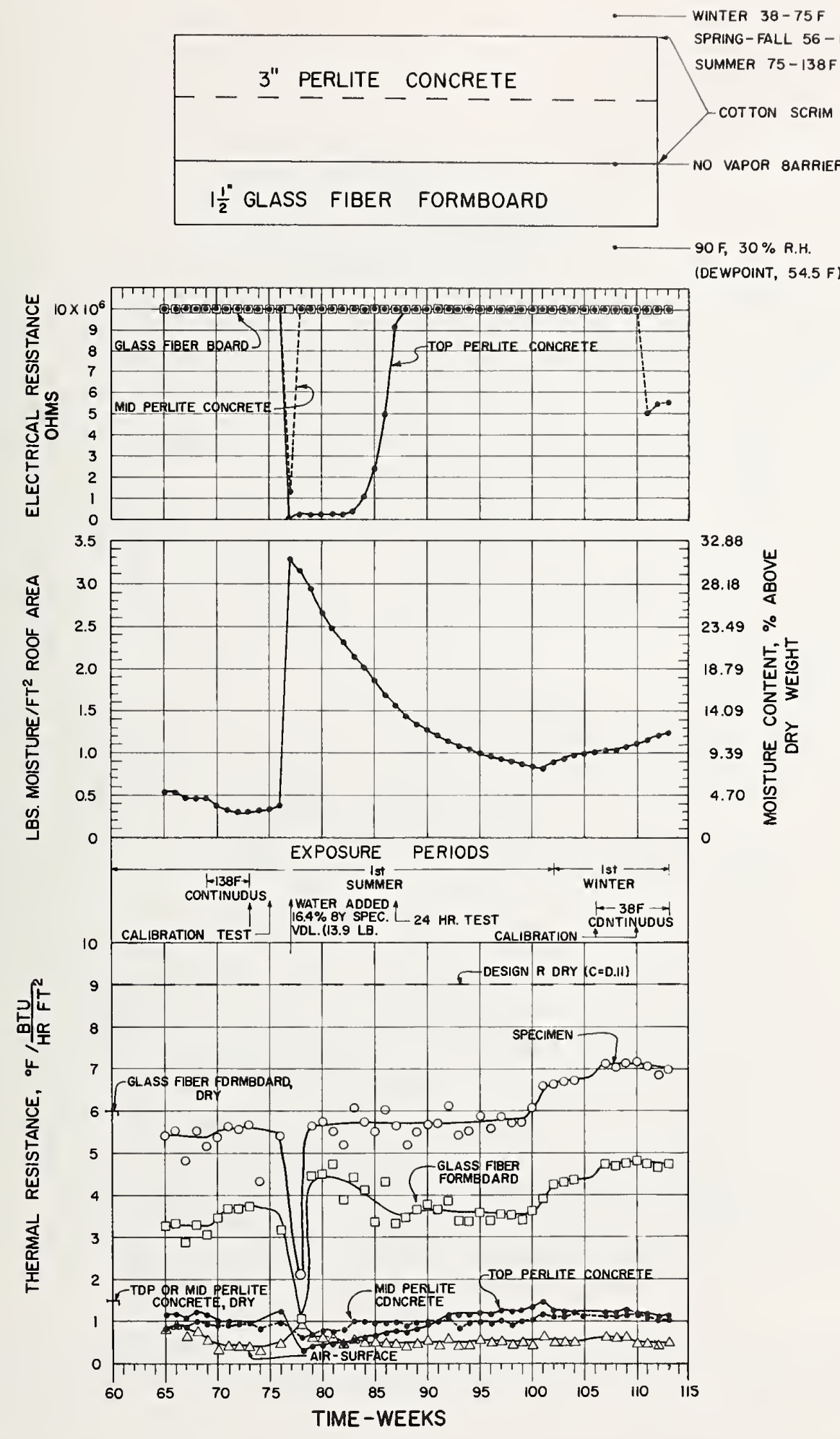

FIGURE 32. Effect of moisture and exposure conditions on the thermal resistance of Specimen 16. 


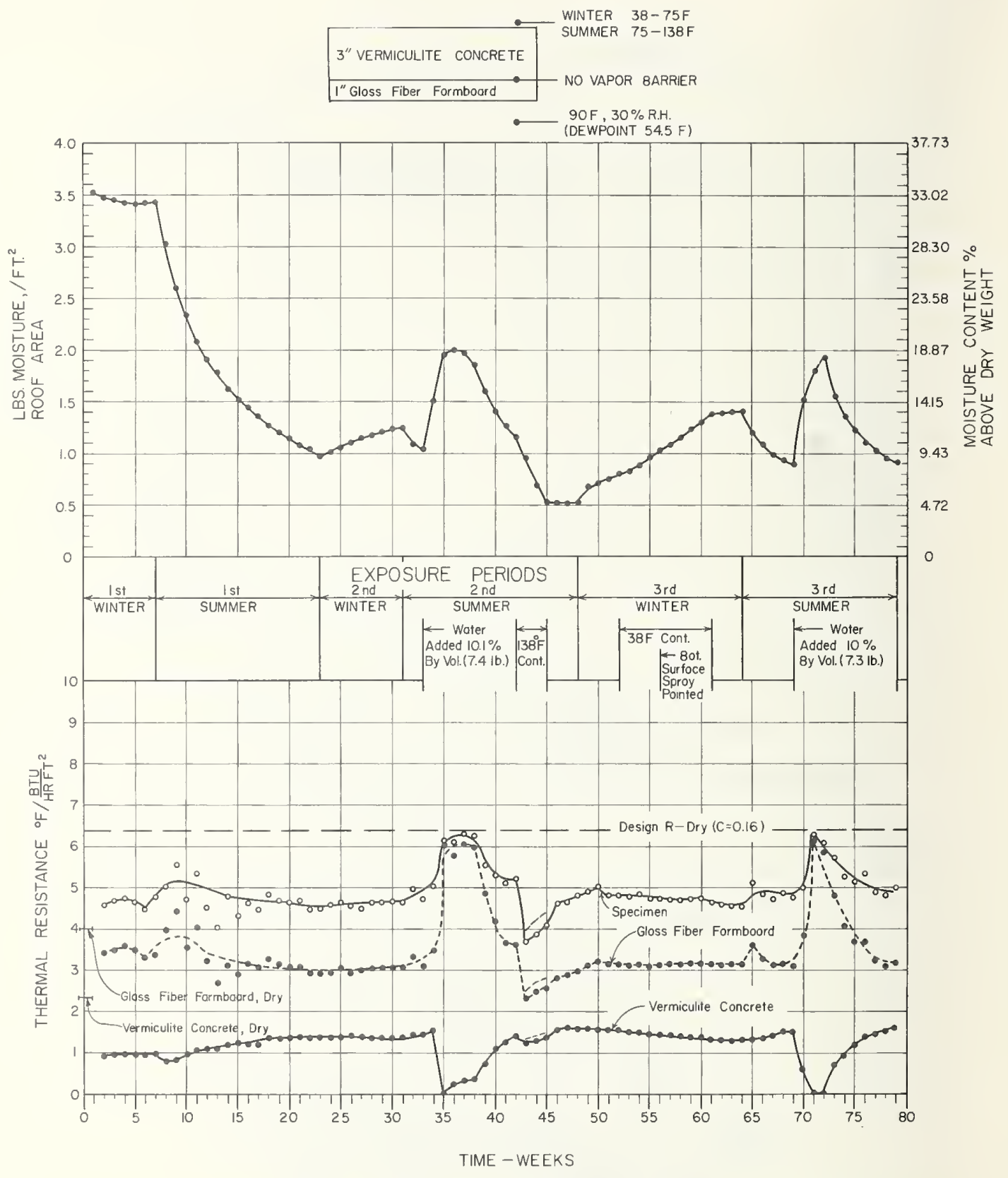

FIGURE 33. Effect of moisture and exposure conditions on the thermal resistance of Specimen 17. 


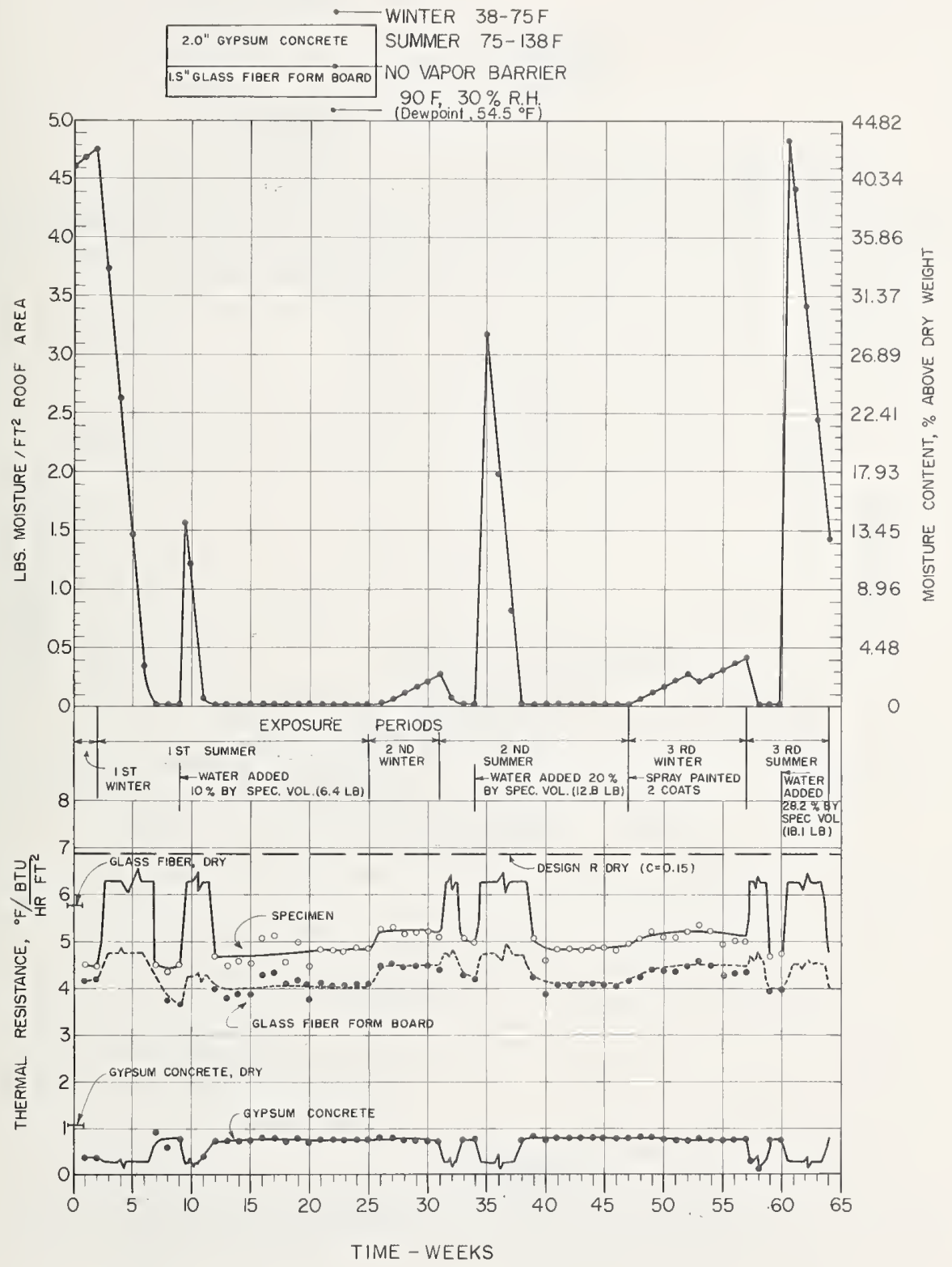

FIGURE 34. Effect of moisture and exposure conditions on the thermal resistance of Specimen 18. 
WINTER $38-75^{\circ} \mathrm{F}$

SPRING \& FALL $56-106^{\circ} \mathrm{F}$

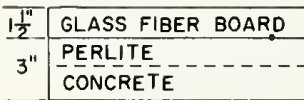

SUMMER $75-130^{\circ}$

3" PERLITE

NO VAPOR BARRIER

$90^{\circ} \mathrm{F}, 30 \%$ R.H

DEWPOINT $54.5^{\circ} \mathrm{F}$

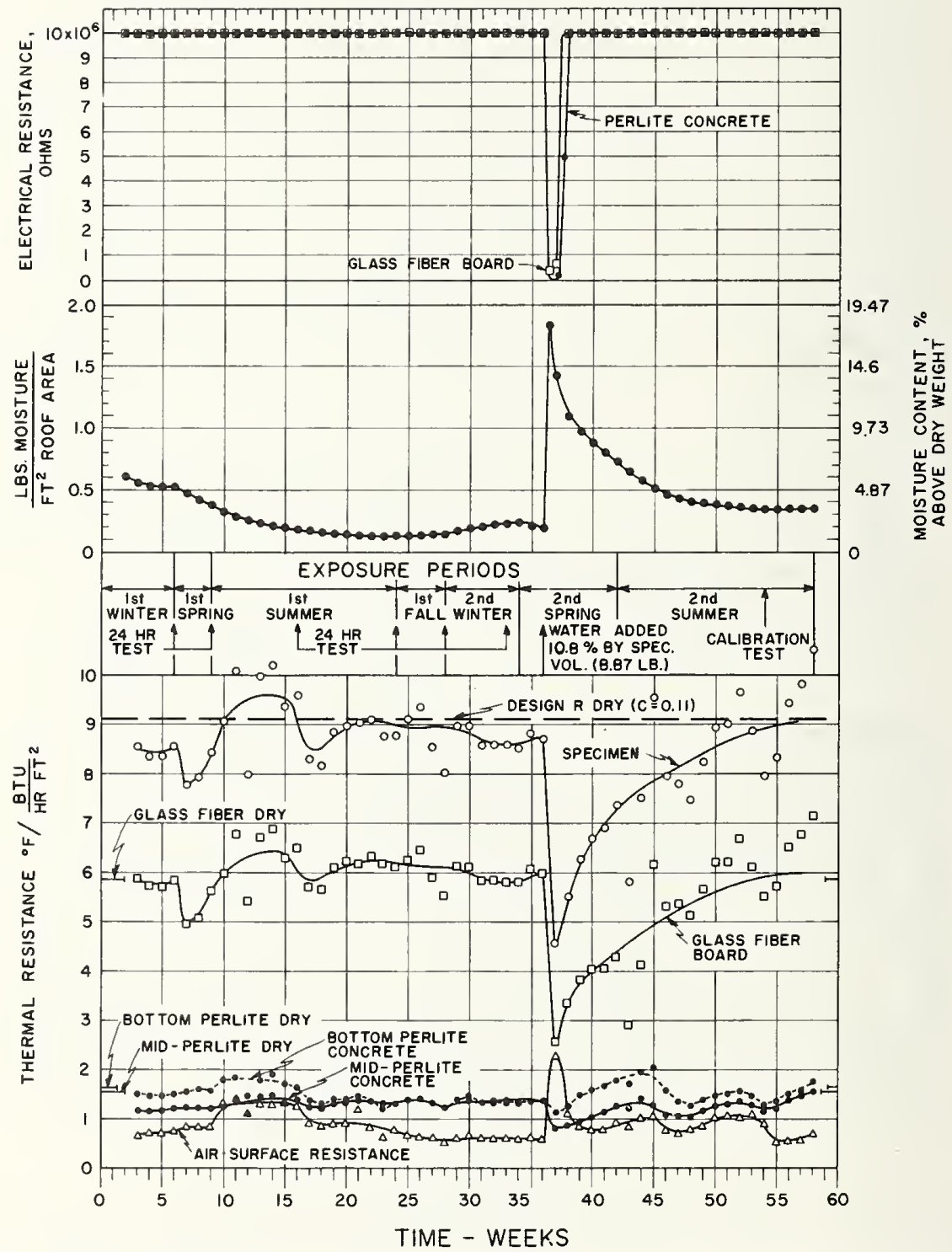

FIGURE 35. Effect of moisture and exposure conditions on the thermal resistance of Specimen 19. 

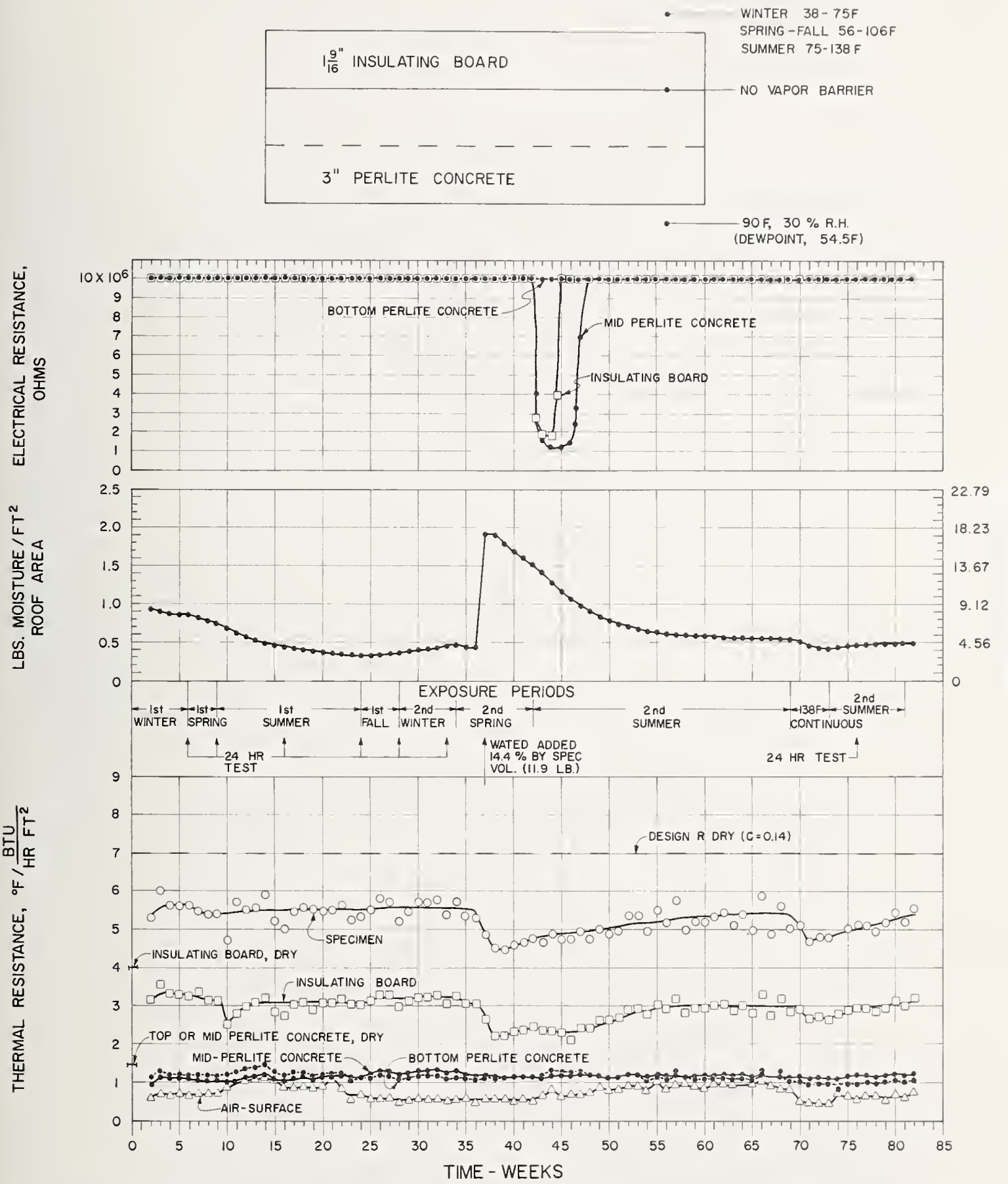

FIGURE 36. Effect of moisture and exposure conditions on the thermal resistance of Specimen 20. 

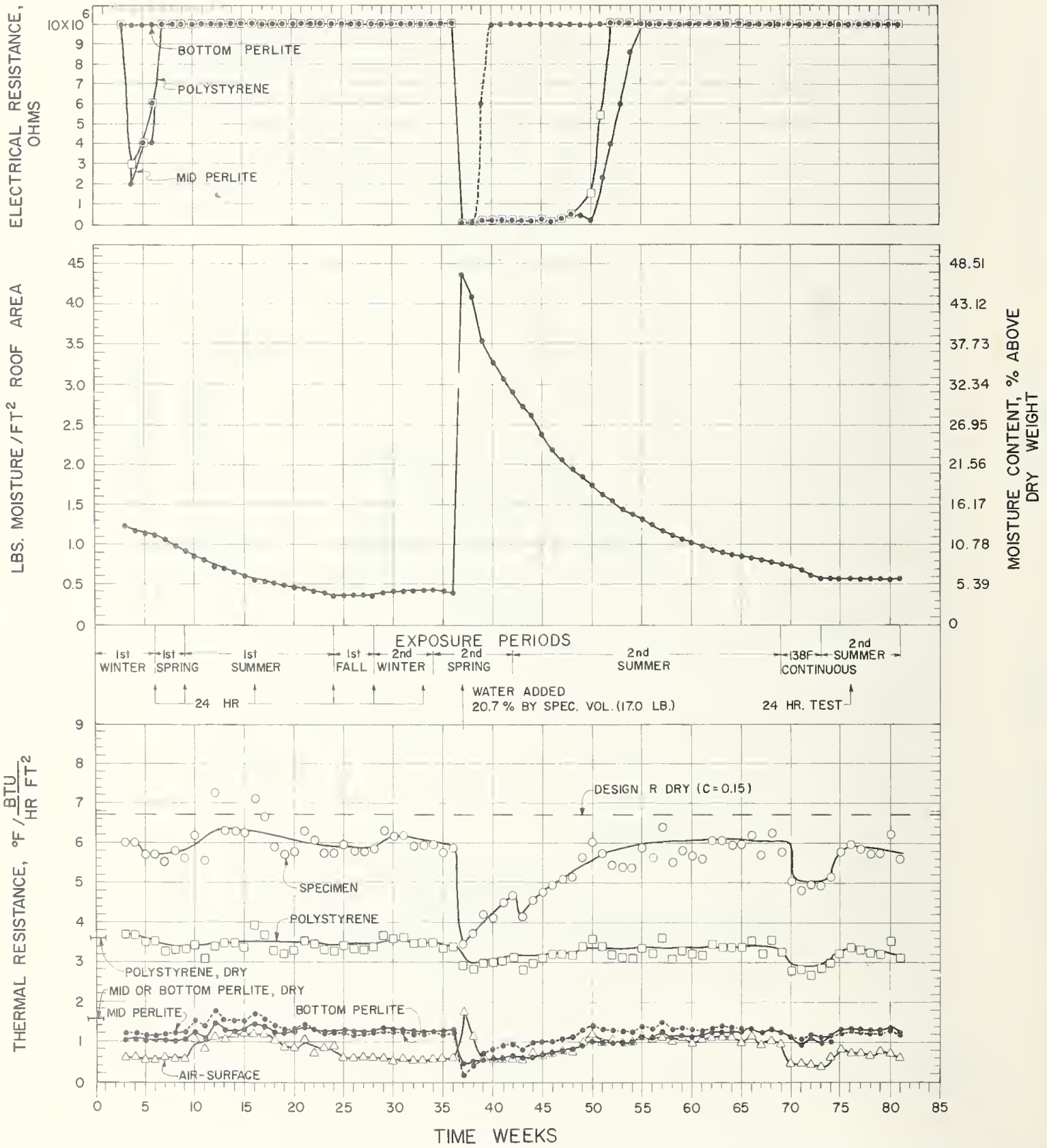

FIGURE 37. Effect of moisture and exposure conditions on the thermal resistance of Specimen 21. 

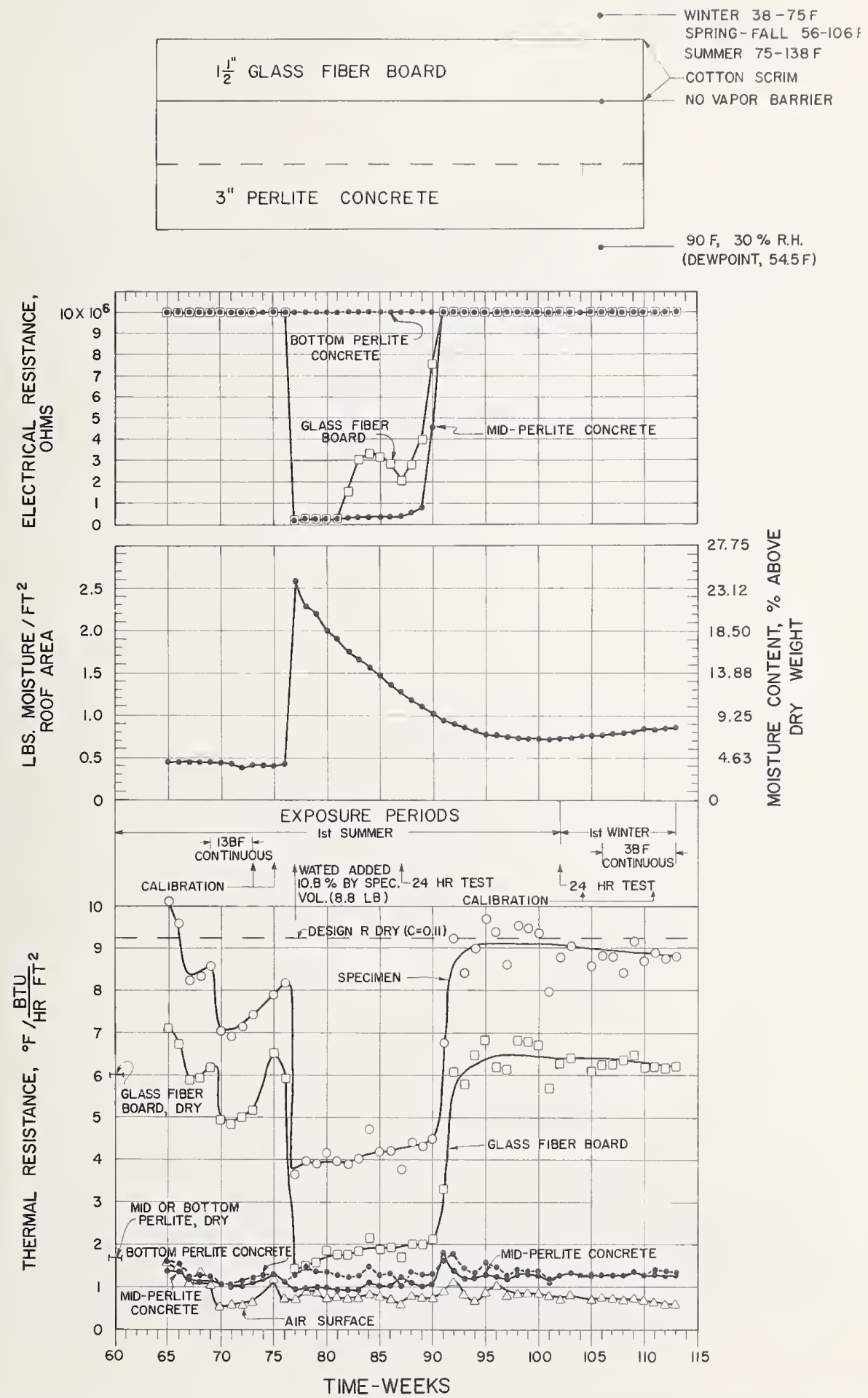

FIGURE 38. Effect of moisture and exposure conditions on the thermal resistance of Specimen 22. 


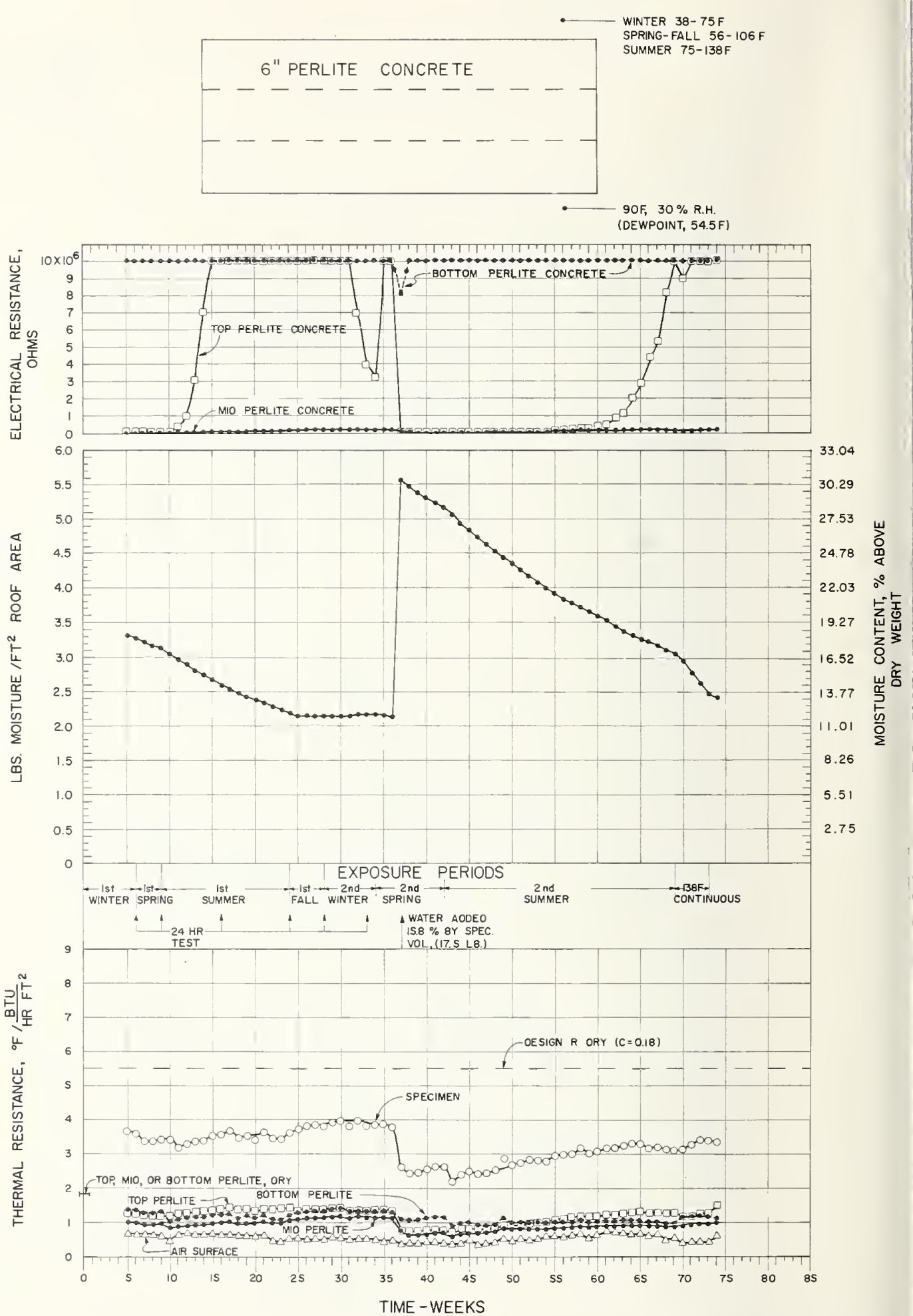

FIGURE 39. Effect of moisture and exposure conditions on the thermal resistance of Specimen 23. 


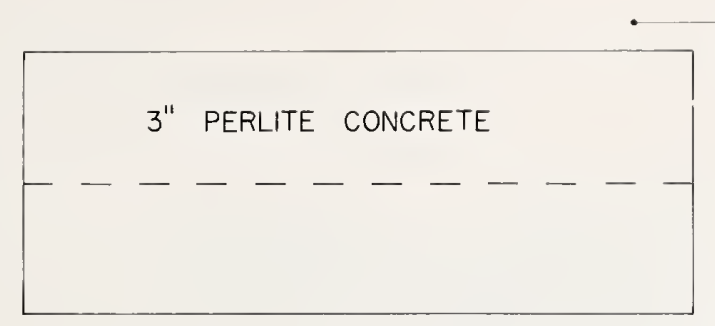

WINTER $38-75 \mathrm{~F}$

SPRING - FALL 56-106 F

SUMMER $75-138 \mathrm{~F}$

- $90 \mathrm{~F}, 30 \% \mathrm{R}, \mathrm{H}$.

(DEWPOINT, 54,5 F)
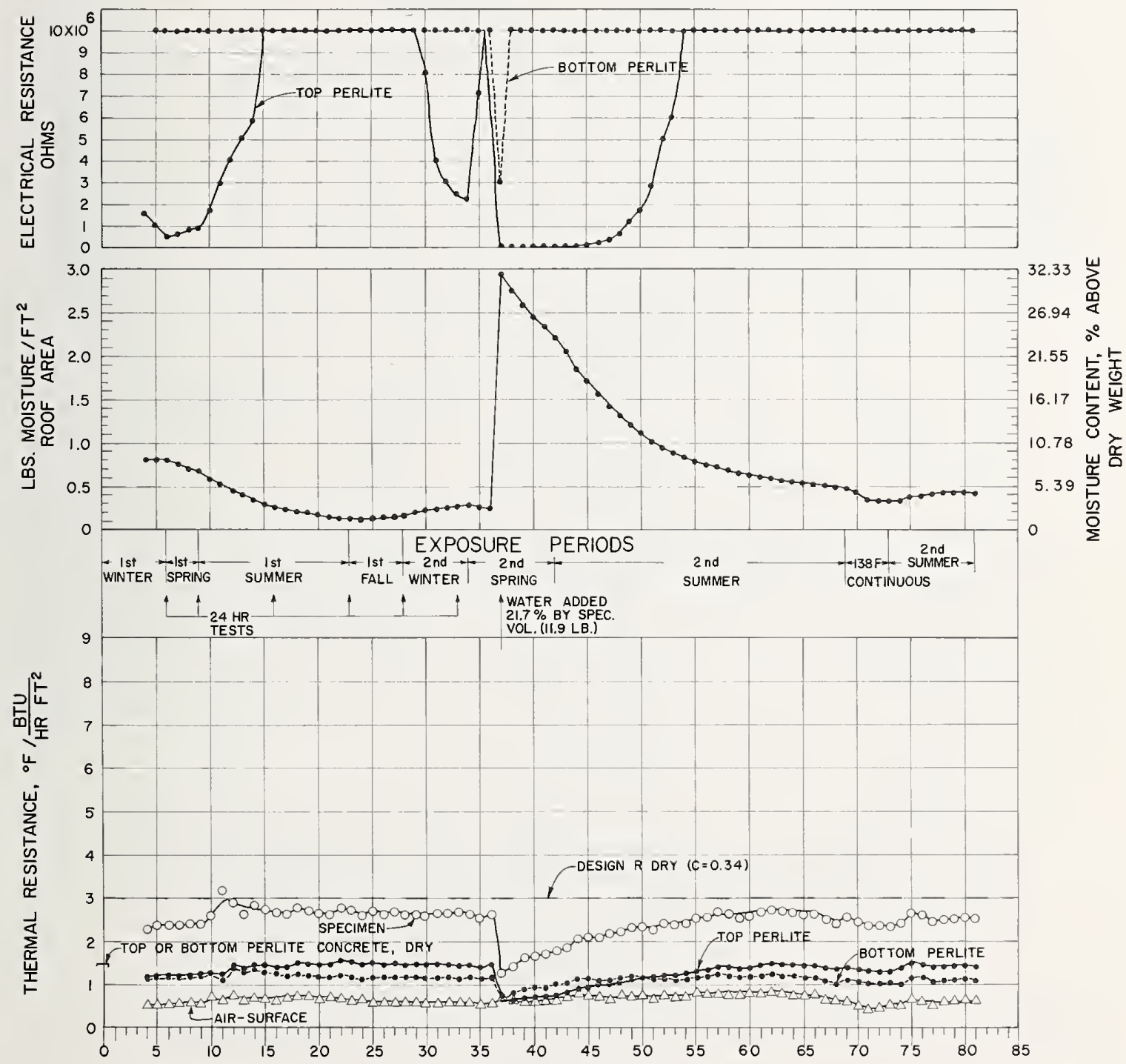

TIME- WEEKS

FIGURE 40. Effect of moisture and exposure conditions on the thermal resistance of Specimen 24. 


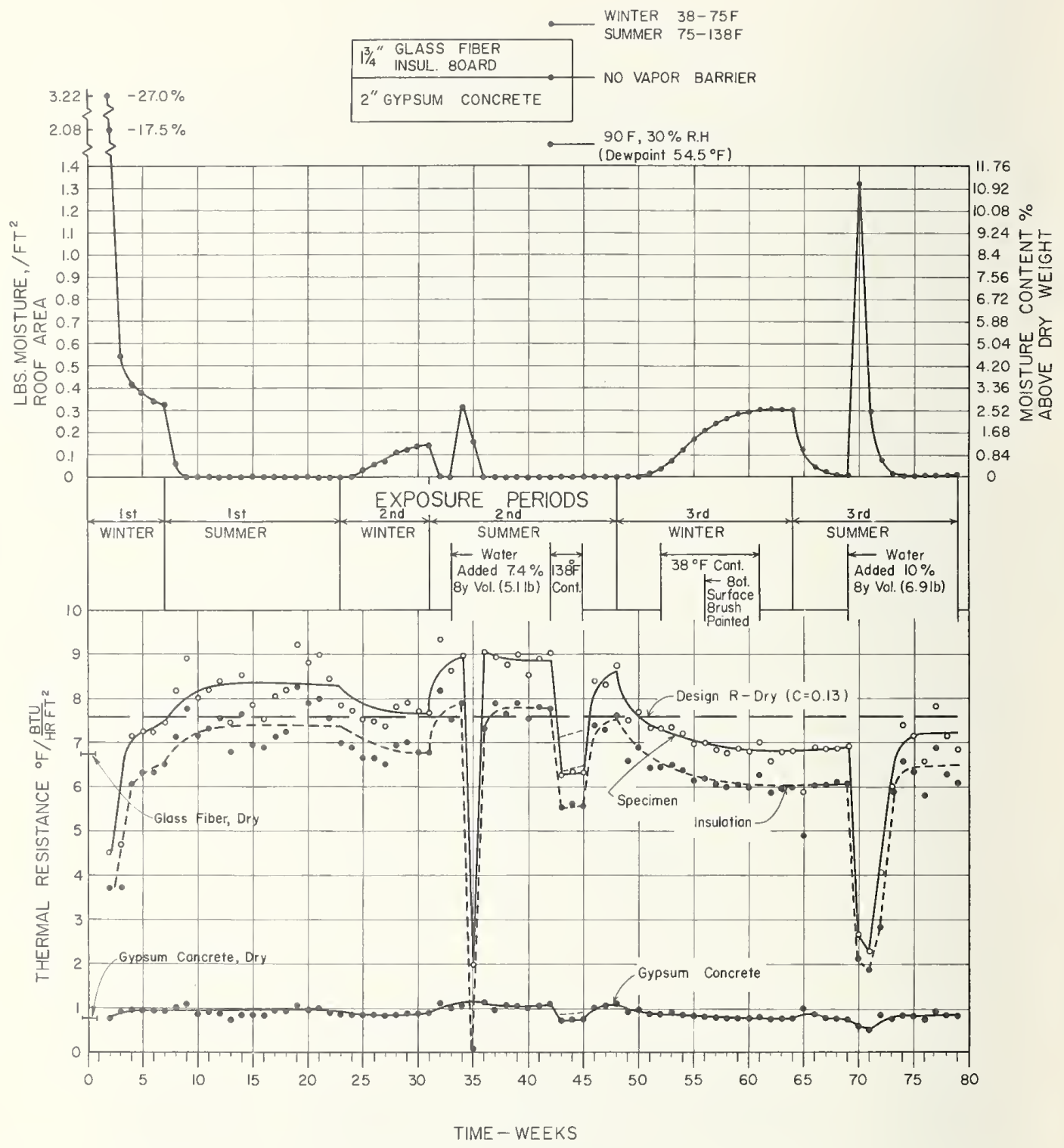

FIGURE 41. Effect of moisture and exposure conditions on the thermal resistance of Specimen 25. 


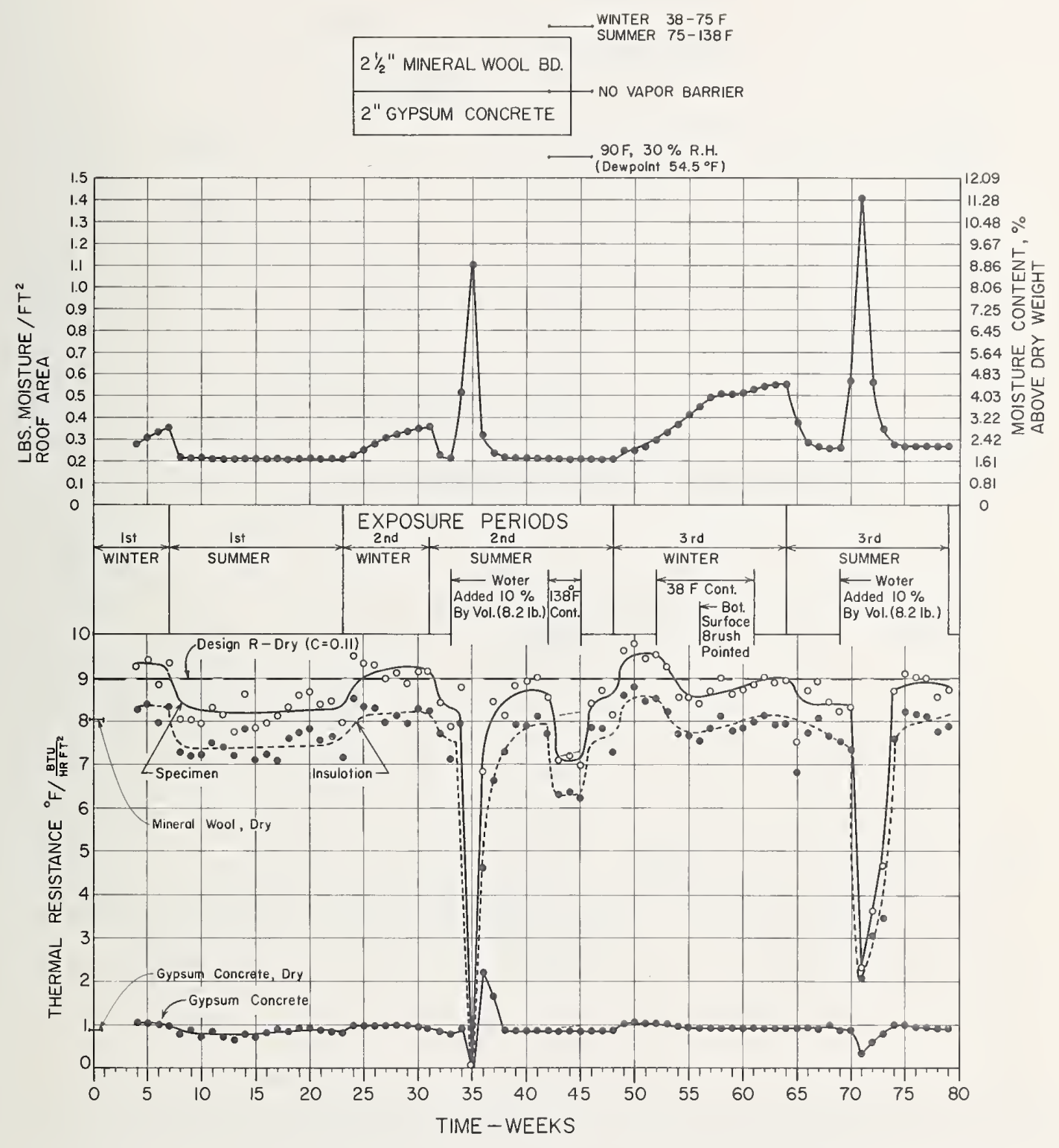

FIGURE 42. Effect of moisture and exposure conditions on the thermal resistance of Specimen 26. 


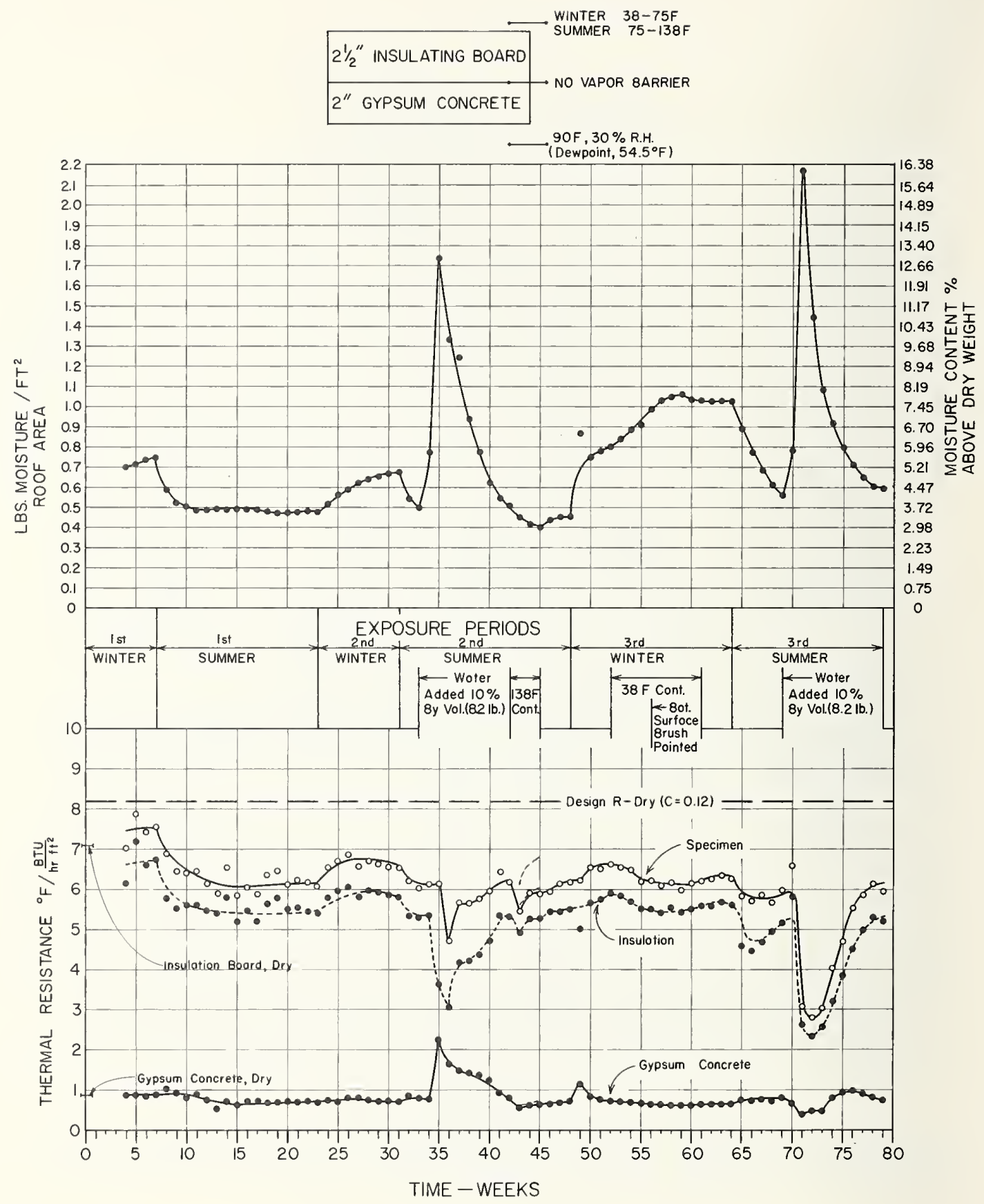

FIGURE 43. Effect of moisture and exposure conditions on the thermal resistance of Specimen 27. 

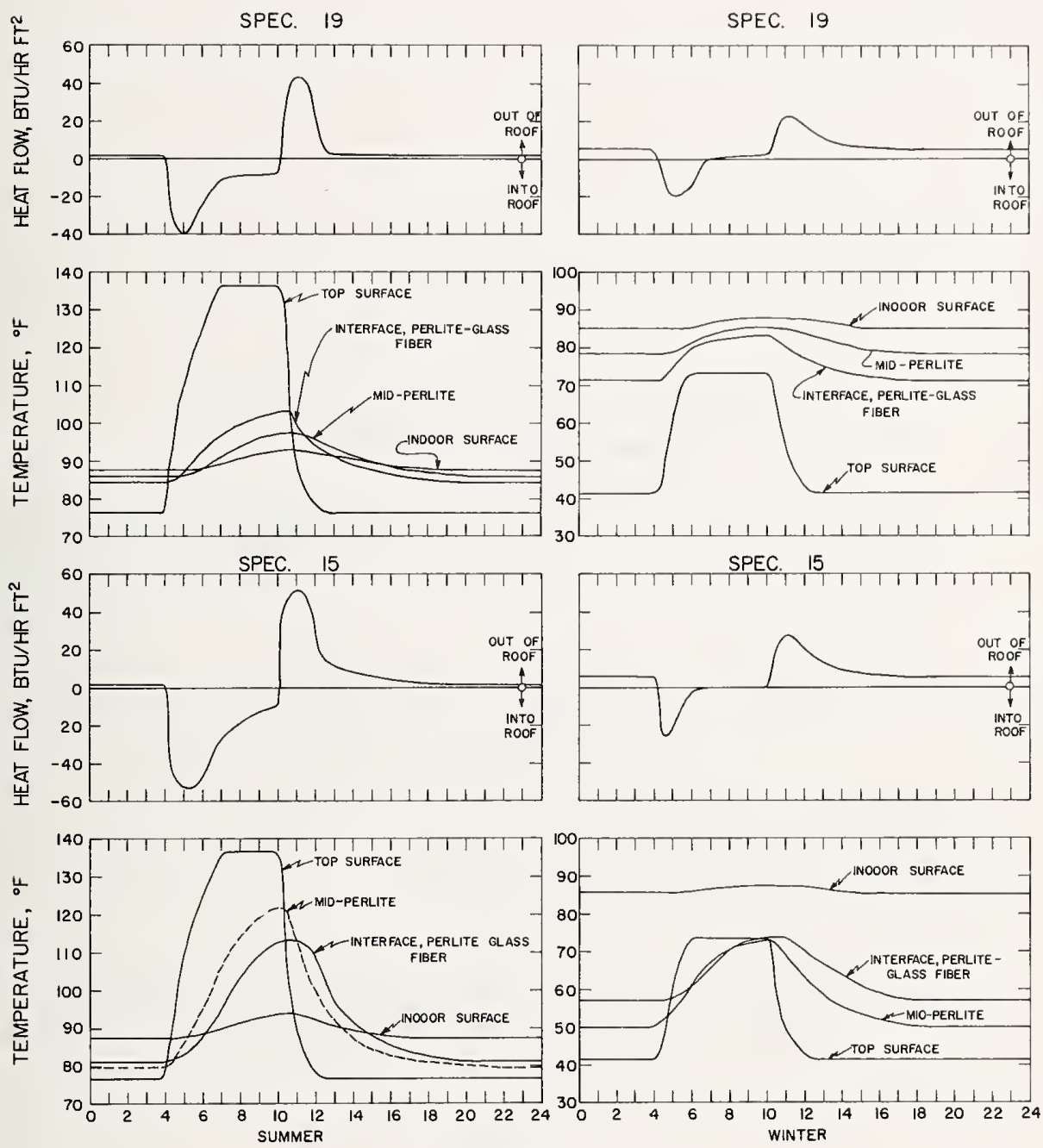

ELAPSED TIME, HOURS

FIGURE 44. Temperatures and top surface heat flux results for one day of a summer and winter exposure condition with specimens at low moisture contents. Specimen 19 contains a deck made from 3-inch-thick perlite aggregate insulating concrete that was covered with a $11 / 2$-inch-thick glass-fiber formboard. Specimen 15 materials were identical to Specimen 19 except that the glass-fiber formboard was the deck and the insulating concrete was used as a top cover. 


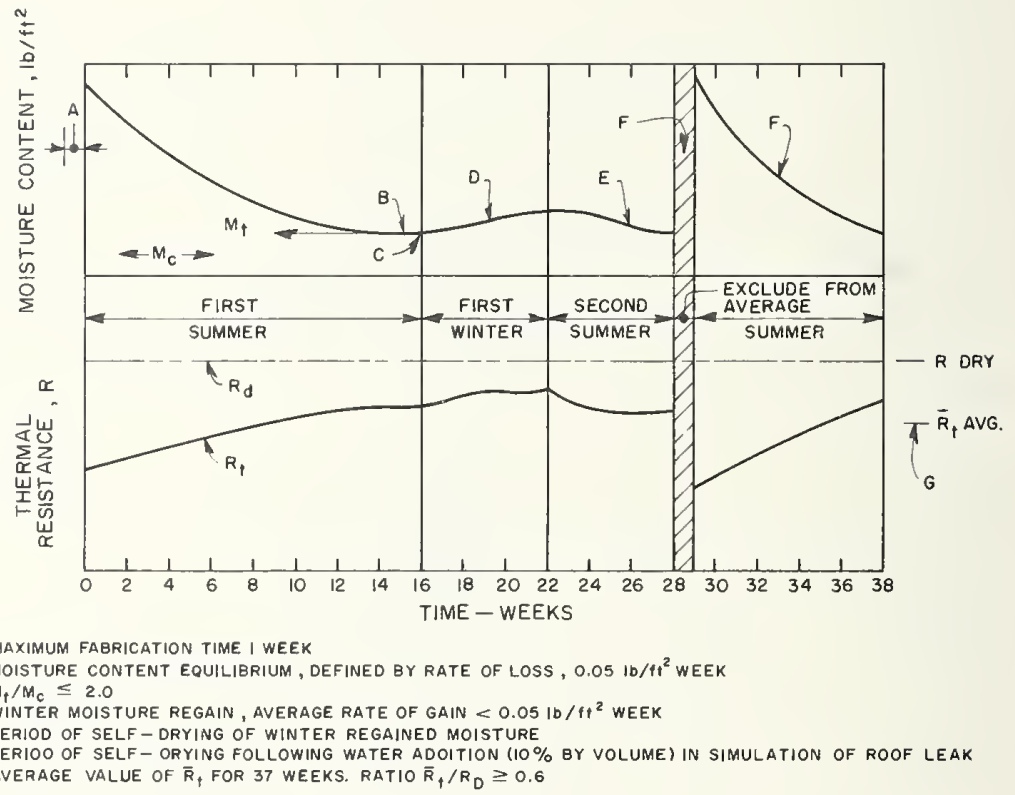

FIGURE 45. A typical laboratory performance characteristic of a specimen that satisfies the suggested criteria for design of insulated self-drying flat-roof deck constructions. 


\section{Announcement of New Publications in Building Science Series}

Superintendent of Documents,

Government Printing Office,

Washington, D. C. 20402

Dear Sir :

Please add my name to the announcement list of new publications to be issued in the series: National Bureau of Standards Building Science Series.

Name

Company

Address

City ___ State

Zip Code

(Notification key $\mathrm{N}-339$ ) 

ORM NBS-114A (1.71)

U.S. DEPT. OF COMM.

BIBLIOGRAPHIC DATA

SHEET

\section{PUBLIC ATION OR REPORT NO. NBS-BSS -37}

4. TITLE AND SUBTITLE

The Effect of Moisture on the Heat Transfer Performance of Insulated Flat-Roof Constructions

\section{AUTHOR(S)}

Frank J。 Powell and Henry E. Robinson

9. PERF ORMING ORGANIZATION NAME AND ADDRESS

NATIONAL BUREAU OF STANDARDS

DEPAR TMENT OF COMMERCE

WASHINGTON, D.C. 20234

12. Sponsoring Organization Name and Address Tri-Services Committee of the Office of the Chiet of Engineers, U.S. Army; the Bureau of Yards and Docks, U.S. Navy; the Office of Civil Engineering, U.S. Air Force. C/o Mr. Stanley Howell, Chm., Room 1C31, Y\&D Bldg. Department of the Navy, Washington, D.C. 20390.

2. Gov't Accession No.

3. Recipient's Accession No.

5. Publication Date

September 1971

6. Performing Organization Code

8. Performing Organization

10. Project/Task/Work Unit No.

4212133

11. Contract/Grant No.

$\mathrm{N} / \mathrm{A}$

13. Type of Report \& Period Covered

Final

14. Sponsoring A gency Code

15. SUPPLEMENTARY NOTES 16. ABSTRACT (A 200-word or less factual summary of most significant information. If document includes a significant
bibliography or literature survey, mention it here.)

A solution to the problem of unwanted moisture in the thermal insulation of flat roofs was found during a recently completed laboratory investigation of the effects of moisture on heat transfer through these constructions. The objective of the research was to ascertain how much the insulating performance of conventional constructions, having insulation over concrete decks, was affected by moisture. This is presented as Part I. Also, the objective was to investigate properties of materials, their arrangement and dimensions which would yield a construction having an adequate degree of self-drying ability, combined with low winter moisture regain rate. This is presented as Part II. The results show that the best insulating and moisture performance was obtained by utilizing the heat of the summer sun on the roof to vaporize and transfer to the room beneath any free moisture contained within the construction. Roof specimens made from moderately vapor-permeable materials without conventional vapor barriers were, in winter able to accommodate the small quantity of slowly accumulated condensation without dripping or severe loss of insulating value. During the nine-year investigation, the performance characteristics of 73 insulated roof deck specimens were obtained and two new methods of measurement were developed. Criteria for the design of self-drying insulated flat roofs were developed and limits of the parameters containing the main variables that affect performance were suggested.

This paper presents complete results of the research which was sponsored jointly by the National Bureau of Standards, the Army, the Navy and the Air Force.

\section{KEY WORDS (Alphabetical order, separated by semicolons)}

Flat roofs; heat transfer; moisture transfer; thermal insulation.

\begin{tabular}{|c|c|c|}
\hline $\begin{array}{l}\text { 18. AVAILABILITY STATEMEN } \Gamma \\
\mathrm{x} \text { UNL IMIT ED. }\end{array}$ & $\begin{array}{l}\text { 19. SECURITY CLASS } \\
\text { (THIS REPURT) } \\
\text { UNCL ASSIFIED }\end{array}$ & $\begin{array}{l}\text { 21. NO. OF PAGES } \\
81\end{array}$ \\
\hline $\begin{array}{l}\text { FOR OFFICIAL DISTRIBUTION. DO NOT RELEASE } \\
\text { TO NTIS. }\end{array}$ & $\begin{array}{l}\text { 20. SECURITY CLASS } \\
\text { (THIS PAGE) } \\
\text { UNCLASSIFIED }\end{array}$ & $\begin{array}{l}\text { 22. Price } \\
75 \text { cents }\end{array}$ \\
\hline
\end{tabular}





\section{PERIODICALS}

JOURNAL OF RESEARCH reports National Bureau of Standards research and development in physics, mathematics, chemistry, and engineering. Comprehensive scientific papers give complete details of the work, including laboratory data, experimental procedures, and theoretical and mathematical analyses. Illustrated with photographs, drawings, and charts.

Published in three sections, available separately:

\section{- Physics and Chemistry}

Papers of interest primarily to scientists working in these fields. This section covers a broad range of physical and chemical research, with major emphasis on standards of physical measurement, fundamental constants, and properties of matter. Issued six times a year. Annual subscription: Domestic, $\$ 9.50 ; \$ 2.25$ additional for foreign mailing.

\section{- Mathematical Sciences}

Studies and compilations designed mainly for the mathematician and theoretical physicist. Topics in mathematical statistics, theory of experiment design, numerical analysis, theoretical physics and chemisty, logical design and programming of computers and computer systems. Short numerical tables. Issued quarterly. Annual subscription: Domestic, \$5.00; $\$ 1.25$ additional for foreign mailing.

\section{- Engineering and Instrumentation}

Reporting results of interest chiefly to the engineer and the applied scientist. This section includes many of the new developments in instrumentation resulting from the Bureau's work in physical measurement, data processing, and development of test methods. It will also cover some of the work in acoustics, applied mechanics, building research, and cryogenic engineering. Issued quarterly. Annual subscription: Domestic, $\$ 5.00 ; \$ 1.25$ additional for foreign mailing.

\section{TECHNICAL NEWS BULLETIN}

'The best single source of information concerning the Bureau's research, developmental, cooperative, and publication activities, this monthly publication is designed for the industry-oriented individual whose daily work involves intimate contact with science and technology-for engineers, chemists, physicists, research managers, product-development managers, and company executives. Annual subscription: Domestic, $\$ 3.00 ; \$ 1.00$ additional for foreign mailing.

\section{NONPERIODICALS}

Applied Mathematics Series. Mathematical tables, manuals, and studies.

Building Science Series. Research results, test methods, and performance criteria of building materials, components, systems, and structures.

Handbooks. Recommended codes of engineering and industrial practice (including safety codes) developed in cooperation with interested industries, professional organizations, and regulatory bodies.

Special Publications. Proceedings of NBS conferences, bibliographies, annual reports, wall charts, pamphlets, etc.

Monographs. Major contributions to the technical literature on various subjects related to the Bureau's scientific and technical activities.

\section{National Standard Reference Data Series.}

NSRDS provides quantitative data on the physical and chemical properties of materials, compiled from the world's literature and critically evaluated.

Product Standards. Provide requirements for sizes, types, quality, and methods for testing various industrial products. These standards are developed cooperatively with interested Government and industry groups and provide the basis for common understanding of product characteristics for both buyers and sellers. Their use is voluntary.

Technical Notes. This series consists of communications and reports (covering both other agency and NBS-sponsored work) of limited or transitory interest.

Federal Information Processing Standards Publications. This series is the official publication within the Federal Government for information on standards adopted and promulgated under the Public Law 89-306, and Bureau of the Budget Circular A-86 entitled, Standardization of Data Elements and Codes in Data Systems.

Consumer Information Series. Practical information, based on NBS research and experience, covering areas of interest to the consumer. Easily understandable language and illustrations provide useful background knowledge for shopping in today's technological marketplace.

NBS Special Publication 305, Supplement 1, Publications of the NBS, 1968-1969. When ordering, include Catalog No. C13.10:305. Price \$4.50; $\$ 1.25$ additional for foreign mailing. 
U.S. DEPARTMENT OF COMMERCE

National Bureau of Standards

Washington, D.C. 20234

\section{OFFICIAL BUSINESS}

Penalty for Private Use, $\$ 300$
POSTAGE AND FEES PAID U.S. DEPARTMENT OF COMMERCE 